\title{
Integrated modulation of sympathetic tone in the microcirculation by oxygen, adenosine, and nitric oxide
}

Bryan Auston Sauls

West Virginia University

Follow this and additional works at: https://researchrepository.wvu.edu/etd

\section{Recommended Citation}

Sauls, Bryan Auston, "Integrated modulation of sympathetic tone in the microcirculation by oxygen, adenosine, and nitric oxide" (2001). Graduate Theses, Dissertations, and Problem Reports. 1409.

https://researchrepository.wvu.edu/etd/1409

This Dissertation is protected by copyright and/or related rights. It has been brought to you by the The Research Repository @ WVU with permission from the rights-holder(s). You are free to use this Dissertation in any way that is permitted by the copyright and related rights legislation that applies to your use. For other uses you must obtain permission from the rights-holder(s) directly, unless additional rights are indicated by a Creative Commons license in the record and/ or on the work itself. This Dissertation has been accepted for inclusion in WVU Graduate Theses, Dissertations, and Problem Reports collection by an authorized administrator of The Research Repository @ WVU.

For more information, please contact researchrepository@mail.wvu.edu. 


\title{
Integrated Modulation of Sympathetic Tone in the Microcirculation by Oxygen, Adenosine, and Nitric Oxide
}

\author{
Bryan Auston Sauls
}

\author{
Dissertation submitted to the \\ School of Medicine at \\ West Virginia University \\ in partial fulfillment of the requirements \\ for the degree of
}
Doctor of Philosophy
In
Physiology

\author{
Matthew A. Boegehold, Ph.D., Chairman \\ Christine Baylis, Ph.D. \\ John Connors, Ph.D. \\ David A. Taylor, Ph.D. \\ Stanley D. Yokota, Ph.D.
}

Department of Physiology

Morgantown, West Virginia

2001

Keywords: Microvascular Control Mechanisms, Endothelium-Derived

Relaxing Factor, Sympathetic Nerves, Local Oxygen Tension 


\section{ABSTRACT}

\section{Integrated Modulation of Sympathetic Tone in the Microcirculation by Oxygen, Adenosine, and Nitric Oxide}

\section{Bryan Auston Sauls}

Despite a profound reduction in hemodynamic shear stress, a sustained release of endothelium-derived nitric oxide (NO) limits arteriolar constriction during periods of increased sympathetic nerve activity in the rat small intestine. In this project, we sought to test the hypothesis that adenosine, formed in response to a flow-dependent fall in local $\mathrm{PO}_{2}$, serves as the stimulus to preserve endothelial NO release under these conditions. Sympathetic nerve stimulation induced frequency-dependent arteriolar constrictions and a flow-dependent fall in local $\mathrm{PO}_{2}$. The arteriolar responses to nerve stimulation were enhanced after inhibition of $\mathrm{NO}$ synthase with $\mathrm{N}^{\mathrm{G}}$-monomethyl-L-arginine (L-NMMA). Under a high $(20 \%) \mathrm{O}_{2}$ superfusate, the fall in local $\mathrm{PO}_{2}$ during nerve stimulation was significantly attenuated, arteriolar constrictions were significantly increased, and these responses were no longer sensitive to L-NMMA. Treatment with adenosine deaminase $(2.0 \mathrm{U} / \mathrm{ml})$ or the selective $A_{1}$ receptor antagonist 8cyclopentyl-1,3-dipropylxanthine $\left(4 \times 10^{-4} \mathrm{M}\right)$ completely blocked the enhancing effect of L-NMMA on sympathetic constriction. In the presence of the 5'ectonucleotidase inhibitor $\alpha, \beta$-methyleneadenosine $5^{\prime}$-diphosphate $\left(4.5 \times 10^{-5} \mathrm{M}\right)$, the enhancing effects of L-NMMA and the high- $\mathrm{O}_{2}$ superfusate on sympathetic constriction were preserved. None of these treatments had an effect on vascular smooth muscle responsiveness to $\mathrm{NO}$ (as judged by arteriolar responses to sodium nitroprusside). The high- $\mathrm{O}_{2}$ superfusate also did not lead to the generation of reactive oxygen species in the arteriolar wall (as determined by the reduction of tetranitroblue tetrazolium dye). In conclusion, these results suggest that a flow-dependent fall in arteriolar wall and/or tissue $\mathrm{PO}_{2}$ leads to the release of intracellularly-formed adenosine, which, through its interaction with endothelial $A_{1}$ receptors, stimulates NO release during neurogenic constriction in this vascular bed. 


\section{PREFACE}

This dissertation will begin with a review of the literature that constitutes the scientific foundation on which these studies are based. The three studies that constitute this dissertation work will then be reported in manuscript form, followed by a general unified discussion of the findings. 


\section{DEDICATION}

I would like to dedicate this work and all that I have accomplished to my family. Without them, none of this would have been possible. To my wife Melanie, you are the star that guides my journey, without you I would be adrift in a sea of unfulfilled dreams. To our daughter Breanna, you are my elixir of life, each time I earn your admiration it charges me onward toward the next challenge. To our son Aidan, your glow touches me in ways that I hope you'll understand someday. I thank god everyday that I have been blessed with each of you. 


\section{ACKNOWLEDGEMENTS}

To start, I would like to thank Dr. Matthew Boegehold for all of his support and for his faith in me. I am certain that everything I accomplish in the coming years will be in no small part due to his influence and to the opportunity he granted me. Although my path may lead me away from science in the near future, I will always cherish the lessons that I have learned under his tutelage. Matt, I am forever in your debt.

I would like to thank my committee, Dr. Chris Baylis, Dr. John Connors, Dr. Mike Michalkiewicz, Dr. Dave Taylor, and Dr. Stan Yokota for all of their help and guidance. In particular, I would like to thank Chris Baylis and Stan Yokota for their considerate comments and suggestions over the years. In addition to my committee I would like to thank all of the members of the Physiology department who have worked to create such a wonderful learning environment. I would also like to thank my fellow graduate students (former and present) who have made everything a little more bearable: Geoff, Russ, Tim, Debbie, J.J., Jolene, Ron, Steve, Kevin, Aaron, Patti, Ranja, Jim, and Van.

Finally, I would like to thank my brother, Jim and sisters, Faith, Fran, and Nedda for all of their love, support, and encouragement. Just knowing that you were behind me made all of the difference in the world. In closing, I would like to thank my parents James Ned and Naomi Faith Sauls for defining the parameters by which I live my life and for always believing that I was capable of anything. To each of you I give my sincerest gratitude. 


\section{TABLE OF CONTENTS}

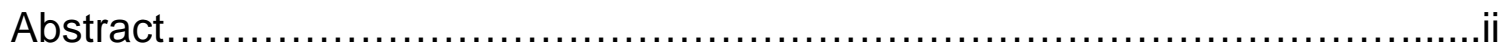

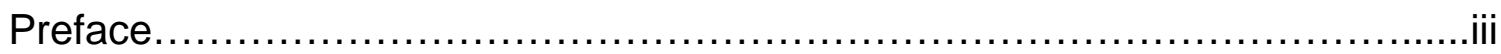

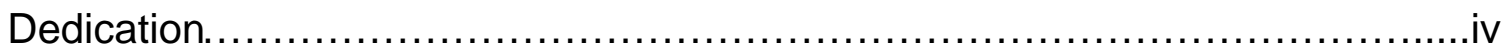

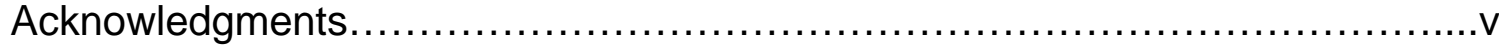

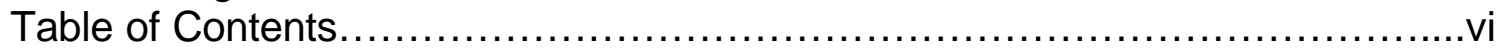

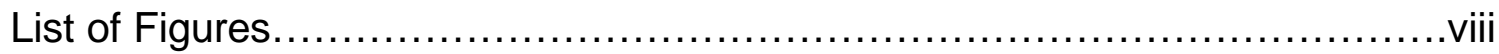

Glossary of Abbreviations..........................................................

I. Literature Review

1. Introduction..............................................................

2. Regulation of Vascular Smooth Muscle Tone.....................................2

A. Endothelium-Dependent Control of Vascular Tone.....................2

1. Endothelium-Derived Nitric Oxide............................................

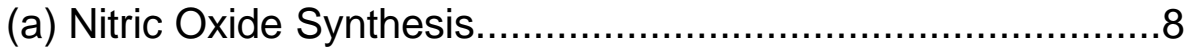

(b) Basal Nitric Oxide Release.............................................11

(c) Stimulated Nitric Oxide Release....................................13

(d) NO Signaling Pathways in Vascular Smooth Muscle...........15

B. Neural Control of Vascular Tone.................................................17

1. The Intestinal Vasculature and its Innervation........................17

2. Sympathetic Adrenergic Neuron Content...............................19

3. Modulation of Arteriolar Diameter and Network Blood Flow by Sympathetic Nerve Activity......................................20

4. Endothelial Modulation of Sympathetic Tone..........................22

(a) Endothelial Metabolism of Norepinephrine .........................23

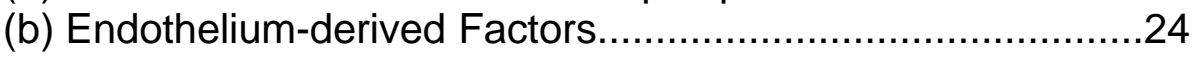

C. Metabolic Control of Vascular Tone ..............................................26

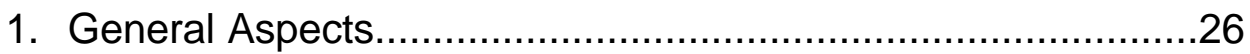

2. Regulation of Vascular Tone by Oxygen..............................27

(a) Oxygen Delivery to the Intestine.....................................27

(b) Effects of Alterations in Oxygen Tension on Vascular Tone.

3. Regulation of Vascular Tone by Adenosine and Adenine Nucleotides.

(a) A Brief History of Purinergic Signaling...............................34

(b) P1-Purinoceptor Classification and Signaling.....................36

(c) P2-Purinoceptor Classification and Signaling.......................37

(d) Formation and Release of Adenosine.................................38

(e) The Role of Adenosine in the Regulation of Vascular Tone. 
(f) The Role of Adenine Nucleotides in the Regulation of Vascular Tone

II. Purpose of this Dissertation Project........................................................44

III. Study I: Arteriolar $\mathrm{Wall}^{\mathrm{PO}_{2}}$ and Nitric Oxide Release during Sympathetic Vasoconstriction in the Rat Intestine.
A. Summary. 48
B. Introduction .49
C. Methods. 50
D. Results. .57
E. Discussion.
F. References. 75

IV. Study II: Reduced $\mathrm{PO}_{2}$ and Adenosine Formation Preserve Arteriolar Nitric Oxide Synthesis during Sympathetic Constriction in the Rat Intestine.
A. Summary 83
B. Introduction
C. Methods. 85
D. Results. .91
E. Discussion. 106
F. References. 112

V. Study III. Adenosine Linking Reduced Oxygen to Arteriolar Nitric Oxide Release in the Intestine in not Formed from Extracellular ATP....118
A. Summary. 119
B. Introduction. 120
C. Methods. 121
D. Results. 128
E. Discussion. 139
F. References. 146

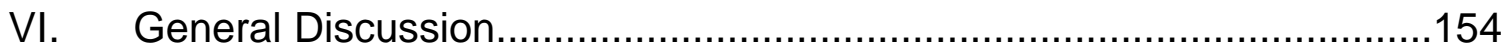

VII. References for Literature Review and General Discussion...................164

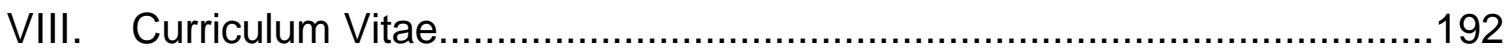




\section{LIST OF FIGURES}

\section{LITERATURE REVIEW}

Figure 1. Schematic of the intestinal microcirculation.......................18

\section{STUDY I.}

Figure 1. Plot of time course for arteriolar diameter responses to sympathetic nerve stimulation before and during exposure to L-NMMA

Figure 2. Bar graph of arteriolar responses to sympathetic nerve stimulation before and during exposure to high- $\mathrm{O}_{2}$ superfusate.

Figure 3. Plot of time course for arteriolar response to sympathetic nerve stimulation under control and high- $\mathrm{O}_{2}$ superfusate.

Figure 4. Plot of time course for arteriolar wall $\mathrm{PO}_{2}$ measurements during sympathetic nerve stimulation under control superfusate and high- $\mathrm{O}_{2}$ superfusate.

Figure 5. Bar graph of arteriolar response to A23187 in the before and during L-NMMA

Figure 6. Bar graph of arteriolar response to sodium nitroprusside under control and high- $\mathrm{O}_{2}$ superfusate.

\section{STUDY II.}

Figure 1. Bar graph of arteriolar responses to adenosine before and during L-NMMA.

Figure 2. Plot of time course of arteriolar diameter response to sympathetic nerve stimulation before and during L-NMMA

Figure 3. Bar graph of arteriolar diameter response to sympathetic nerve stimulation under control and high- $\mathrm{O}_{2}$ superfusate. 
Figure 4. Plot of time course of tissue PO2 during sympathetic nerve stimulation under control and high- $\mathrm{O}_{2}$ superfusate

Figure 5. Bar graph of arteriolar diameter response to sympathetic nerve stimulation in the presence of adenosine deaminase under control and high- $\mathrm{O}_{2}$ superfusate. 102

Figure 6. Bar graph of arteriolar diameter response to sympathetic nerve stimulation in the presence of DPCPX under control and high- $\mathrm{O}_{2}$ superfusate.

Figure 7. Bar graph of arteriolar responses to adenosine (top panel) or CCPA (bottom panel) before and during DPCPX

Figure 8. Bar graph of arteriolar response to sodium nitroprusside under control and in the presence of adenosine deaminase (top panel); and DPCPX (bottom panel)

\section{STUDY III.}

Figure 1. Bar graph of arteriolar response to AMP before and during AOPCP

Figure 2. Bar graph of arteriolar response to ATP before and during L-NMMA (top panel) and DPCPX (bottom panel)

Figure 3. Bar graph of arteriolar response to ATP before and during exposure to AOPCP and AOPCP+L-NMMA

Figure 4. Bar graph of arteriolar diameter response to sympathetic nerve stimulation in the presence of adenosine deaminase under control and high- $\mathrm{O}_{2}$ superfusate. 
Figure 5. Bar graph of arteriolar diameter response to sympathetic nerve stimulation in the presence of DPCPX under control and high- $\mathrm{O}_{2}$ superfusate

Figure 6. First-order linear regression of the relationship between arteriolar-venular separation distance and enhancement of vasoconstriction by L-NMMA or high $\mathrm{O}_{2}$ superfusate

Figure 7. Bar graph of arteriolar response to sodium nitroprusside before and during exposure to AOPCP.......138

\section{Discussion}

Figure 1. Summary of the results of this project.............................163 


\section{GLOSSARY OF ABBREVIATIONS}

\begin{tabular}{|c|c|}
\hline AA & Arachidonic acid \\
\hline$A C$ & Adenylyl cyclase \\
\hline ADO & Adenosine \\
\hline ADP & Adenosine 5'diphosphate \\
\hline AOPCP & $\alpha, \beta$-methyleneadenosine 5'-diphosphate \\
\hline ATP & Adenosine 5'tripohsphate \\
\hline ATPase & Adenosine triphosphatase \\
\hline $\mathrm{BH}_{4}$ & Tetrahydrobiopterin \\
\hline $\mathrm{Ca}^{2+}$ & Calcium \\
\hline$\left[\mathrm{Ca}^{2+}\right]_{\mathrm{i}}$ & Intracellular calcium concentration \\
\hline $\mathrm{CaM}$ & Calmodulin \\
\hline cAMP & 3',5'-cyclic adenosine monophosphate \\
\hline CCPA & 2-chloro- $\mathrm{N}^{6}$-cyclopentyl-adenosine \\
\hline cGMP & 3',5'-cyclic guanosine monophosphate \\
\hline cGMP-PK & 3',5'-cyclic guanosine monophosphate protein kinase \\
\hline DAG & Diacylglycerol \\
\hline DPCPX & 8-cyclopentyl-1,3-dipropylxanthine \\
\hline EDRF & Endothelium-derived relaxing factor \\
\hline eNOS & Endothelial nitric oxide synthase \\
\hline FAD & Flavin adenine nucleotide \\
\hline FMN & Flavin mononucleotide \\
\hline
\end{tabular}




\begin{tabular}{|c|c|}
\hline $\mathrm{Gi}$ & Inhibitory G-protein \\
\hline $\mathrm{Gq}$ & Stimulatory G-protein \\
\hline iNOS & Inducible nitric oxide synthase \\
\hline $\mathrm{IP}_{3}$ & Inositol 1,4,5-triphosphate \\
\hline $\mathrm{K}^{+}$ & Potassium \\
\hline L-NMMA & $N^{G}$-monomethyl-L-arginine \\
\hline MAPK & Mitogen activated protein kinase \\
\hline $\mathrm{mm} \mathrm{Hg}$ & Millimeters of mercury \\
\hline $\mathrm{NAD}(\mathrm{P}) \mathrm{H}$ & Nicotinomide adenine dinucleotide phosphate \\
\hline NE & Norepinephrine \\
\hline NO & Nitric Oxide \\
\hline nNOS & Neuronal nitric oxide synthase \\
\hline NOS & Nitric oxide synthase \\
\hline $\mathrm{O}_{2}$ & Oxygen \\
\hline PIP & Phosphatidylinositol-4-phosphate \\
\hline $\mathrm{PIP}_{2}$ & Phosphatidylinositol \\
\hline $\mathrm{PGl}_{2}$ & Prostacyclin \\
\hline $\mathrm{PO}_{2}$ & Partial pressure of oxygen \\
\hline PKC & Protein kinase C \\
\hline $\mathrm{PLA}_{2}$ & Phospholipase $A_{2}$ \\
\hline PLC & Phospholipase C \\
\hline SNP & Sodium nitroprusside \\
\hline
\end{tabular}




\section{LITERATURE REVIEW}

\section{INTRODUCTION}

The primary function of the cardiovascular system is to transport oxygenated blood from the lungs to the tissues and deoxygenated blood from the tissues to the lungs. To this end, the cardiovascular system has evolved into an extremely effective and efficient delivery system. The distribution of cardiac output among the different organs is dependent upon a variety of factors that influence the contractile activity of vascular smooth muscle, and thereby vascular smooth muscle tone. These factors can be divided into two categories: (1) those originating within the organ (local or intrinsic factors) (2) those originating from outside of the organ (central or extrinsic factors). Among the most important intrinsic influences acting on vascular smooth muscle are endothelium-derived vasoactive factors, local metabolites, and alterations in transmural pressure (i.e., myogenic stimuli). Extrinsic control of vascular smooth muscle is achieved primarily by the activity of postganglionic autonomic neurons and by circulating vasoactive (humoral) factors. The combination of these intrinsic and extrinsic factors is responsible for the moment-to-moment regulation of arteriolar tone and the overall distribution of blood flow throughout the vasculature.

Although each of these factors contributes importantly to the regulation of vascular smooth muscle tone, this review will focus only on those factors most relevant to the study at hand: endothelium-dependent, neurogenic, and metabolic 
influences. In each of the following sections, a detailed account will be made of the current scientific evidence relating to the mechanism under discussion.

\section{REGULATION OF VASCULAR SMOOTH MUSCLE TONE}

\section{A. ENDOTHELIUM-DEPENDENT CONTROL OF VASCULAR TONE}

1. General Aspects. Prior to the 1980's the vascular endothelium was considered to be a relatively inert layer of cells with no major functional properties. It is now well documented that endothelial cells are extremely important modulators of local vascular smooth muscle tone. The microvascular endothelium can modulate vascular smooth muscle tone by several different mechanisms. First, studies in vascular beds of several different species indicate that the endothelium can produce potent vasodilating and/or vasoconstricting substances, termed endothelium-derived relaxing factors (EDRFs) and endothelium-derived contracting factors (EDCFs), respectively (Marshall and Kontos, 1990). Second, the endothelium can act as a physical barrier to certain blood-borne vasoactive compounds, preventing the passage of certain size molecules to the underlying vascular smooth muscle cells (Ryan and Ryan, 1982). Third, the endothelium contains surface enzymes that can degrade/inactivate specific vasoactive agents (Ryan et al., 1976; Tesfamariam et al., 1987; Cohen and Weisbrod, 1988).

The primary mechanism by which the endothelium influences vascular smooth muscle tone is through the production and release of vasoactive 
substances. The release of endothelium-derived factors can be induced by a variety of substances, including acetylcholine, the calcium ionophore A23187, bradykinin, norepinephrine (NE), thrombin, and endothelin, as well as by physical stimuli such as the shear stress associated with luminal blood flow (Vanhoutte, 1989). Despite a great deal of heterogeneity related to the particular species and vascular bed (Boegehold, 1998), it is generally accepted that the endothelium can produce at least three distinct types of vasorelaxing factors. The first factor, originally named EDRF, was discovered in 1980 by Furchgott and Zawadzki. This substance, since identified as nitric oxide (NO), causes relaxation of vascular smooth muscle through activation of soluble guanylyl cyclase and a subsequent increase in intracellular cyclic guanosine 3', 5'-monophosphate (cGMP) (Rapoport and Murad, 1983; Furchgott et al., 1984). The second type of vasorelaxing factor produced by endothelial cells in a variety of vascular beds is the vasodilatory prostanoids such as prostacyclin $\left(\mathrm{PGI}_{2}\right)$ and prostaglandin $\mathrm{E}_{2}$ $\left(\mathrm{PGE}_{2}\right)$, both of which are derived from arachidonic acid metabolism (Gerritsen, 1987; Bassenge, 1996). Once released from the endothelium, these factors stimulate vascular smooth muscle adenylyl cyclase (AC), leading to increased formation of adenosine $3^{\prime}, 5^{\prime}$-cyclic monophosphate (cAMP) and subsequent vascular smooth muscle relaxation (Gerritsen, 1987). However, not all endothelium-dependent relaxations are dependent on the release of NO or prostanoids. Studies conducted by numerous investigators indicate that endothelium-dependent relaxations can be partially or totally resistant to 
cyclooxygenase and NOS inhibition (Bény and Brunet, 1988; Richard et al., 1990; Cowan and Cohen, 1991; Illiano et al., 1992; Nagao and Vanhoutte, 1992), suggesting the existence of a third class of endothelium-derived dilators. This $\mathrm{NO}$ /prostanoid-independent relaxation is preceded by vascular smooth muscle hyperpolarization, resulting in the closure of voltage-dependent $\mathrm{Ca}^{2+}$ channels and a subsequent reduction in $\left[\mathrm{Ca}^{2+}\right]_{i}$ (Fisslthaler et al., 2000). Due to the hyperpolarizing effect these substances are known as endothelium-derived hyperpolarizing factors (EDHF). It is now clear that there are probably several distinct EDHFs specific to different species and vascular beds. For instance, inhibition of the cytochrome P450 monooxygenase abolishes EDHF-mediated responses in bovine and porcine arteries (Bauersachs et al., 1994; Fulton et al., 1995), but has no effect on the EDHF-mediated responses in rat and guinea pig blood vessels (Corriu et al., 1996; Fukao et al., 1997). The arachidonic acid derivative anandamide has been suggested as a possible EDHF in rat mesentery and heart (Randall et al., 1997), but anandamide has since been rejected as an EDHF in bovine coronary, rat mesenteric, pig coronary, and guinea pig carotid arteries (Pratt et al., 1998; Chataigneau et al., 1998). Once released, EDHFs cause vascular smooth muscle hyperpolarization through the activation of potassium channels. In some species, the EDHF response is blocked by apamin, which suggests the involvement of low conductance $\mathrm{Ca}^{2+}$-dependent $\mathrm{K}^{+}$ channels (Garcia-Pascual et al., 1995; Murphy and Brayden, 1995). In others, a combination of charybdotoxin (an inhibitor of both large conductance $\mathrm{Ca}^{2+}$ - 
sensitive and voltage-sensitive $\mathrm{K}^{+}$channels) and apamin is required to abolish the EDHF response (Corriu et al., 1996; Chataigneau et al., 1998).

In addition to releasing vasodilatory agents, the endothelium also releases agents that promote vasoconstriction. The principal mediators of this response are certain cyclooxygenase products and endothelin (De Mey et al., 1982). Vasoconstrictor agents of cyclooxygenase origin include thromboxane $A_{2}$, prostaglandin $\mathrm{H}_{2}$ and superoxide anion. In some vessels, arachidonic acid and calcium ionophore A23187 cause endothelium-dependent contractions that are prevented by inhibitors of cyclooxygenase and/or thromboxane synthetase (Katusic et al., 1988; Katusic and Sheperd, 1991). In other vessels, the superoxide anion scavenger superoxide dismutase can prevent the endotheliumdependent contraction to A23187 (Katusic and Sheperd, 1991). Endothelial cells can also produce the peptide endothelin (La and Reid, 1995). Three endothelin isoforms (ET-1, ET-2, and ET-3) have been identified, with ET-1 the most potent and prevalent isoform (Haynes and Webb, 1998). Once released from endothelial cells, ET-1 binds to one of two different vascular smooth muscle endothelin receptors, the $\mathrm{ET}_{\mathrm{A}}$ subtype (ET-1 selective) or the $\mathrm{ET}_{\mathrm{B}}$ subtype (nonselective). The binding of $\mathrm{ET}-1$ to either the $\mathrm{ET}_{\mathrm{A}}$ or $\mathrm{ET}_{\mathrm{B}}$ receptor produces G-protein dependent activation of phospholipase C (PLC), which leads to the hydrolysis of phosphatidyl inositol and generation of inositol 1,4,5-triphosphate $\left(\mathrm{IP}_{3}\right)$ (Griendling et al., 1989). Once generated, $\mathrm{IP}_{3}$ diffuses to the endoplasmic reticulum where it triggers the release of intracellular calcium (Hirata et al., 1988), 
which, in association with calmodulin, activates myosin light-chain kinase and enhances vascular smooth muscle contractile activity. In addition, ET-1 has been shown to enhance the entry of calcium into the vascular smooth muscle cell by increasing the conductance of voltage-gated $\mathrm{Ca}^{2+}$ channels (Kanaide, 1996) and reducing the conductance of $\mathrm{K}^{+}$channels (Haynes and Webb, 1993).

The second general mechanism by which the endothelium modulates vascular smooth muscle tone is through its ability to function as a diffusion barrier. With its position at the interface of the vessel wall and lumen, this thin sheet of squamous cells acts as a partially selective diffusion barrier between the plasma and vascular smooth muscle. As one might imagine, there are regional and segmental differences in the size and density of endothelial pores, and in the characteristics of not only the endothelial membrane, but also the junctions between adjacent endothelial cells. As a result, different-sized molecules may or may not pass selectively through the endothelium depending on the vessel type. In general, endothelial cells of peripheral arteries and arterioles are linked by a combination of tight junctions and gap junctions (Spagnoli et al., 1982). Endothelial pores and tight junctions can allow ions, small hydrophilic molecules and proteins up to the size of albumin to pass through to the interstitium (Palade et al., 1978). In addition, small lipid-soluble substances and lipolysis products such as diglycerides, monoglycerides and free fatty acids may also cross this barrier, whereas macromolecules cannot permeate the endothelium and must be actively transported through the cell (Palade et al., 1978). 
Finally, in addition to its paracrine and barrier functions, the endothelium also contains surface enzymes capable of degrading, inactivating, or otherwise transforming vasoactive substances. For example, endothelial cells contain angiotensin-converting enzymes that can convert inactive angiotensin I into angiotensin II as well as degrade bradykinin (Ryan et al., 1976), as well as monamine oxidase and catechol-O-methyl transferase, which can actively degrade norepinephrine (Tesfamariam et al., 1987; Cohen and Weisbrod, 1988; Weiss, 1988). In addition, the endothelium contains $5^{\prime}$-ectonucleotidase, adenosine deaminase, and adenosine kinase, which are capable of modulating the local concentrations of ATP and its vasoactive metabolites ADP, AMP, and adenosine (Pearson and Gordon, 1985; Schrader and Decking, 1996).

2. Endothelium-Derived Nitric Oxide. Although Furchgott and Zawadski first described EDRF in 1980, it was several years before the precise chemical nature of this compound was known (Furchgott and Zawadski, 1980). Thanks to the efforts of Palmer and coworkers, as well as Ignarro and colleagues, the chemical identity of EDRF was known by 1987. Palmer and coworkers (1987) identified EDRF as NO on the basis of the reaction between EDRF and ozone to yield a chemiluminescent product indistinguishable from that yielded by the reaction between authentic NO and ozone. Ignarro and colleagues (1987), employing two different chemical approaches, concluded that EDRF and NO were either very closely related or the same chemical compound. 
(a) Nitric Oxide Synthesis. Nitric oxide is synthesized by three isoforms of the enzyme nitric oxide synthase (NOS). To date, these isoforms include, the constitutively-expressed isoforms NOS I, found mainly in neuronal cells, and NOS III, expressed mainly in endothelial cells, as well as the inducible isoform NOS II, first isolated in murine macrophages (Li and Förstermann, 2000). All three isoforms require heme, flavin adenine dinucleotide (FAD), flavin mononucleotide (FMN), tetrahydro-L-biopterin (BHT), nicotinamide adenine dinucleotide phosphate (NADPH), oxygen, and calmodulin (CaM) to be functional (Marletta, 1988; Marletta, 1993; Knowles and Moncada, 1994; Masters, 1994; Stuehr, 1997). All three are also homodimers of a polypeptide in which the heme- and BHT-binding domain is linked via a CaM-binding sequence to a flavoprotein with binding sites for one FAD, one FMN, and NADPH (Bredt et al., 1991; Klatt et al., 1992; McMillan et al., 1992; White and Marletta, 1992). The isoforms differ in their tissue localization, regulation, and function. For instance, nNOS is longer than the other isoforms due to the presence of a PDZ region at the amino terminus that is involved in subcellular targeting of the protein (Brenman et al., 1995). Similarly, eNOS contains specialized myristolyation and palmitoylation sites at the amino terminus that serve to stabilize the enzyme at the cell membrane (Garcia-Cardeña et al., 1996). Furthermore, nNOS and eNOS are constitutive enzymes that are regulated by calcium-dependent binding of CaM to the CaM-binding site. Therefore, their activity is regulated by changes in $\left[\mathrm{Ca}^{2+}\right]_{\mathrm{i}}$ (Moncada and Higgs, 1993; Nathan and Xie, 1994). In contrast, iNOS 
binds $\mathrm{CaM}$ in an essentially calcium-independent manner, with its activity regulated transcriptionally by cytokines rather than by changes in intracellular calcium concentration (Cho et al., 1992; Moncada and Higgs, 1993; Natha and Xie, 1994; Li and Förstermann, 2000).

Upon activation, the three isoforms catalyze the same two-step reaction. They oxidize L-arginine to the stable intermediate $\mathrm{N}$-hydroxy-L-arginine, and subsequently oxidize this intermediate to NO and L-citruline (Moncada et al., 1991; Nathan, 1992). Both of these steps are NADPH- and oxygen-dependent (Stuehr, 1997; Knowles and Moncada, 1994). The electrons required for the reaction flow from NADPH to $F A D$, then to $F M N$, and finally to the heme iron atom. The flow of electrons from FMN to the heme iron is regulated by the binding of CaM to the CaM-binding site and is therefore the site of calciumdependent regulation of nNOS and eNOS activity (Abou-Soud and Steuhr, 1993; Garcia-Cardeña et al., 1997).

Nitric oxide synthesis can be stimulated by both receptor-mediated and receptor-independent mechanisms. In the receptor-mediated mechanism, an increase in intracellular free $\mathrm{Ca}^{2+}$ concentration and the subsequent binding of calcium to CaM is necessary for NOS activation (Ayajiki et al., 1996; Korenaga et al., 1993; Luckoff et al., 1988). Some examples of the agonists that can stimulate NO synthesis include: acetylcholine, ATP, bradykinin, norepinephrine, serotonin, thrombin, the $\mathrm{Ca}^{2+}$ ionophore $\mathrm{A} 23187$, polycations and calciumATPase inhibitors (Ayajiki et al., 1996; Busse et al., 1993; Hecker et al., 1992; 
Korenaga et al., 1993). Although the precise mechanism by which these substances stimulate NO synthesis has not been fully elucidated, several key steps have been. Upon binding to their respective receptors, these agonists initiate a cascade that involves the activation of receptor-coupled $G$ proteins that subsequently activate phospholipase $\mathrm{C}$ and initiate the hydrolysis of phophatidylinositol bisphosphate $\left(\mathrm{PIP}_{2}\right)$ into diacylglycerol (DAG) and inositol1,4,5-trisphosphate $\left(\mathrm{IP}_{3}\right)$ (Adams, 1989). Once generated, $\mathrm{IP}_{3}$ diffuses to the endoplasmic reticulum where it binds to its receptor and promotes the release of $\mathrm{Ca}^{2+}$ from intracellular stores (Bredt and Snyder, 1991). The release of intracellular $\mathrm{Ca}^{2+}$ contributes to the initial rise in cytosolic $\mathrm{Ca}^{2+}$ levels, but its most important role is to enhance extracellular calcium entry into the cell (Ayajiki et al., 1996; Korenaga et al., 1993; Luckoff et al., 1988) by promoting membrane hyperpolarization through the activation of calcium-activated $\mathrm{K}^{+}$channels. Ultimately, this cascade results in a substantial increase in $\left[\mathrm{Ca}^{2+}\right]_{\mathrm{i}}$, thus promoting the formation of the calcium/CaM complex.

In at least one receptor-independent mechanism of endothelial NO synthesis, the response to hemodynamic shear stress, NO synthesis is only transiently dependent on the intracellular $\mathrm{Ca}^{2+}$ concentration (Muller et al., 1999). Just as with agonist-dependent NOS activation, agonist-independent NOS activation appears to involve activation of endothelial membrane G proteins (Gudi et al., 1996; Kuchan et al., 1994) which are responsible for the activation of phospholipase $\mathrm{C}$ and a subsequent increase in intracellular $\mathrm{IP}_{3}$ levels (Nollert et 
al., 1990; Prasad et al., 1993). As stated above, $\mathbb{I P}_{3}$ can diffuse to the endoplasmic reticulum where it promotes the release of intracellular $\mathrm{Ca}^{2+}$ stores (Bredt and Snyder, 1991). Once released, this $\mathrm{Ca}^{2+}$ promotes the entry of $\mathrm{Ca}^{2+}$ from outside the cell possibly by the activation of an outward potassium current (Olesen et al., 1988). Together, these responses promote an increase in $\left[\mathrm{Ca}^{2+}\right]_{\mathrm{i}}$ that may provide an important rapid component to the endothelial response to elevated hemodynamic shear.

The sustained release of NO during increased shear stress does not require an increase in intracellular $\mathrm{Ca}^{2+}$, but rather depends on the phosphorylation of eNOS by tyrosine and serine/threonine kinases (Ishida et al., 1996; Muller et al., 1999; Fisslthaler et al., 2000). In recent years, various elements of known signaling pathways have been studied in an attempt to elucidate the mechanism of endothelial shear stress transduction. Ishida and coworkers (1996) found that both flow and $\beta 1$ integrin activation stimulate protein tyrosine phosphorylation, mitogen-activated protein kinase (MAP) kinase, and focal adhesion kinase (FAK) in human umbilical vein endothelial cells (HUVEC). Also working with HUVECs, Pearce and colleagues (1996) found that, in addition to activating MAP kinase, shear activates cytosolic phospholipase $\mathrm{A}_{2}(\mathrm{CPLA})$. Shear-dependent activation of $\mathrm{K}^{+}$channels and stretch-activated $\mathrm{Ca}^{2+}$ channels has also been reported as a possible mechanism for signal transduction (Davies, 1995; Jo et al., 1997).

(b) Basal Nitric Oxide Release. Many investigators have reported that there is a basal release of NO from the vascular endothelium (Griffith et al., 1984; 
Förstermann et al., 1985; Martin et al., 1986; Bohlen, 1998b; Lash and Bohlen, 1999; Bohlen and Nase, 2000; Bohlen and Nase, 2001; Nase and Bohlen, 2001). For example, using a NO-sensitive microelectrode, Bohlen demonstrated that small arteries and arterioles in the rat intestine continuously release NO (Bohlen, 1998b; Bohlen and Nase, 2000; Bohlen and Nase, 2001; Nase and Bohlen, 2001). The overall importance of basal NO release in cardiovascular regulation is illustrated by findings that systemic NOS inhibition with the L-arginine analog L-NMMA significantly increases arterial blood pressure, and that this effect is reversed by L-arginine (Rees et al., 1989; Gardiner et al., 1990; Baylis et al., 1992). In-vivo microscopy has revealed that NOS inhibition with various Larginine analogs also significantly increases resistance vessel tone in several vascular beds (Hester et al., 1993; Boegehold, 1995; Friebel et al., 1995; Pries et al., 1995; Bohlen and Lash, 1996). However, NOS inhibition does not affect vascular tone in every vascular bed or vessel segment (Nase and Boegehold, 1996; Nurkiewicz and Boegehold, 1999). While these latter findings indirectly suggest that some vascular beds lack basal NO release, it is important to realize that this may not necessarily be true. Since resting arteriolar tone is the result of vascular smooth muscle's integration of numerous ongoing vasoactive signals, changes in the activity of any of these signals may be accompanied by changes in the other signals, thereby preserving the level of tone.

The intrinsic stimulus for tonically released NO is not known for certain, but recent studies suggest that a prime candidate is hemodynamic shear stress 
(Bohlen and Lash, 1996; Bohlen and Nase, 2000). It is well documented that shear-induced release of $\mathrm{NO}$ is important in mediating the local arteriolar dilation in response to acute increases in blood flow (Boegehold, 1995), and it is also possible that resting blood flow acts as a continuous background stimulus for vasodilation (Robard, 1975). Bohlen and Nase (2000) demonstrated that collateral occlusion of first-order arterioles increases parallel arteriolar blood flow, diameter, and shear rate by $90 \%, 10 \%$, and $20 \%$, respectively. This $20 \%$ increase in shear rate translated into a $40 \%$ increase in periarteriolar NO concentration. Based on this and other evidence, Bohlen and Nase (2000) concluded that $60-80 \%$ of the basal NO release in rat intestinal arterioles was due to the influence of shear stress on the endothelium.

(c) Stimulated Nitric Oxide Release. In addition to the basal release of endothelial NO, its synthesis can be enhanced in virtually every vascular bed by receptor-dependent agonists such as acetylcholine, adenosine, ATP, norepinephrine and bradykinin (Koller et al., 1989; Nakumura and Prewitt, 1991; Korenaga et al., 1993; Ayajiki et al., 1996) and receptor-independent agonists such as calcium ionophores (Busse et al., 1993). For any of these agonists to increase eNOS activity, it is absolutely necessary for them to somehow elevate $\left[\mathrm{Ca}^{2+}\right]_{\mathrm{i}}$ (Muller et al., 1999). As mentioned above, agonist-induced increases in $\left[\mathrm{Ca}^{2+}\right]_{\mathrm{i}}$ can be achieved by a transient $\mathrm{IP}_{3}$-mediated release of intracellular $\mathrm{Ca}^{2+}$ and a more sustained transmembrane influx of $\mathrm{Ca}^{2+}$ from the extracellular space. A number of studies have found that removal of extracellular $\mathrm{Ca}^{2+}$ inhibits 
bradykinin-, thimerosal-, ATP-, and acetylcholine-induced NO synthesis (Luckoff et al., 1988; Korenaga et al., 1993; Ayajiki et al., 1996), verifying that it is the influx of $\mathrm{Ca}^{2+}$ from the extracellular space that drives $\mathrm{NO}$ synthesis in response to these agonists.

Other factors such as fluid shear stress (Boegehold, 1995; Bohlen and Nase, 2000; Friebel et al., 1995), and decreases in perivascular $\mathrm{PO}_{2}$ (Blitzer et al., 1996; Pohl and Busse, 1989; Pries et al., 1995) can also enhance NO synthesis. Hemodynamic shear stress has been shown to contribute importantly to the control of vascular resistance in the intact arteriolar networks of skeletal muscle (Boegehold, 1995), the intestine (Bohlen and Lash, 1996; Bohlen and Nase, 2000) and the mesentery (Smiesko et al., 1989). Hemodynamic shear stress contributes importantly to the maintenance of basal NO release, but it also represents an important mechanism by which individual vessels can modulate their own resistance in response to changes in either the upstream or downstream resistance. Following an acute change in luminal flow, there is an initial phase during which vascular diameter does not change, leading to either an increase or decrease in shear stress on the endothelial cell membrane (Koller and Kaley, 1990a). This change in shear stress elicits the increased or decreased release of relaxing factors from the endothelium, resulting in vasodilation or vasoconstriction and a partial restoration of wall shear stress toward control levels (Smiesko et al., 1989; Koller et al., 1994; Boegehold, 1995). In addition to sensing mechanical forces such as shear stress, the vascular 
endothelium may also act as a local sensor and effector system for the regulation of tissue oxygen supply. For a full review of this topic, please see section C: Metabolic Control of Vascular Tone.

(d) Nitric Oxide Signaling Pathways in Vascular Smooth Muscle. Once formed, NO quickly diffuses into the vascular smooth muscle cytoplasm where it binds to and activates soluble guanylyl cyclase (Katsuki et al., 1977), which catalyzes the conversion of GTP to cGMP. Cyclic GMP then activates cGMPdependent protein kinase (cGMP-PK), which promotes vascular smooth muscle relaxation principally by lowering $\left[\mathrm{Ca}^{2+}\right]_{l}$ (Lincoln and Cornwell, 1993). Depending on the species and vascular bed, cGMP could affect $\left[\mathrm{Ca}^{2+}\right]_{i}$ in up to four different ways: (1) by reducing the influx of extracellular $\mathrm{Ca}^{2+}$, (2) by increasing the efflux of intracellular $\mathrm{Ca}^{2+},(3)$ by promoting $\mathrm{Ca}^{2+}$ sequestration in the sarcoplasmic reticulum, and (4) by decreasing the release of $\mathrm{Ca}^{2+}$ from intracellular stores. Cyclic GMP-dependent mechanisms have been shown to reduce $\mathrm{Ca}^{2+}$ influx via inhibition of voltage-dependent $\mathrm{L}$-type $\mathrm{Ca}^{2+}$ channels either through a direct reduction of channel activity or by hyperpolarization of the vascular smooth muscle membrane due to increased $\mathrm{K}_{\mathrm{Ca}}$ channel activity (Archer et al., 1994; Carrier et al., 1997; Ruiz-Velasco et al., 1998). Increased efflux of $\mathrm{Ca}^{2+}$ from the vascular smooth muscle may be accomplished by activation of the plasma membrane $\mathrm{Ca}^{2+}$-pumping ATPase and the $\mathrm{Na}^{+} / \mathrm{Ca}^{2+}$ exchanger. The driving force for $\mathrm{Ca}^{2+}$ removal from the cell by the $\mathrm{Na}^{+} / \mathrm{Ca}^{2+}$ exchanger, in turn, may be dependent on the depletion of intracellular $\mathrm{Na}^{+}$via activation of $\mathrm{Na}^{+}-\mathrm{K}^{+}$ 
ATPase. The $\mathrm{Ca}^{2+}$-pumping ATPase and the $\mathrm{Na}^{+} / \mathrm{K}^{+}$ATPase in the plasma membrane are activated by cGMP through cGMP-PK (Yoshida et al., 1992; Tamaoki et al., 1997a). Cyclic GMP promotes sequestration of $\mathrm{Ca}^{2+}$ by activating the sarcoplasmic reticulum $\mathrm{Ca}^{2+}$-pumping ATPase (Andriantsitohaina et al., 1995). The molecular mechanism underlying this effect appears to be cGMP-PK phosphorylation of phospholamban, as demonstrated by Sabine and colleagues (1995). Finally, cGMP has also been shown to limit mobilization of intracellular $\mathrm{Ca}^{2+}$ by inhibiting the $\mathrm{IP}_{3}$ signal transduction pathway. Various investigators have reported that cGMP blocks agonist-induced $\mathrm{IP}_{3}$ formation and induces cGMP-PK-mediated phosphorylation of the $\mathrm{IP}_{3}$ receptor in the sarcoplasmic reticulum, which substantially reduces the affinity of these receptors for $\mathrm{IP}_{3}$ (Ruth et al., 1993; Komalavilas and Lincoln, 1994; Komalavilas and Lincoln, 1996).

In addition to its effect on $\mathrm{Ca}^{2+}$ homeostasis, $\mathrm{NO}$ has been shown to promote vasodilation through activation of vascular smooth muscle $\mathrm{K}^{+}$channels (Murphy and Brayden, 1995; Corriu et al., 1996; Yuan et al., 1996; Li et al., 1997; Zhao et al., 1997). NO has been shown to hyperpolarize the underlying vascular smooth muscle through the activation of ATP-sensitive $\mathrm{K}$ in rabbit mesenteric arteries (Murphy and Brayden, 1995) and in guinea-pig carotid artery (Corriu et al., 1996). In the bovine coronary artery, NO promotes hyperpolarization and relaxation through the activation of both large conductance $\mathrm{Ca}^{2+}$-activated $\mathrm{K}^{+}$ channels and delayed rectifier $\mathrm{K}^{+}$channels (Li et al., 1997). 


\section{B. NEURAL CONTROL OF VASCULAR TONE.}

1. The Intestinal Vasculature and its Innervation. As shown in Figure 1 (next page), the small intestine of the rat is composed of three layers, the mucosa where nutrients are absorbed, the submucosa where glandular tissue is located, and the visceral smooth muscle that mixes and propels the food (Bohlen, 1998a). Microvascular perfusion of these layers originates from branches of the superior and inferior mesenteric arteries, and these small feed arteries supply first-order arterioles that penetrate both muscle layers of the muscularis externa (Bohlen, 1995). These arterioles then give rise to secondorder arterioles, which form anastomoses between adjacent first-order arterioles. Second-order arterioles in turn give rise to third-order arterioles that perfuse the individual arterioles of one or more mucosal villi (Bohlen, 1998). Third-order arterioles also give rise to fourth-order arterioles, which ascend through the muscle layers and ultimately give rise to fifth-order arterioles that supply the capillaries of the longitudinal muscle. The venular drainage mirrors the arteriolar inflow system. The capillaries converge into fourth-order venules, which supply third-order venules. The third-order venules then descend through both muscle layers and drain into second-order venules. Finally, the second-order venules drain into first-order venules, which return the blood to the small mesenteric veins.

All of the available evidence indicates that neurogenic constriction of arterioles in the small intestine results solely from the activation of extrinsic 


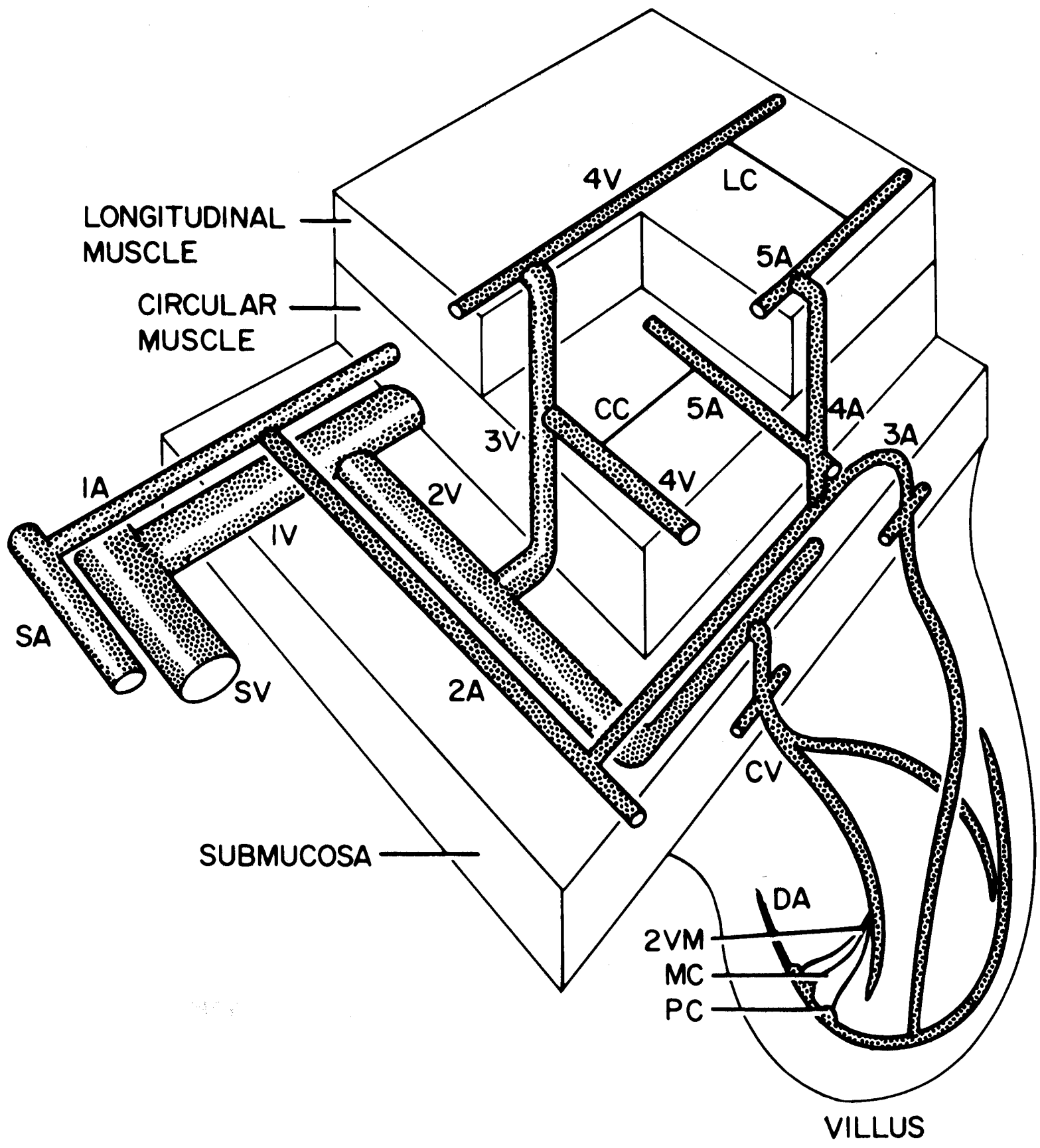

Figure 1. Microvascular branching pattern in the rat small intestine. Arterioles are consecutively numbered from largest to smallest branches; SA and SV are the small artery and vein that run parallel to the mesenteric border of the bowel and are in turn perfused by arteries in the mesentery. 
sympathetic nerves, which originate in the prevertebral celiac and mesenteric ganglia (Furness and Costa, 1987; Hirst, 1989; Surprenant; 1994). In the rat, cat, guinea pig, and rabbit, these sympathetic vasoconstrictor neurons have been shown to densely innervate intestinal arterioles while only sparsely innervating intestinal veins and venules (Furness, 1971; Silva et al., 1971). This pattern of innervation allows for neurogenic constriction along the entire network of the arteries and arterioles (Furness, 1971; Silva et al., 1971), resulting in a considerable rise in vascular resistance.

2. Sympathetic Adrenergic Neuron Content. The concept of cotransmission was originally presented by Burnstock (1976) who, through comparative studies on the evolution of the autonomic nervous system, provided evidence that ATP acts as a co-transmitter with NE in sympathetic nerves. The co-existence of different neurotransmitters within sympathetic nerve terminals is now widely accepted, and a number of potential co-transmitters have been identified, including ATP and neuropeptide Y (NPY). However, the significance of these co-stored agents for the regulation of vascular tone is a subject of great debate that goes beyond the scope of this review. Therefore, I will limit this discussion to those most relevant to the study at hand.

In most blood vessels that have been studied, a purinergic component of sympathetic neurogenic vasoconstriction has been demonstrated, but the relative contributions of ATP and NE to the response varies greatly among blood vessels. 
For instance, ATP only makes about a $10 \%$ contribution to peak constriction of the rat tail artery (Bao et al., 1993), whereas ATP is totally responsible for the neurogenic constriction in the rabbit mesenteric artery (Ramme et al., 1987). Within the intestinal circulation, both NE and ATP play a major role in neurogenic vasoconstriction. In submucosal arterioles, neurogenic vasoconstriction is mediated almost entirely by the binding of ATP to $P_{2 x}$-purinoceptors located on the vascular smooth muscle (Evans and Surprenant, 1992; Surprenant, 1994). However, in the larger arterioles of the circular muscle layer, NE appears to be the primary mediator of neurogenic vasoconstriction (Nase and Boegehold, 1996; Nase and Boegehold, 1998). One possible determinant of the relative contributions of ATP and NE to neurogenic constriction is the frequency of nerve stimulation (Kennedy et al., 1986; Bao et al., 1993). In the rabbit ear artery, ATP plays a much more prominent role than NE at low nerve stimulation frequencies, whereas the role of NE progressively increases as nerve stimulation frequency increases (Kennedy et al., 1986).

3. Modulation of Arteriolar Diameter and Network Blood Flow by Sympathetic Nerve Activity. Tonic sympathetic nerve activity contributes importantly to the maintenance of resting arteriolar tone in the intestine (Folkow, 1964) and in a number of vascular beds (Bohlen and Gore, 1977; Laurikainen et al., 1997; Villanueva et al., 1994; Bevan et al., 1993). In the intestine, Folkow (1964) indirectly determined that the resting discharge rate of sympathetic nerves 
innervating the vasculature ranges between 1 and $3 \mathrm{~Hz}$, and that these discharge rates can increase to as much as $8-10 \mathrm{~Hz}$ during reflex activity. Folkow's inference about the resting discharge rates of these nerves has been confirmed by direct measurement of postganglionic sympathetic fiber discharge rates (Kollai and Koizumi, 1980).

During periods of increased sympathetic nerve activity, there is an increase in vascular resistance throughout the network and a subsequent reduction in network blood flow. For example, in the rat intestine, sympathetic nerve stimulation induces frequency-dependent arteriolar constrictions that persist throughout the stimulation period (Bohlen et al., 1978; Nase and Boegehold, 1996; Nase and Boegehold, 1997a, Nase and Boegehold, 1997b; Nase and Boegehold, 1998). In other vascular beds sympathetic nerve stimulation causes a transient vasoconstriction followed by a return of some vessel diameters to near resting levels, possibly in response to changes in local metabolite or oxygen levels (Eriksson and Lisander, 1972; Folkow et al., 1971; Furness and Marshall, 1974; Marshall, 1982; Boegehold and Johnson, 1988a; Boegehold and Johnson, 1988b; Pal et al., 1998; Lautt et al., 1988).

Studies in various vascular beds have revealed segmental differences in the response to sympathetic nerve stimulation. Furness and Marshall (1974) reported that all arterioles of the rat mesentery constrict by $25-75 \%$ during sympathetic nerve stimulation with the exception of precapillary arterioles, which do not respond. Working in the cat sartorius muscle, Boegehold and Johnson 
(1988b) also found segmental differences in the vascular response to sympathetic nerve stimulation, with the fourth-order arterioles constricting to a greater degree than either more proximal or more distal arterioles. In the rat intestine, Bohlen and colleagues (1978) demonstrated that sympathetic nerve stimulation induces a greater increase in second- and third-order arteriolar resistance than fourth- and fifth-order arteriolar resistance. More recently, Nase and Boegehold (1996) found that sympathetic nerve stimulation reduces secondorder arteriolar diameter by $29-71 \%$ while only reducing first-order arteriolar diameter by $20-52 \%$ and small feed artery diameter by $13-47 \%$.

In the rat intestine, the effect of increased sympathetic nerve activity on blood flow depends on the stimulation frequency and the vessel type. For example, Bohlen and colleagues (1978) found that sympathetic nerve stimulation at $4 \mathrm{~Hz}$ has no effect on arteriolar blood flow in the mucosa, whereas stimulation at 8 and $16 \mathrm{~Hz}$ produced a frequency-dependent reduction in serosal blood flow with mucosal blood flow reduced by $43-70 \%$ (Bohlen et al., 1978). In the circular muscle layer, Nase and Boegehold $(1996,1998)$ found that sympathetic nerve stimulation at 3-16 Hz reduced flow in small feed arteries by $47-91 \%$ and in firstorder arterioles by $33-92 \%$.

4. Endothelial modulation of sympathetic tone. There are at least two mechanisms by which the endothelium can limit sympathetic adrenergic constriction. First, the endothelium can limit sympathetic adrenergic constriction 
by participating in the uptake and extraneuronal metabolism of neurally-released NE (Rorie, 1982; Tesfamariam et al., 1987; Cohen and Weisbrod 1988). Second, the endothelium can release substances such as NO and vasodilator prostanoids that in turn attenuate adrenergic constriction (Kadowitz et al., 1971; Hedqvist, 1972; Martin et al., 1986; Tesfamariam and Halpern, 1987; Tesfamariam et al., 1987; Cohen and Weisbrod, 1988; Greenberg et al., 1989; Chatziantoniou and Arehdshorst, 1992; Ohyanagi et al., 1992; Jones et al., 1993; Schwarz et al., 1995; Thomas and Victor, 1998; VanVlack et al., 1998; Mendizabal et al., 1999; Smith et al., 1999; Costa et al., 2001).

(a) Endothelial Metabolism of Norepinephrine. After its release, NE is removed from the vasculature by a number of different processes, including its deactivation by the enzymes catechol-O-methyltransferase and monoamine oxidase (Rorie, 1982; Tesfamariam et al., 1987; Cohen and Weisbrod 1988). By metabolizing NE, these enzymes reduce the effective concentration of NE at its postjunctional receptors and thereby limit the increase in vascular tone. Rorie (1982) demonstrated that in the canine pulmonary artery pretreated with tritiated $\mathrm{NE}$, endothelial metabolism of NE is significantly reduced when extraneuronal uptake of NE is inhibited and that removal of the endothelium reduced the amounts of O-methylated NE metabolites collected during adrenergic stimulation. Tesfamariam and colleagues (1987) reported that removal of rabbit carotid artery endothelium augments nerve stimulation-induced constriction, and that inhibition of NE metabolism and extraneuronal uptake with cocaine, hydrocortisone and 
parglyine augments the adrenergic constriction of endothelium-intact segments more than endothelium-denuded segments. In addition, they found that the combined inhibition of guanylyl cyclase and NE disposition abolished the difference between the responses of endothelium-intact and endotheliumdenuded segments. Cohen and Weisbrod (1988) demonstrated that NE overflow was significantly greater in endothelium-denuded arteries than in endotheliumintact arteries. They also demonstrated that addition of cocaine, hydrocortisone and parglyine significantly enhanced NE overflow in endothelium-intact arteries without an appreciable effect on endothelium-denuded arteries. Taken together, the above studies suggest that reduction of NE concentration by endothelial cell enzymes is sufficient to attenuate adrenergic constriction in the absence of any other intervention.

(b) Endothelium-derived factors. As stated above, endothelium-derived factors, including NO and vasodilator prostanoids, have been shown to limit neurogenic constriction in a variety of vascular beds. However, in the rat intestine, vasodilator prostanoids do not appear to play a role in the endothelium's ability to modulate neurogenic constriction (Nase and Boegehold, 1997). Therefore, for the purpose of this discussion, I will only consider the role of $\mathrm{NO}$ in modulating neurogenic constriction.

Historically the role of $\mathrm{NO}$ in the modulation of neurogenic tone has been explored by evaluating the effects of NOS inhibition, NO scavenging, and/or endothelial removal on the vascular response to exogenous NE application or to 
the release of neuronal NE by electrical field stimulation. In one of the earliest studies conducted along these lines, Martin and colleagues (1986) found that the application of exogenous NE increases rat and rabbit aortic ring tension significantly more in endothelium-denuded segments than in endothelium-intact segments, and that the NO scavenger hemoglobin abolishes this difference. Also in the rat aorta, Ayotunde and Triggle (1993b) found that endothelial removal enhances the response of ring segments to exogenous NE, and that the NOS inhibitors L-NMMA and L-NAME, but not their D-isomers, also enhance the responsiveness of endothelium-intact segments to exogenous NE. Working in the canine epicardium, Jones and colleagues (1993) found that L-NMMA significantly enhances the responsiveness of large arterioles to exogenous NE. Most recently, Mendizabal and colleagues (1999) demonstrated that NO attenuates the constrictor response to exogenous $\mathrm{NE}$ in the perfused rat mesentery.

Electric field stimulation has been used to investigate the modulation of sympathetic tone by a number of different investigators. In isolated rat mesenteric and femoral arteries, Urabe and colleagues (1991) found that the response of endothelium-intact ring segments to transmural nerve stimulation was potentiated by NO scavenging with methylene blue or by endothelial removal. In the rat caudal artery, Phong and colleagues (1992) reported that treatment with L-NAME, hemoglobin or methylene blue enhances sympathetic nerve-induced constriction in endothelium-intact but not endothelium-denuded 
vessels. More recently, King-VanVlack and colleagues (1998) found that LNAME enhances the increase in vascular resistance that accompanies sympathetic nerve stimulation in the canine gastrocnemius muscle. While studying the effect of exercise on sympathetic vasoconstriction in the rat hindlimb, Thomas and Victor (1998) found that L-NAME partially reversed the limiting influence of exercise on neurogenic constriction, thus resulting in an enhanced sympathetic vasoconstriction in contracting hindlimb. Of particular interest to the study at hand, Nase and Boegehold (1996) found that inhibition of NOS with L-NMMA enhances arteriolar responses to sympathetic nerve stimulation in the rat intestine. In a subsequent study, they found that functional inactivation of the endothelium with a microembolism also enhances the vascular response to sympathetic nerve stimulation, with no further enhancement by LNMMA (Nase and Boegehold, 1997).

\section{METABOLIC CONTROL OF VASCULAR TONE.}

1. General Aspects. The relationship between tissue metabolic activity and blood flow has been recognized for well over a century (Gaskell, 1876a; 1876b) with blood flow increasing in proportion to the metabolic demands of the tissue. In skeletal muscle, there is a positive correlation between tissue blood flow and muscle contraction frequency (Hilton et al., 1978; Mackie and Terjung, 1983), and between tissue blood flow and muscle oxygen consumption (Mohrman, 1982; Mohrman and Regal, 1988). Because of this relationship between 
metabolic activity and blood flow, it has been hypothesized that the local metabolic state of the tissue directly affects blood flow by altering arteriolar tone and therefore vascular resistance. To date, the vasoactive properties of a variety of biochemical compounds have been studied in pursuit of elucidating the mechanism of metabolic regulation. The remainder of this section will be an overview of some likely mediators of this metabolic modulation that are most relevant to the study at hand.

\section{Regulation of Vascular Tone by Oxygen.}

(a) Oxygen delivery to the intestine. The transport of oxygen from the atmosphere to the mitochondria can be divided into two stages. The first stage consists of the movement of oxygen from the lung alveoli to the microcirculation within a tissue, and the second stage is the transfer of oxygen from the red blood cell $(\mathrm{RBC})$ to the cell mitochondria. Oxygen moves from the alveoli into the pulmonary capillaries by passive diffusion. The transfer of oxygen from air to blood is altered by ventilation/perfusion abnormalities and by changes in inspired oxygen concentration (Wilson et al., 1977). In the pulmonary capillary blood, oxygen binds to hemoglobin in a four stage chemical process resulting in the sigmoid shaped oxyhemoglobin dissociation curve. From the lungs, blood is transported to the tissue capillaries by the pumping action of the heart. The second stage of oxygen transport comprises numerous cellular and subcellular processes, such as (1) microvascular control mechanisms that match blood flow with tissue metabolic requirements, (2) the diffusion of oxygen from hemoglobin 
to the tissues, and (3) the rate of cellular oxygen utilization (Renkin, 1984). The major determinants of this second diffusive stage are, tissue metabolic rate, the density of perfused capillaries, local vascular resistance, oxygen consumption rate, oxygen extraction, and ATP production.

In the microvessels, oxygen dissociates from hemoglobin and moves into the tissues by passive diffusion (Krogh, 1919). This oxygen exchange is influenced by many factors (Pittman, 1986). For example, capillary hematocrit is as much as $50 \%$ lower than systemic hematocrit (Sarelius and Duling, 1982). Variations in capillary hematocrit provide the microvasculature with yet another control mechanism to ensure an appropriate delivery of oxygen into the tissues. As demonstrated by Desjardins and Duling (1987), capillary hematocrit can vary widely with increases in tissue oxygen demand. Microscopic studies also show that the RBCs tend to follow the path of highest flow. In other words, at capillary bifurcations, the capillary with the greater blood flow also has a greater hematocrit (Fung, 1973; Gaehtgens, 1984), thus providing an excellent system for channeling oxygen to the place where the need is greatest.

Capillary hematocrit (Duling and Desjardins, 1987) and flow (Gutierrez et al., 1988; Ivanov et al., 1985) influence other microvascular parameters that are important for tissue oxygenation, such as RBC velocity, intracapillary $\mathrm{PO}_{2}$, and the space between the RBCs. The velocity and path taken by the RBCs in the capillary network determine their transit time through these exchange vessels (Sarelius and Duling, 1982; Tyml et al., 1981). In well-oxygenated tissues, 
changes in capillary transit time probably have little influence on gas exchange. However, under conditions of severe hypoxia or greatly elevated metabolic rate, the time needed by the RBCs to release oxygen may decrease, thereby increasing the rate of capillary oxygen delivery (Gutierrez, 1986; Honig and Odoroff, 1984). Microscopic flow studies have shown that RBCs tend to take the longest path through a given capillary network, thereby maximizing capillary transit time (Sarelius, 1986).

Capillary recruitment is a mechanism by which the microvasculature can rapidly increase the surface area available for oxygen exchange (Honig et al., 1980). In some tissues, a large fraction of the available capillaries are closed and do not participate in oxygen transport under resting conditions. The proportion of capillaries open at any given time in resting dog gracilis muscle has been estimated at $40 \%$ (Bordeau-Martini et al., 1974), a number that increases in a graded fashion in response to exercise or hypoxia. In addition to increasing the vascular surface area available for exchange, capillary recruitment also promotes oxygen delivery by decreasing the mean diffusion distance from a perfused capillary to any given parenchymal cell.

August Krogh (1919) was the first to quantify the diffusion of oxygen from the microvasculature to various tissues. Krogh reasoned that oxygen diffuses in a radial fashion from the center of the capillaries into the tissues. In cooperation with the mathematician Erlang, Krogh proposed a mathematical model that was later modified by Kety (1957) and Tenney (1974). In the modified model, oxygen 
transport takes place in a capillary of cylindrical geometry as blood moves from the arterial to the venous end. The major determinants of oxygen diffusion in this model are as follows: the difference between capillary and tissue oxygen pressures, the tissue oxygen diffusion coefficient, the radius of the capillary, and the diffusion distance. According to Krogh's model, tissue $\mathrm{PO}_{2}$ declines radially outward from the capillaries and along the length of the capillary. The cylindrical model predicts that the highest and the lowest tissue $\mathrm{PO}_{2}$ levels will be around the arterial and venous ends, respectively. The region with the lowest tissue $\mathrm{PO}_{2}$ is called the "lethal corner." Those cells located in the "lethal corner" should be the first to experience the effect of hypoxia.

The capillaries are not the only site of $\mathrm{O}_{2}$ exchange between the tissue and the circulation. Oxygen delivery to the tissues occurs throughout the entire circulation and is the consequence of a balance between the velocity at which $\mathrm{O}_{2}$ is carried by the blood and the rate at which $\mathrm{O}_{2}$ leaks out of the blood vessels (Ellsworth and Pittman, 1990; Mirhashemi et al., 1987). Studies conducted by Duling and Berne (1970) indicate that about one-third of arterial $\mathrm{O}_{2}$ exits the circulation prior to arrival at the capillaries. Similar magnitudes of oxygen loss from arterioles have been found in the pial microcirculation (Duling et al., 1979; Ivanov et al., 1982). In the hamster skinfold, Torres and colleagues (1996) reported that intraluminal $\mathrm{PO}_{2}$ decreased longitudinally from $58 \mathrm{~mm} \mathrm{Hg}$ in firstorder arterioles to $35 \mathrm{~mm} \mathrm{Hg}$ in fourth-order arterioles. 
(b) Effects of alterations in oxygen tension on vascular tone. Although oxygen's ability to modulate vascular tone has been recognized for decades, the precise mechanism by which oxygen exerts this influence has not been elucidated. Some studies suggest that oxygen may have a direct effect on vascular smooth tone by influencing the activity of smooth muscle cell ion channels (Gebremedhi et al., 1994; Welsh et al., 1998; McCulloch et al., 1999). For instance, in cat cerebral arteries, Gebremedhin and coworkers (1994) found that hypoxia increased the activity of calcium-sensitive potassium channels, thereby inducing smooth muscle cell hyperpolarization and relaxation. Similarly, studies conducted in rat renal and cremaster muscle microvessels suggest that reduced oxygen levels may lead to reduced formation of 20hydroxyeicosatetraenoic acid, a constitutively-produced cytochrome P-450 metabolite that normally acts as a potent vasoconstrictor (Harder et al., 1996). However, Welsh and colleagues (1998) found that hyperoxia increases vascular tone in hamster cheek pouch arterioles by activating L-type calcium channels. Taken together, these results suggest that alterations in oxygen tension can act directly at the level of the vascular smooth muscle to either increase or decrease vascular tone, depending on the prevailing oxygen tension.

In addition to having a direct effect on vascular tone, changes in oxygen tension have been shown to exert a considerable influence on the release of endothelium-derived vasoactive factors (Busse et al., 1983; Pohl and Busse, 1989; Myers et al., 1991; Okada, 1991; Gräser and Rubanyi, 1992; Messina et 
al., 1992; Park et al., 1992; Busse et al., 1993; Fredricks et al., 1994; Blitzer et al., 1996; Jimenez, 1996; Ward, 1996; Bryan and Marshal, 1999a; Bryan and Marshall, 1999b). In one of the earliest studies conducted on the subject, Busse and coworkers (1983) found that removal of the endothelium abolishes the dilatory response of isolated rat tail and canine femoral arteries to intraluminal hypoxia. Furthermore, incubation with the cyclooxygenase inhibitor indomethacin, significantly attenuated this dilatory response to hypoxia, suggesting that prostacyclin may be a mediator of this response. In support of this finding, other investigators have reported that treatment with indomethacin completely abolishes the hypoxic dilation of vessels from canine heart (Myers et al., 1991), rat heart (Okada et al., 1991), and rat cremaster muscle (Messina et al., 1992), as well as the rat middle cerebral artery and femoral arteries (Fredricks et al., 1994a; Fredricks et al., 1994b).

The role of NO in the vascular response to hypoxia was not elucidated until the late nineteen-eighties. Then, in what has become the seminal work on the role of NO in hypoxic vasodilation, Pohl and Busse (1989) demonstrated that hypoxia stimulates NO release in isolated rabbit aorta and femoral artery segments. In their study, Pohl and Busse found that exposure of endotheliumintact vessel segments to hypoxia promotes a vasodilation that is completely abolished by hemoglobin, whereas exposure of endothelium-denuded segments to hypoxia produces no effect. Furthermore, exposure of an endotheliumdenuded segment to the effluent of cultured endothelial cells that had been 
exposed to hypoxia results in dilation of the vessel segment, and this dilation can be significantly attenuated by the use of a delay coil to allow time for the metabolic inactivation of NO. Over the past decade, a considerable body of evidence has been collected in support of Pohl and Busse's findings. For example, hypoxia has been shown to increase NO synthesis in a variety of vessels and vascular beds including rat aorta (Gräser and Rubanyi, 1992), guinea pig heart (Park et al., 1992), bovine pulmonary artery (Hampl et al., 1995), pig heart (Xu et al., 1995; Jimenez et al., 1996), human forearm (Blitzer et al., 1996), dog diaphragm (Ward, 1996), and rat intestine (Bohlen and Nase, 2000; Bohlen and Nase, 2001). Although the exact mechanism by which hypoxia stimulates NO release from endothelial cells has not been established, some studies suggest that a reduction in oxygen tension increases intracellular calcium levels, which promotes both basal and stimulated NO production (Busse et al., 1993; Hampl et al., 1995; Friebel et al., 1995).

In contrast to the preceding discussion, other investigators have reported that reduced $\mathrm{O}_{2}$ tension leads to a reduction in NO activity (Hassoun et al., 1994; Herget et al., 2000; Wood et al., 2000). For instance, Hassoun and coworkers (1994) reported that exposure of isolated bovine pulmonary artery smooth muscle cells to hypoxic media enhances the transcription of xanthine dehydrogenase/xanthine oxidase. In the rat, Wood and colleagues (2000) found that systemic hypoxia leads to increased reactive oxygen species secondary to leukocyte activation. Once formed these reactive oxygen species can quickly 
react with and subsequently inactivate NO (Beckman and Koppenol, 1996). For instance one of these reactive oxygen species, superoxide anion, has been shown to react with NO to generate peroxynitrite at a rate that is only limited by its diffusion coefficient (Mateo et al., 2000). Therefore, under hypoxic conditions it is possible that increased generation of these reactive oxygen species could limit the bio-availability of NO.

In addition to the effects just described, reduced oxygen tension can indirectly influence vascular tone by promoting the release of vasoactive factors such as adenosine and ATP (Forrester and Williams, 1977; Schrader et al. 1977; Headrick et al., 1992; Raatikainen et al., 1994; Cohen et al., 1995; Ellsworth et al., 1995; Decking et al., 1997; Dietrich et al., 2000; Ellsworth, 2000; Jagger et al., 2001). The regulation of vascular tone by these factors will be discussed in detail in the following sections.

3. Regulation of vascular tone by adenosine and adenine nucleotides.

(a) A Brief History of Purinergic Signaling. The earliest evidence describing the physiological importance of extracellular adenine compounds was first reported by Drury and Szent-Györgyi (1929). Thirty years later, Holton (1959) showed that during antidromic stimulation of sensory nerves, ATP was released in sufficient quantities to produce vasodilation of rabbit ear arteries. A few years later, Berne (1963) first suggested that adenosine might be the physiological regulator of coronary blood flow during reactive hyperemia. Over the next 
decade, interest peaked with regard to the extracellular signalling mechanisms of adenosine. By the end of the nineteen-seventies, Burnstock (1978) had provided a basis for distinguishing the two major types of vascular purinergic receptors. Burnstock classified the purinergic receptors based on their selectivity for the various purines, with the P1-purinoceptors selective for adenosine and the P2purinoceptors selective for adenine nucleotides. The P1-purinoceptors were the first to be subdivided into $A_{1}$ and $A_{2}$ subtypes (Van Calker et al., 1979; Londos et al., 1980), followed by the subdivision of P2-purinoceptors into P2X and P2Y subtypes (Burnstock and Kennedy, 1985). In the following decade, a number of additional subtypes were added to the P2-purinoceptor family, including P2U, P2D, P2Z, and P2T (Dubyak and el-Moatassim, 1993; Harden et al., 1995). However, with the advent of molecular cloning the need for a new nomenclature soon arose and the classification just described was replaced by the current nomenclature that designated all P2-purinoceptors as either P2Y or P2X. The first P2-purinoceptor to be cloned was a G-protein-coupled receptor isolated from

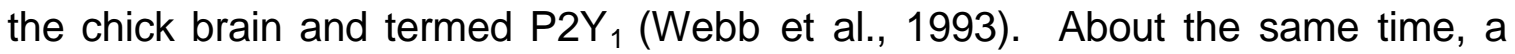
second G-protein-coupled receptor $\left(\mathrm{P}_{2} \mathrm{Y}_{2}\right)$ was identified from mouse neuroblastoma (Lustig et al., 1993). A year later, the first P2 ligand-gated ion channel receptors $\mathrm{P} 2 \mathrm{X}_{1}$ and $\mathrm{P} 2 \mathrm{X}_{2}$ cloned from rat vas deferens and rat $\mathrm{PC} 12$ cells, respectively (Valera et al., 1994; Brake et al., 1994). For a further review of P2-purinoceptor classification please see section (c) "P2-Purinoceptor Classification and Signaling". 
(b) P1-Purinoceptor Classification and Signaling. Currently, four P1purinoceptors have been cloned, $\left(A_{1}, A_{2 A}, A_{2 B}\right.$, and $\left.A_{3}\right)$ with selective agonists and antagonists identified for each subtype except $A_{B B}$ (Fredholm et al., 1994; Olah and Stiles, 1995; Jacobson and Suzuki, 1996). As stated above, the adenosine $A_{1}$ and $A_{2}$ receptors were the first subdivisions, made on the basis of their ability to inhibit or stimulate adenylyl cyclase, respectively (Van Calker et al., 1979; Londos et al., 1980). There is evidence that these adenosine receptors may signal via G proteins (Fredholm et al., 2000).

Through activation of $G$ proteins, $A_{1}$ receptors mediate inhibition of adenylyl cyclase, activation of several types of potassium channels, inactivation of various calcium channels, and activation of phospholipases leading to the enhanced formation of $\mathrm{IP}_{3}$ and arachidonic acid (Freund et al., 1994; Gerwins and Fredholm 1995; Freissmuth et al., 1991). In some tissues, $A_{1}$ adenosine receptor activation has also been shown to stimulate phospholipid turnover and increase intracellular calcium levels, whereas in others, $A_{1}$ receptor activation inhibits phospholipid turnover and decreases intracellular calcium levels (Olah and Stiles, 1995). In contrast to $A_{1}$ receptors, both $A_{2 A}$ and $A_{2 B}$ receptors stimulate the formation of cyclic AMP (Olah, 1997; Pierce et al., 1992), and like $A_{1}$ receptors, activation of these receptors promotes mobilization of intracellular calcium (Offerman and Simon, 1995; Gao et al., 1999; Linden et al., 1999). In vascular smooth muscle, $A_{2}$ receptor activation can also influence the activity of ATP- 
dependent potassium channels, which may be involved in mediating endothelium-independent vasorelaxation (Kleppisch and Nelson, 1995).

(c) P2-Purinoceptor Classification and Signaling. Currently, there are five recognized members of the $\mathrm{P} 2 \mathrm{Y}$ receptor family $\left(\mathrm{P}_{2} \mathrm{Y}_{1}, \mathrm{P} 2 \mathrm{Y}_{2}, \mathrm{P} 2 \mathrm{Y}_{4}, \mathrm{P} 2 \mathrm{Y}_{6}\right.$, and P2Y ${ }_{11}$ ) and seven recognized members of the P2X family (P2X $\left.\mathrm{X}_{1-7}\right)$ (Di Virgilio et al., 2001). These receptors were initially classified on the basis of pharmacological and functional criteria, with receptors classified as either Gprotein-coupled P2Y receptors or as ion-gated channel P2X receptors (Abbracchio and Burnstock, 1994). However, as molecular techniques evolved, so did the classification of these receptors, and the original classification was replaced by the current system that is based on molecular structure.

P2Y receptors are seven-membrane-spanning proteins, numbering from 328 to 379 amino acids, with a molecular mass of 41 to $53 \mathrm{kd}$ after glycosylation (Ralevic and Burnstock, 1998). Typically, signal transduction occurs via the classical pathways triggered by most seven-membrane-spanning receptors with activation of phospholipase $\mathrm{C}$ and/or stimulation/inhibition of adenylyl cyclase. However, not all P2Y receptors operate through the same intracellular signal transduction pathway. For example, $\mathrm{P}_{2} \mathrm{Y}_{1}$ and $\mathrm{P}_{2} \mathrm{Y}_{2}$ are coupled to stimulation of phospholipase C- $\beta$ and inhibition of adenylyl cyclase via $G_{/ / 11}$ and $G_{1}$ proteins,

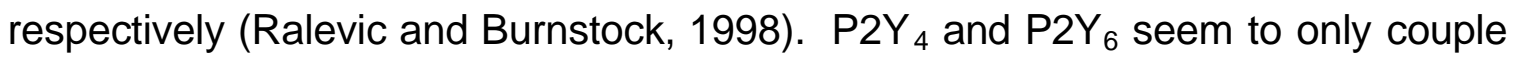
to phosphoinositide breakdown, and $\mathrm{P}_{2} \mathrm{Y}_{11}$ stimulates activation of both the phosphoinositide and the adenylyl cyclase pathways (Di Virgillio et al., 2001). 
P2X receptors are ATP-gated ion channels that were originally cloned and characterized in excitable cells (Brake et al., 1994; Valera et al., 1994) and subsequently shown to be ubiquitous receptors capable of mediating fast permeability changes to sodium, potassium, and calcium (Di Virgillio et al., 1998; Soto et al., 1997). P2X receptors range from 379 to 595 amino acids and are thought to have two transmembrane hydrophobic domains separated by a bulky extracellular region (Ralevic and Burnstock, 1998; Brake et al., 1994; Valera et al., 1994). Signal transduction occurs via fast sodium and calcium influx and potassium efflux, leading to depolarization of the plasma membrane and an increase in cytosolic calcium concentration.

(d) Formation and Release of Adenosine. Within the cell, adenosine is typically formed by one of two pathways (Meghji, 1993). In the first pathway, adenosine formation proceeds in a manner that is augmented by reduced oxygen availability with the sequential hydrolysis of ATP $\rightarrow$ ADP $\rightarrow$ AMP $\rightarrow$ adenosine (Shyrock and Belardinelli, 1997). The final conversion in this sequence, the hydrolysis of AMP to adenosine, is catalyzed by the enzyme 5'-nucleotidase, which is present in two forms, an intracellular cytosolic form and an extracellular membrane-bound form (Shyrock and Belardinelli, 1997). In the second pathway, adenosine formation proceeds in a manner that is insensitive to changes in oxygen availability, with the sequential hydrolysis of ATP $\rightarrow$ Sadenosylmethionine $\rightarrow$ S-adenosylhomocysteine, which in turn is hydrolyzed to adenosine by S-adenosylhomocysteine hydrolase (Shyrock and Belardinelli, 
1997). Once formed within the cytosol, adenosine can readily cross the cell membrane via a nucleoside transporter (Conant and Jarvis, 1994).

Adenosine can also be formed extracellularly by the same enzymatic conversions described above (Shyrock and Belardinelli, 1997). The enzyme 5'ecto-nucleotidase, which is widespread on the outer surface of vascular smooth muscle and endothelial cells (Borst and Schrader, 1991; Shyrock and Belardinelli, 1997), is responsible for the ultimate conversion of adenine nucleotides to adenosine. The endothelium plays a key role in the uptake and metabolism of adenosine, but is also a major source of endogenous adenine nucleotides and adenosine (Kroll et al., 1989). The release of adenine nucleotides from the endothelium can be stimulated by a variety of factors, including $\beta$-adrenergic stimulation and hypoxia (Schrader et al. 1977; Borst and Schrader, 1991; Headrick et al., 1992; Raatikainen et al., 1994; Cohen et al., 1995; Decking et al., 1997).

(e) The Role of Adenosine in the Regulation of Vascular Tone. As stated above, numerous investigators have demonstrated that adenosine is released by tissues under low oxygen conditions (Schrader et al. 1977; Headrick et al., 1992; Raatikainen et al., 1994; Cohen et al., 1995; Decking et al., 1997). As a result of this release and adenosine's vasoactive properties, adenosine is well suited to play an important role in the metabolic regulation of blood flow. In fact, increases in vascular conductance during systemic hypoxia can be reduced by $50 \%$ by the adenosine receptor antagonists 8-phenyl theophylline (8-PT) and 8-sulphophenyl 
theophylline (8-SPT) and by adenosine deaminase (Neylon and Marshall, 1991; Thomas et al., 1994). Similarly, Simpson and Phillis (1991) found that local application of adenosine deaminase attenuates hypoxia-induced dilation of rat pial arterioles.

In addition to its role as a mediator of hypoxic vasodilation, adenosine has been shown to contribute importantly to other microvascular control mechanisms including autoregulation and active hyperemia. In the guinea pig heart, adenosine levels increase as coronary perfusion pressure is reduced, thereby maintaining coronary blood flow (Schrader et al., 1977). In the hamster cremaster muscle, blockade of local adenosine activity with either adenosine deaminase or theophylline reduces the level of active hyperemia (Proctor and Duling, 1982; Proctor, 1984). Later, Proctor (1986) reported that these same treatments significantly reduced, but did not eliminate, the level of absorptive hyperemia in the rat intestine. Similarly, other investigators have reported a role for adenosine in the mediation of active hyperemia in the cat soleus and gracilis muscle, the dog gracilis muscle, and in the dog heart (Schwartz and McKenzie, 1990; Goonewardene and Karim, 1991; Karim and Goonewardene, 1996).

Adenosine-induced dilation of blood vessels has long been considered to be mediated by the activation of $A_{2}$ adenosine receptors present on the vascular smooth muscle (Abebe, et al., 1994; Dubey et al., 1998). However, a number of recent studies suggest that adenosine may also promote vasodilation through the activation of endothelial adenosine receptors (Danialou et al., 1997; Li et al., 
1998; Hein et al., 1999; Peralta et al., 1999; Bryan and Marshall, 1999a; Bryan and Marshall, 1999b). For instance, Hein and coworkers (1999) demonstrated that activation of endothelial $A_{2 A}$ adenosine receptors dilates porcine coronary arterioles through the release of endothelial NO. Similarly, other groups have found that activation of endothelial $A_{2}$ adenosine receptors stimulates NO synthesis in human and porcine arterial endothelial cells (Li et al., 1998) and in the rat liver (Peralta et al., 1999). However, there appears to be some heterogeneity among vascular beds in the adenosine receptor subtype involved in this response. For example, Danialou and colleagues (1997) found that activation of both $A_{1}$ and $A_{2}$ adenosine receptors can stimulate arteriolar NO synthesis in the rat diaphragm, although the $A_{1}$ mediated response predominates. Similarly, Bryan and Marshall (1999), found that activation of both $A_{1}$ and $A_{2}$ adenosine receptors by systemically administered adenosine causes NO-dependent increases in rat femoral vascular conductance, but that only the $A_{1}$ receptor subtype mediates the increased vascular NO synthesis during systemic hypoxia. A number of other studies have demonstrated that adenosine is capable of stimulating endothelial NO synthesis ( $\mathrm{Li}$ et al., 1995; Davis et al., 1998; Ishibashi et al., 1998; Hein and Kuo, 1999; Yada et al., 1999; Carpenter et al., 2000; Konduri and Mital, 2000).

In addition to its direct effect on vascular tone, adenosine can attenuate the presynaptic release of NE in vessels of the rat heart (Richardt et al., 1989) and dog heart (Abe et al., 1997), and in the dog pulmonary artery (Tamaoki et al., 
1997b). However, this does not appear to occur in all vascular beds. Kuan and Jackson (1988) found that endogenous adenosine does not limit NE release in the rat mesentery. Taken together, these studies indicate that adenosine can influence vascular tone by at least two and possibly three different mechanisms, including a direct effect on vascular smooth muscle, promoting the release of endothelium-derived NO, and in some cases, by limiting the release of NE from sympathetic nerve terminals.

(f) The Role of Adenine Nucleotides in the Regulation of Vascular Tone. In recent years, a new model has been presented in which the erythrocyte, in addition to its role as an oxygen carrier, is the sensor and effector in the local regulation of oxygen delivery (Ellsworth, 2000). This model is based on two factors: the release of ATP from erythrocytes in response to reduced oxygen tension (Forrester and Williams, 1977; Ellsworth et al., 1995; Dietrich et al., 2000; Ellsworth, 2000; Jagger et al., 2001), and the vasoactive properties of ATP. As stated above, the earliest evidence describing the physiological activities of extracellular adenine compounds was first reported by Drury and Szent-Györgyi (1929). Since then, numerous groups have illustrated the vasoactive properties of ATP. DeMey and Vanhoutte (1981) demonstrated that ATP was capable of stimulating the production of NO. Ellsworth and colleagues (1995) found that intraluminal application of ATP induces arteriolar dilations that are conducted over $100 \mu \mathrm{m}$ upstream from the application site. Similarly, McCullough and coworkers (1997) reported that, in hamster cheek pouch, intraluminal ATP 
application induced NO-dependent arteriolar dilations that were conducted upstream. Furthermore, extraluminal ATP application resulted in a conducted vasoconstriction that was enhanced in the presence of L-NAME. That same year, You and colleagues (1997) reported that luminal application of ATP and ADP elicited dose-dependent dilations that were abolished by removal of the endothelium and by treatment with L-NAME. In rat cerebral arterioles, Janigro and colleagues (1997) demonstrated that ATP elicits a NO-dependent vasodilation regardless of the application polarity, although arteriolar responses were greater when ATP was applied intraluminally. Similarly, studies conducted by others demonstrate that under certain conditions abluminal application of ATP produces NO-dependent vasodilation of rat skeletal muscle arterioles (Koller et al., 1991) and hamster cheek pouch arterioles (Duza et al., 2001). Taken together, these results suggest that under most conditions, exogenously-applied ATP produces vasodilation or vasoconstriction depending upon whether the application is luminal or abluminal. The characteristics of each response are presumably a consequence of the distribution of different purinergic receptors (Abbracchio and Burnstock, 1994). 


\section{PURPOSE OF THIS DISSERTATION PROJECT}

Since the vasoactive effects of $\mathrm{O}_{2}$ were first reported, numerous investigators have attempted to elucidate the mechanism by which $\mathrm{O}_{2}$ effects vascular tone. As previously stated, many studies have demonstrated that changes in $\mathrm{O}_{2}$ tension alter vascular tone through both direct and indirect mechanisms. Of those studies that have demonstrated an indirect effect of reduced $\mathrm{O}_{2}$ tension on vascular tone, only a few have investigated the mechanism by which reduced $\mathrm{O}_{2}$ promotes the release of endothelium-derived vasoactive factors. Some of these studies have reported that the increase in NO synthesis under low $\mathrm{O}_{2}$ conditions is associated with an increase in $\left[\mathrm{Ca}^{2+}\right]_{\text {i }}$. However, the mechanism by which $\left[\mathrm{Ca}^{2+}\right]_{\mathrm{i}}$ and NO synthesis increase remains unclear. In this dissertation project, I endeavored to explore the possible link between reduced $\mathrm{O}_{2}$ tension and $\mathrm{NO}$ synthesis at the microvascular level in the absence of any systemic effects. Moreover, the level to which $\mathrm{O}_{2}$ was reduced in these studies was not some arbitrary value, but rather the normal response of the tissue to sympathetic nerve stimulation at physiological frequencies.

\section{Study I}

Endothelium-derived NO normally attenuates neurogenic constriction of the arterioles in rat intestine despite a marked reduction in hemodynamic shear, which is considered the primary stimulus for basal NO release in these vessels. During neurogenic constriction there is a frequency-dependent fall in arteriolar 
blood flow, which should result in a flow-dependent reduction of arteriolar wall $\mathrm{PO}_{2}$. The purpose of this first study was to determine if reduced arteriolar wall $\mathrm{PO}_{2}$ serves as a stimulus for sustained $\mathrm{NO}$ synthesis during neurogenic constriction in the rat intestine.

\section{Study II}

Study I demonstrated that reduced $\mathrm{O}_{2}$ tension serves as a stimulus for endothelial NO synthesis during neurogenic constriction in the rat intestine. Hypoxia-induced formation of the vasoactive metabolite adenosine has been demonstrated in a number of vascular beds, and adenosine, at moderately low concentrations, has been shown to stimulate NO release in some types of arterioles. Therefore, the purpose of this study was to determine if adenosine serves as the link between reduced $\mathrm{O}_{2}$ tension and $\mathrm{NO}$ synthesis during neurogenic constriction.

\section{Study III}

Study II illustrated that adenosine, through its interaction with endothelial $A_{1}$ receptors, promotes NO synthesis during neurogenic constriction. Recent studies have suggested that erythrocytes release ATP in response to reduced $\mathrm{O}_{2}$ tension, and that the enzymes necessary for the sequential hydrolyzation of ATP to adenosine are prevalent in and around the microvascular wall. The purpose of this study was to determine the origin of adenosine production during neurogenic 
constriction. Specifically, we evaluated two possible sources of adenosine: (1) the extracellular conversion of ATP to adenosine (2) the nearby paired venule. 
Study I: Arteriolar Wall $\mathrm{PO}_{2}$ and Nitric Oxide Release during Sympathetic Vasoconstriction in the rat intestine 


\section{SUMMARY}

Endothelium-derived nitric oxide (NO) attenuates arteriolar constriction in the rat small intestine during periods of increased sympathetic nerve activity. This study was undertaken to test the hypothesis that a flow-dependent fall in arteriolar wall $\mathrm{PO}_{2}$ serves as the stimulus for endothelial $\mathrm{NO}$ release under these conditions. Sympathetic nerve stimulation at $3-16 \mathrm{~Hz}$ induced frequencydependent arteriolar constriction, with arteriolar wall $\mathrm{PO}_{2}$ falling from $67 \pm 3$ to as low as $41 \pm 6 \mathrm{~mm} \mathrm{Hg}$. Arteriolar responses to nerve stimulation were enhanced after inhibition of NO synthase with $\mathrm{N}^{a}$-monomethyl-L-arginine (L-NMMA). Under a high $(20 \%) \mathrm{O}_{2}$ superfusate, the fall in wall $\mathrm{PO}_{2}$ was significantly attenuated, arteriolar constrictions were increased by $57 \pm 9$ to $66 \pm 12 \%$, and these responses were no longer sensitive to L-NMMA. The high $\mathrm{O}_{2}$ superfusate had no effect on vascular smooth muscle responsiveness to NO (as judged by arteriolar responses to sodium nitroprusside) or on arteriolar wall oxidant activity (as determined by the reduction of tetranitroblue tetrazolium dye). These results indicate that a flow-dependent fall in arteriolar wall $\mathrm{PO}_{2}$ may serve as a stimulus for the release of endothelium-derived NO during periods of increased sympathetic nerve activity. 


\section{INTRODUCTION}

It is well established that the endothelium exerts a considerable local influence on microvascular tone and blood flow through the release of diffusible vasoactive factors such as nitric oxide (NO) and various cyclooxygenase products $(15,30)$. The release of these factors is governed by the immediate chemical environment of the endothelial cell (including the binding of various agents to membrane-bound receptors) and by physical forces acting on the vessel wall $(2,8,12)$. In addition to a direct effect on vascular smooth muscle, endothelium-derived factors can indirectly influence microvascular tone by modulating the activity of other microvascular control mechanisms $(23,24,26)$. Studies in rat cremaster muscle and canine epicardium have demonstrated that arteriolar constriction in response to exogenous norepinephrine (NE) is enhanced after inhibition of NO synthesis $(19,26)$. This laboratory has more recently reported that endothelium-derived NO normally decreases arteriolar constriction during periods of increased sympathetic nerve activity in the rat intestine $(23,24)$. This arteriolar NO release occurs despite a marked reduction in luminal shear stress, and does not depend on the binding of neurally-released NE to endothelial $\alpha_{2}$ receptors (25).

The sympathetic constriction of resistance vessels is accompanied by a reduction in local blood flow $(3,4,23)$ and a consequent fall in arteriolar wall $\mathrm{O}_{2}$ levels (4). There is mounting evidence that a reduction in vascular wall $\mathrm{PO}_{2}$ can promote vasodilation via the release of endothelium-derived NO $(1,10-12,16$, 
$21,22,27-29,35)$. The aim of the current study was to investigate the functional significance of any relationship between arteriolar wall $\mathrm{O}_{2}$ tension and local $\mathrm{NO}$ activity in the intestine. More specifically, we tested the hypothesis that a reduction in arteriolar wall $\mathrm{PO}_{2}$ serves as the stimulus for arteriolar $\mathrm{NO}$ production during periods of increased sympathetic nerve activity. If this hypothesis is correct, then minimizing the fall in arteriolar wall $\mathrm{PO}_{2}$ should diminish the stimulus for NO release and lead to augmented sympathetic constriction. To test this prediction, arteriolar responses to sympathetic nerve stimulation were assessed under normal conditions and under a hyperoxic superfusate (to maintain arteriolar wall $\mathrm{O}_{2}$ delivery) before and during inhibition of $\mathrm{NO}$ synthesis with $\mathrm{N}^{\mathrm{p}}$ monomethyl-L-arginine (L-NMMA). Arteriolar wall $\mathrm{PO}_{2}$ was directly measured with $\mathrm{O}_{2}$ sensitive microelectrodes to verify the effects of sympathetic nerve stimulation and increased superfusate $\mathrm{O}_{2}$ content on arteriolar wall $\mathrm{O}_{2}$ levels.

\section{METHODS}

All surgical and experimental procedures were approved by the West Virginia University Animal Care and Use Committee. Male Sprague-Dawley rats aged 8-9 wk (Harlan Sprague Dawley, Indianapolis, IN) were anesthetized with sodium thiopental (100 mg/kg ip) and placed on a heating mat to maintain a $37^{\circ} \mathrm{C}$ rectal temperature. To ensure adequate gas exchange rats were intubated and ventilated by a rodent ventilator (Harvard Apparatus, South Natick, MA). Arterial 
pressure was measured directly with a Gould P23 ID pressure transducer (Cleveland, $\mathrm{OH}$ ) connected to a cannula inserted into the right carotid artery.

The small intestine was prepared for microscopic observation as previously described (23). Briefly, a 14-cm loop of small intestine (ileum) was gently exteriorized through a midline abdominal incision. The loop was initially bathed in warm Normosol-R electrolyte solution (Abbott Laboratories, Chicago, IL) and then continuously superfused with a physiological electrolyte solution (in $\mathrm{mM}$ : $119 \mathrm{NaCl}, 25 \mathrm{NaHCO}_{3}, 6 \mathrm{KCl}$, and $3.6 \mathrm{CaCl}_{2}$ ) that was warmed to $37^{\circ} \mathrm{C}$ and equilibrated with a gas mixture to either mimic normal in-vivo conditions $\left(5 \% \mathrm{O}_{2}\right.$ $5 \% \mathrm{CO}_{2}-90 \% \mathrm{~N}$ ) $(5)$ or create a hyperoxic environment $\left(20 \% \mathrm{O}_{2}-5 \% \mathrm{CO}_{2}-75 \%\right.$ $\mathrm{N}_{2}$ ). Isoproterenol (10 mg/l; Sigma, St. Louis, MO) and phenytoin $(20 \mathrm{mg} / \mathrm{l}$; Parke-Davis, Morris Plains, NJ) were added to the superfusate to suppress intestinal motility. At these concentrations neither agent alters resting arteriolar tone in this vascular bed (9). After the ileum was exteriorized, 2 small incisions 6 $\mathrm{cm}$ apart were made by thermal cautery along the antimesenteric border, and chyme was flushed from the lumen through these incisions. The bowel was then secured over a transparent pedestal by 4 sutures tied to the antimesenteric border. Most of the preparation was covered with polyvinyl film, with the superfusate flow directed beneath the film. With the normal $\left(5 \% \mathrm{O}_{2}\right)$ superfusate, this arrangement stabilizes solution $\mathrm{PO}_{2}$ above the tissue at $40-50 \mathrm{mmHg}(6)$.

After surgery, the rat was transferred to the stage of an Olympus BHTU intravital microscope (Hyde Park, NY) fitted with a CCD video camera (Dage 
MTI, Michigan City, IN). Video images were displayed on a Panasonic highresolution video monitor and stored on videotape for off-line analysis. Observations were made with a x10 eyepiece and Nikon x10 water immersion objective (final video magnification $=x 730$ ). Arteriolar inner diameters were measured with a video caliper (Microcirculation Research Institute, Texas A \& M University) during videotape replay.

Arteriolar wall $\mathrm{PO}_{2}$ was measured with Whalen-type $\mathrm{O}_{2}$ microelectrodes (tip diameter $=2-3 \mu \mathrm{m}$, Diamond General, Ann Arbor, MI) that were calibrated immediately before and after each experiment. Data from electrodes exhibiting more than a $5 \%$ change in gain from pre- to postexperimental calibrations were discarded. For calibration, electrodes were placed in a tonometer (model 1251, Diamond General), and current output was recorded in superfusates equilibrated with $10 \%$ and $20 \% \mathrm{O}_{2}$ gas mixtures $\left(\mathrm{PO}_{2}=71\right.$ and $142 \mathrm{~mm} \mathrm{Hg}$, respectively). Zero-level $\mathrm{PO}_{2}$ was determined by placing the electrode tip in an actively respiring yeast mixture as described by Whalen et al (36).

For sympathetic nerve stimulation, a bipolar platinum electrode secured in a micromanipulator was used to stimulate the sympathetic postganglionic efferents in the sheath surrounding a mesenteric artery-vein pair upstream from the arteriole under study. The electrode and artery-vein pair were briefly raised above the superfusate and the nerves were stimulated with square-wave pulses at supramaximal voltage $(5-6 \mathrm{~V})$ and a pulse duration of $10 \mathrm{~ms}$. These stimulation parameters elicit frequency-dependent arteriolar constrictions that are 
abolished by the non-selective $\alpha$-receptor antagonist phentolamine (23) and the selective $\alpha_{1}$-receptor antagonist prazosin (25), verifying that these responses are due to sympathetic nerve activation.

Experimental Protocols. The first series of experiments was designed to define the relationship between arteriolar wall $\mathrm{O}_{2}$ tension and $\mathrm{NO}$ during periods of increased sympathetic nerve activity. During superfusion with either the normal $\left(5 \% \mathrm{O}_{2}\right)$ or hyperoxic $\left(20 \% \mathrm{O}_{2}\right)$ solution, a first-order arteriole was selected for study and an $\mathrm{O}_{2}$ microelectrode was positioned with the tip in light contact with the outer vessel wall. After a 1-min control period, the sympathetic nerves were stimulated for $1 \mathrm{~min}$ at 3,8 , or $16 \mathrm{~Hz}$, followed by a 3-min recovery period. This sequence was repeated 2 more times so that the arteriole was subjected to all 3 levels of increased sympathetic nerve activity, delivered in random order. The superfusate was then changed (from normal to hyperoxic or from hyperoxic to normal), and the sequence of nerve stimulations was repeated. The nerve stimulation sequences under both the normal and hyperoxic superfusates were then repeated during continuous exposure of the vasculature to the NO synthase (NOS) inhibitor $\mathrm{N}^{a}$-monomethyl-L-arginine (L-NMMA, $1 \times 10^{-4}$ M superfusate concentration). Finally, adenosine was added to the superfusate $\left(10^{-3} \mathrm{M}\right.$ final concentration), and passive arteriolar diameter was measured.

The second series of experiments was designed to assess L-NMMA's efficacy as a NOS inhibitor under our experimental conditions by evaluating its 
effect on first-order arteriolar responses to A23187 (Sigma), a calcium ionophore that stimulates NO synthesis in various vascular beds (33). A23187 was initially dissolved in dimethyl sulfoxide (DMSO, Sigma) and then added to the superfusate. Control measurements verified that DMSO at its final superfusate concentration $(0.2 \%)$ had no direct effect on arteriolar tone. Due to a prolonged vasoactive effect of $A 23187$, it was necessary to conduct these experiments in 2 groups of rats. In the first group, A23187 was applied to the preparation at final superfusate concentrations of $1 \times 10^{-5} \mathrm{M}$ and $2 \times 10^{-5} \mathrm{M}$. In the second group, A23187 was applied at these same concentrations in the presence of $10^{-4} \mathrm{~L}$ NMMA. At the end of each experiment, passive arteriolar diameters were measured under $10^{-3} \mathrm{M}$ adenosine.

A third series of experiments was designed to determine if the hyperoxic superfusate used in this study causes any change in the inherent responsiveness of arteriolar smooth muscle to NO. First-order arteriolar responses to the NOdonor sodium nitroprusside (SNP, Sigma) were assessed under both the normal and hyperoxic superfusates. For these experiments, SNP was applied directly to the arteriolar wall by microiontophoresis. Glass micropipettes (2-3 $\mu \mathrm{m}$ inner tip diameter) were filled with $0.5 \mathrm{M} \mathrm{SNP}$ in distilled water and connected to an iontophoresis current programmer (model 260, World Precision Instruments, Sarasota, FL). A retaining current of $40 \mathrm{nA}$ was used to prevent diffusion of SNP from the pipette tip, and net ejection currents of 5, 20, and $40 \mathrm{nA}$ (in random order) were used to deliver SNP to the vessel wall. Each vessel was observed 
during a 2-min control period, a 2-min application period, and a 2-min recovery period. To avoid potential complications related to acute changes in endogenous NO production, these experiments were conducted in the presence of $10^{-4} \mathrm{~L}$ NMMA. Finally, the passive diameter of each arteriole was measured under $10^{-3}$ $M$ adenosine.

A fourth series of experiments was designed to determine if any apparent change in NO activity under the hyperoxic superfusate could be due to the unintended generation of reactive $\mathrm{O}_{2}$ species (32). Oxidant activity within the arteriolar wall was assayed under the normal and hyperoxic superfusates by the tetranitroblue tetrazolium (TNBT) reduction method, as described by Swei et al (34). Upon coming into contact with reactive $\mathrm{O}_{2}$ species, TNBT is reduced to formazan, an insoluble blue/black compound (34). After a 1-hour equilibration period under either the normal or hyperoxic superfusate, TNBT (Vector Laboratories, Burlingame, CA) was added to the superfusate ( $2 \%$ final concentration) and the preparation was continuously exposed to TNBT at the prevailing superfusate $\mathrm{O}_{2}$ level for 1 hour. The preparation was then rinsed with the original superfusate, fixed with a 10\% formalin solution (Sigma), and excised. Each whole-muscle specimen was placed on a glass slide and viewed under an Olympus BHMJ microscope with a Nikon $x 40$ water immersion objective (final video magnification $=x 2920)$. Images were captured and digitized with a frame grabber and image analysis software (MetaMorph Imaging System 3.5, West Chester, PA). Using a $4 \times 10 \mu \mathrm{m}$ video photometric window, a series of average 
gray-value measurements were made along the wall of first-order arterioles. To quantify arteriolar wall formazan content (an index of oxidative stress), these measurements were used to calculate wall light absorption $(A): A=\ln \left(I_{t} / I_{0}\right)$, where $I_{t}$ is the arteriolar wall gray value and $I_{o}$ is the gray value for an immediately adjacent avascular region. Positive controls for superoxide anion generation were produced under both the normal and hyperoxic superfusates by continuous infusion of hypoxanthine $(\mathrm{HX}, 0.12 \mathrm{mg} / \mathrm{min})+$ xanthine oxidase $(\mathrm{XO}, 0.15 \mathrm{U} / \mathrm{min})$ into the carotid artery for 1 hour. HX and XO were obtained from ICN Biomedical Inc. (Aurora, OH).

Data and Statistical Analysis. All data are expressed as means \pm SE. Statistical analysis was carried out using commercially available software (Sigma Stat, Jandel Scientific, San Rafael, CA). ANOVA for repeated measures was used to compare arteriolar dilations to A23187 and SNP before and after treatment with L-NMMA or the high- $\mathrm{O}_{2}$ superfusate, respectively. ANOVA for repeated measures was also used to compare arteriolar constrictions to sympathetic nerve stimulation before and after L-NMMA under the low and high$\mathrm{O}_{2}$ superfusates, as well as for comparison of arteriolar wall $\mathrm{PO}_{2}$ values under the high and low- $\mathrm{O}_{2}$ superfusate. For all ANOVA procedures, the Student NewmanKeuls multiple range procedure for post hoc analysis was used to identify differences among specific groups. Significance was assessed at $\mathrm{P}<0.05$ for all statistical tests. 


\section{RESULTS}

Eleven Sprague-Dawley rats $(274 \pm 11 \mathrm{~g}$ b.w.) were used in the first series of experiments to explore the relationship between arteriolar wall $\mathrm{O}_{2}$ tension and the influence of local NO on arteriolar sympathetic constriction. Under the normal superfusate, the first-order arterioles selected for study had a resting diameter of $63 \pm 3 \mu \mathrm{m}$ and a passive diameter of $88 \pm 3 \mu \mathrm{m}$. Sympathetic nerve stimulation induced frequency-dependent constrictions, with arteriolar diameters being reduced to $55 \pm 3,48 \pm 3$, and $41 \pm 3 \mu \mathrm{m}$ during stimulation at 3,8 , and $16 \mathrm{~Hz}$, respectively (Fig. 1). In the presence of $10^{-4} \mathrm{M}$ L-NMMA, resting arteriolar diameters were unchanged $(60 \pm 3 \mu \mathrm{m})$, but responses to each level of sympathetic nerve stimulation were significantly enhanced. During L-NMMA exposure, stimulation at 3,8 , and $16 \mathrm{~Hz}$ reduced arteriolar diameters to $47 \pm 2$, $40 \pm 3$, and $35 \pm 3 \mu \mathrm{m}$, respectively.

Resting arteriolar diameters under the hyperoxic superfusate were similar to those under the normal superfusate $(63 \pm 3 \mu \mathrm{m})$, but arteriolar responses to sympathetic nerve stimulation were significantly enhanced under these conditions (Fig. 2). Stimulation at 3, 8, and $16 \mathrm{~Hz}$ elicited steady-state arteriolar constrictions of $9 \pm 2,15 \pm 1$, and $21 \pm 2 \mu \mathrm{m}$ from control under the normal superfusate vs. $15 \pm 2,24 \pm 3$, and $33 \pm 3 \mu \mathrm{m}$

from control under the hyperoxic superfusate. As under the normal superfusate, L-NMMA did not alter resting arteriolar diameters $(62 \pm 3 \mu \mathrm{m})$ under the hyperoxic 
superfusate. However, in contrast to the normal superfusate, L-NMMA no longer enhanced arteriolar responses to sympathetic nerve stimulation under the hyperoxic superfusate (Fig. 3). Stimulation at 3, 8, and $16 \mathrm{~Hz}$ reduced arteriolar diameters to $49 \pm 2,38 \pm 2$, and $30 \pm 2 \mu \mathrm{m}$ in the absence of L-NMMA vs. $49 \pm 2$, $40 \pm 2$, and $33 \pm 2 \mu \mathrm{m}$ in the presence of L-NMMA.

Under the normal superfusate, resting arteriolar wall $\mathrm{PO}_{2}$ averaged $69 \pm 6$ $\mathrm{mm} \mathrm{Hg}$ and tended to fall (but not significantly) during sympathetic nerve stimulation at $3 \mathrm{~Hz}$. However, during nerve stimulation at 8 and $16 \mathrm{~Hz}$, wall $\mathrm{PO}_{2}$ rapidly fell to a new steady-state level that was dependent on stimulation frequency (Fig. 4). Exposure to the hyperoxic superfusate did not significantly change resting wall $\mathrm{PO}_{2}(78 \pm 6 \mathrm{~mm} \mathrm{Hg})$, but the fall in wall $\mathrm{PO}_{2}$ during sympathetic constriction was significantly attenuated under these conditions. Stimulation at 3 , 8, and $16 \mathrm{~Hz}$ reduced arteriolar wall $\mathrm{PO}_{2}$ to $59 \pm 4,50 \pm 5$, and $42 \pm 5 \mathrm{~mm} \mathrm{Hg}$ under the normal superfusate vs. $70 \pm 5,62 \pm 5$, and $53 \pm 5 \mathrm{~mm} \mathrm{Hg}$ under the hyperoxic superfusate. The steady-state wall $\mathrm{PO}_{2}$ values reached during 3 and $8 \mathrm{~Hz}$ stimulation under the hyperoxic superfusate $(70 \pm 5$ and $62 \pm 5 \mathrm{~mm} \mathrm{Hg})$ were not significantly different from resting wall $\mathrm{PO}_{2}$ under the normal superfusate.

The effectiveness of L-NMMA as a NOS inhibitor in the rat intestine was tested in the second series of experiments by evaluating arteriolar responses to A23187 in 5 rats $(259 \pm 25 \mathrm{~g})$ and arteriolar responses to A23187 + L-NMMA in 4 rats $(247 \pm 26 \mathrm{~g})$. Resting and passive arteriolar diameters averaged $73 \pm 4 \mu \mathrm{m}$ and $109 \pm 9 \mu \mathrm{m}$, respectively, for the first group ( $\mathrm{n}=10$ vessels), and $74 \pm 3 \mu \mathrm{m}$ and 
$94 \pm 4 \mu \mathrm{m}$, respectively, for the second group ( $\mathrm{n}=10$ vessels). Figure 5 shows arteriolar diameter responses to A23187 in these 2 groups. In the first group, $1 \times 10^{-5} \mathrm{M}$ and $2 \times 10^{-5} \mathrm{M}$ A23187 significantly increased arteriolar diameter to $96 \pm 7$ $\mathrm{m}$ and $105 \pm 8 \mu \mathrm{m}$, respectively (dilations of $29 \pm 3$ and $42 \pm 5 \%$ from control). In the second group, L-NMMA completely abolished the vasoactive response to A23187, with steady-state diameters in the presence of either concentration averaging $72 \pm 5 \mu \mathrm{m}$, or $4 \pm 4 \%$ below control. This finding indicates that we were able to maximally inhibit NO synthesis with L-NMMA in this preparation.

Eight rats $(258 \pm 18 \mathrm{~g})$ were used in the third series of experiments to evaluate the effect of the hyperoxic superfusate on vascular smooth muscle responsiveness to NO. The arterioles studied in these experiments had resting and passive diameters of $62 \pm 1 \mu \mathrm{m}$ and $106 \pm 3 \mu \mathrm{m}$, respectively ( $\mathrm{n}=8$ vessels). The steady-state diameters reached during iontophoretic application of SNP at 5, 20, and $40 \mathrm{nA}$ averaged $83 \pm 3,94 \pm 3$, and $103 \pm 4 \mu \mathrm{m}$ under the normal superfusate, and were not significantly different from those reached during SNP application under the hyperoxic superfusate $(81 \pm 6,92 \pm 5$, and 102 $\pm 5 \mu \mathrm{m})$ (Fig. 6).

Twenty rats $(287 \pm 7 \mathrm{~g})$ were used in the fourth series of experiments to evaluate oxidative stress in the arteriolar wall under the normal or hyperoxic superfusates. The calculated light absorption values indicated that there was no difference in arteriolar wall formazan content (and therefore oxidant activity) between vessels exposed to TNBT under the normal superfusate (absorption = 4.8 \pm 0.9 units) and those exposed to TNBT under the hyperoxic superfusate 
(absorption $=-4.7 \pm 0.5$ units). Following arterial infusion of $\mathrm{HX} / \mathrm{XO}$, arteriolar wall formazan content was significantly increased to the same level under both superfusates (absorption $=-7.9 \pm 0.5$ units under the normal superfusate and $7.9 \pm 0.4$ units under the hyperoxic superfusate), indicating elevated oxidant activity. 


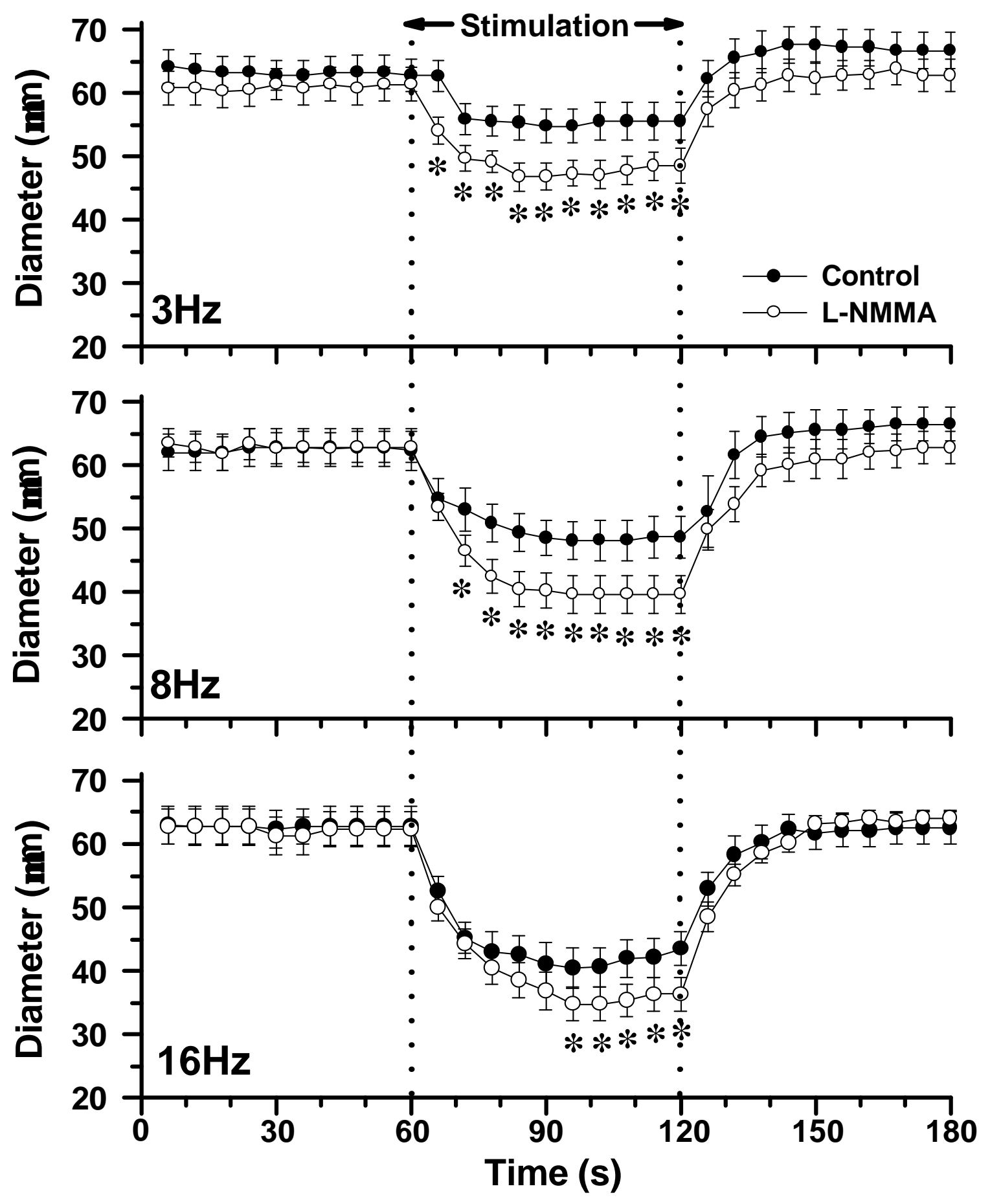

Figure 1. First-order arteriole diameter responses to sympathetic nerve stimulation at 3,8 , and $16 \mathrm{~Hz}$ under normal superfusate (closed circles) and normal superfusate $+10^{-4}$ M L-NMMA (open circles). $n=11$ vessels. ${ }^{*} P<0.05$ vs. normal superfusate. 


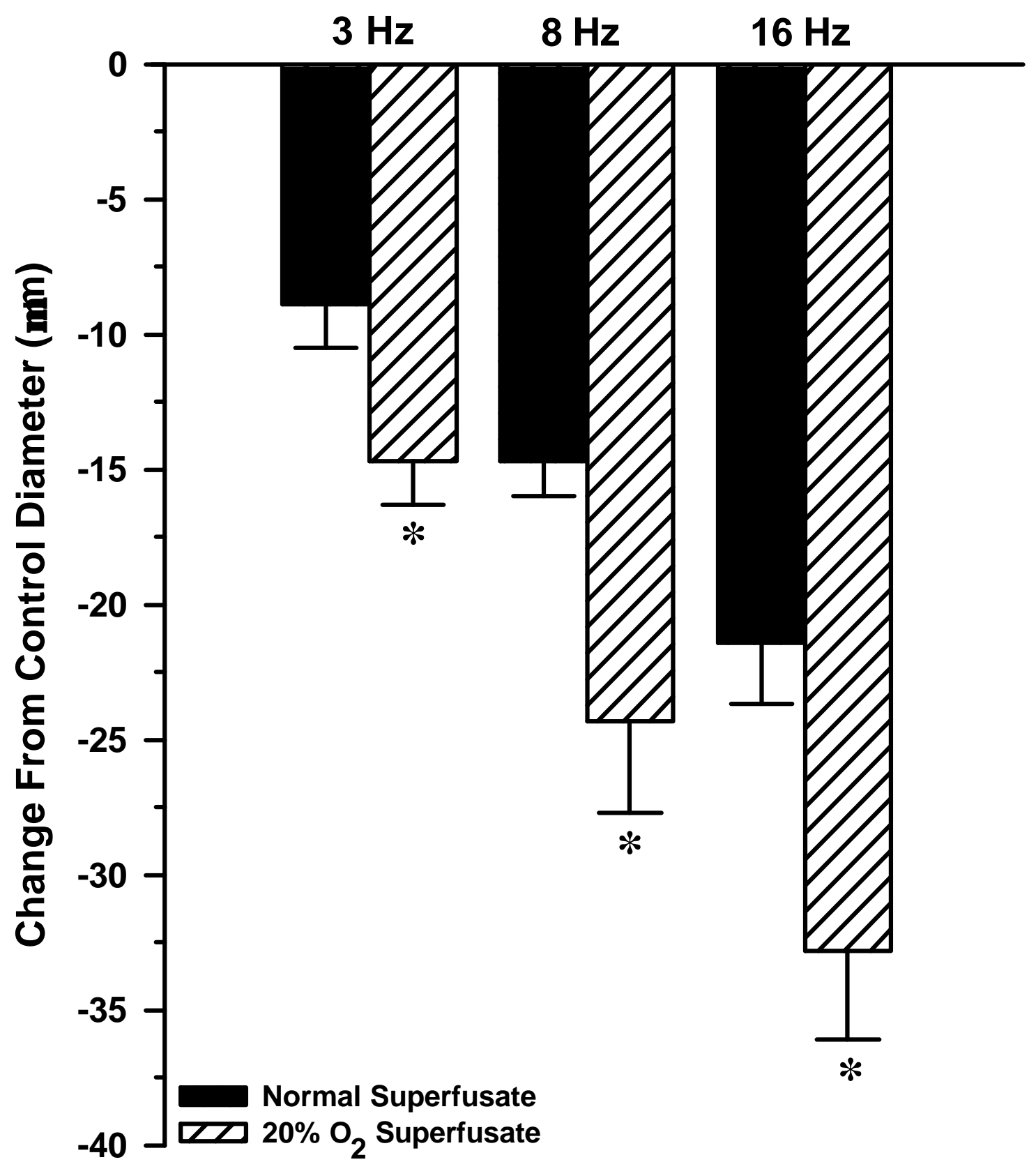

Figure 2. Magnitude of arteriolar constriction (in $\mu \mathrm{m}$ ) induced by sympathetic nerve stimulation at 3,8 , and $16 \mathrm{~Hz}$ under normal superfusate (solid bars) and $20 \% \mathrm{O}_{2}$ superfusate (hatched bars). $\mathrm{n}=11$ vessels. ${ }^{*} \mathrm{P}<0.05$ vs. normal superfusate. 


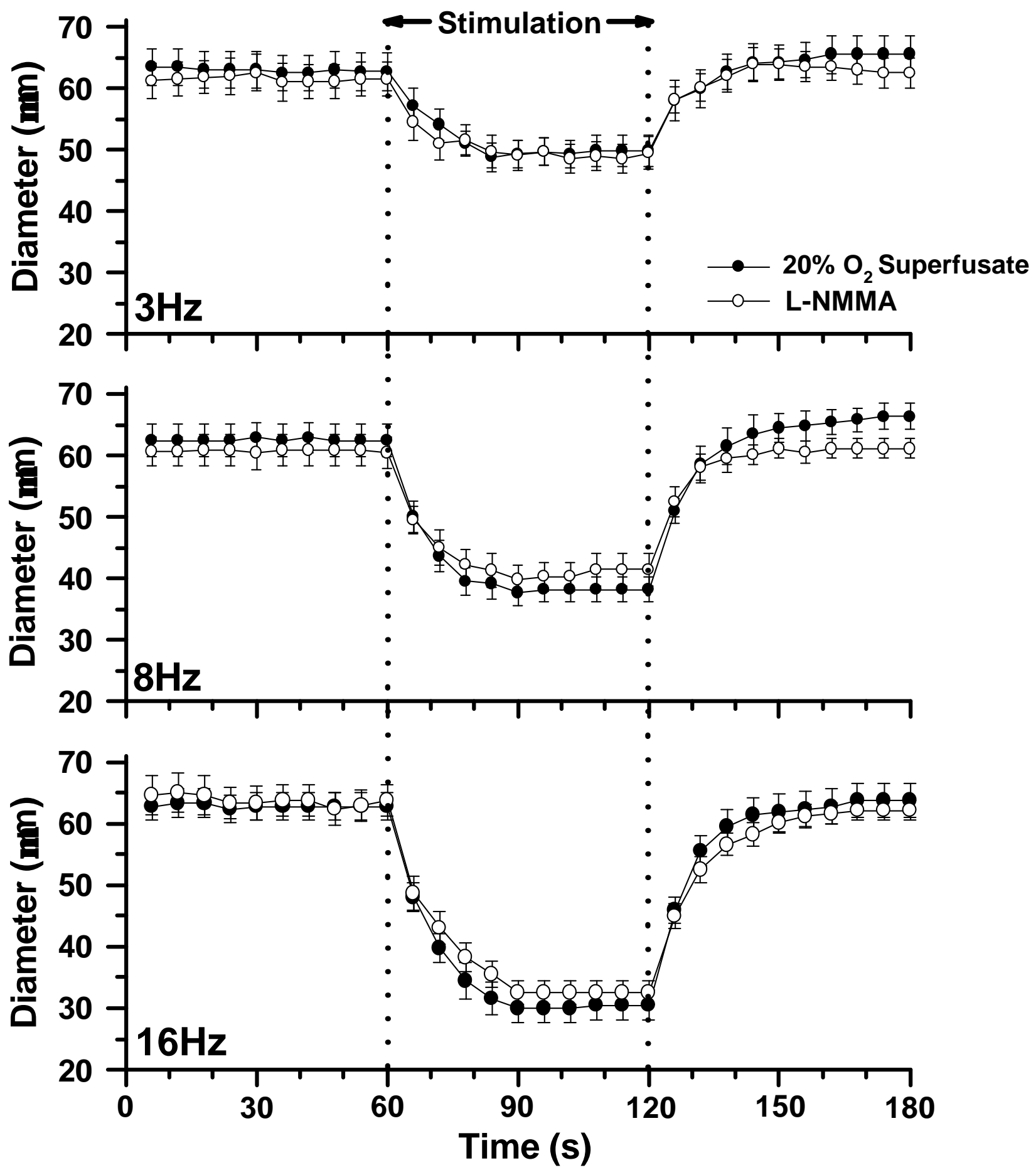

Figure 3. First-order arteriole diameter responses to sympathetic nerve stimulation at 3,8 , and $16 \mathrm{~Hz}$ under $20 \% \mathrm{O}_{2}$ superfusate (closed circles) and $20 \% \mathrm{O}_{2}$ superfusate $+10^{-4} \mathrm{M} \mathrm{L-NMMA}$ (open circles). $n=11$ vessels. 


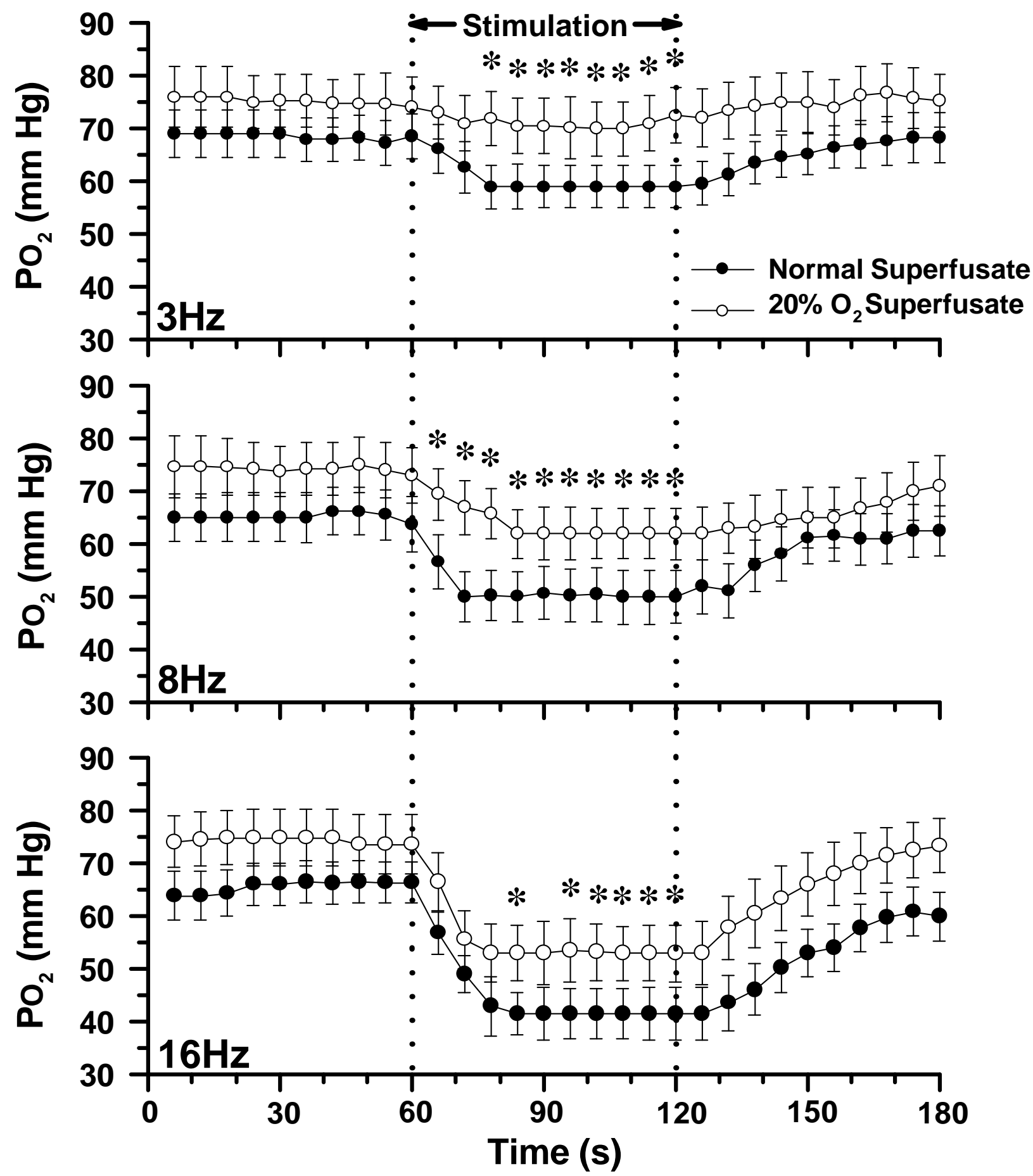

Figure 4. Arteriolar wall $\mathrm{PO}_{2}$ during sympathetic nerve stimulation at 3,8 , and 16 $\mathrm{Hz}$ under normal superfusate (closed circles) and $20 \% \mathrm{O}_{2}$ superfusate (open circles). $n=8$ vessels. ${ }^{*} \mathrm{P}<0.05$ vs. normal superfusate. 


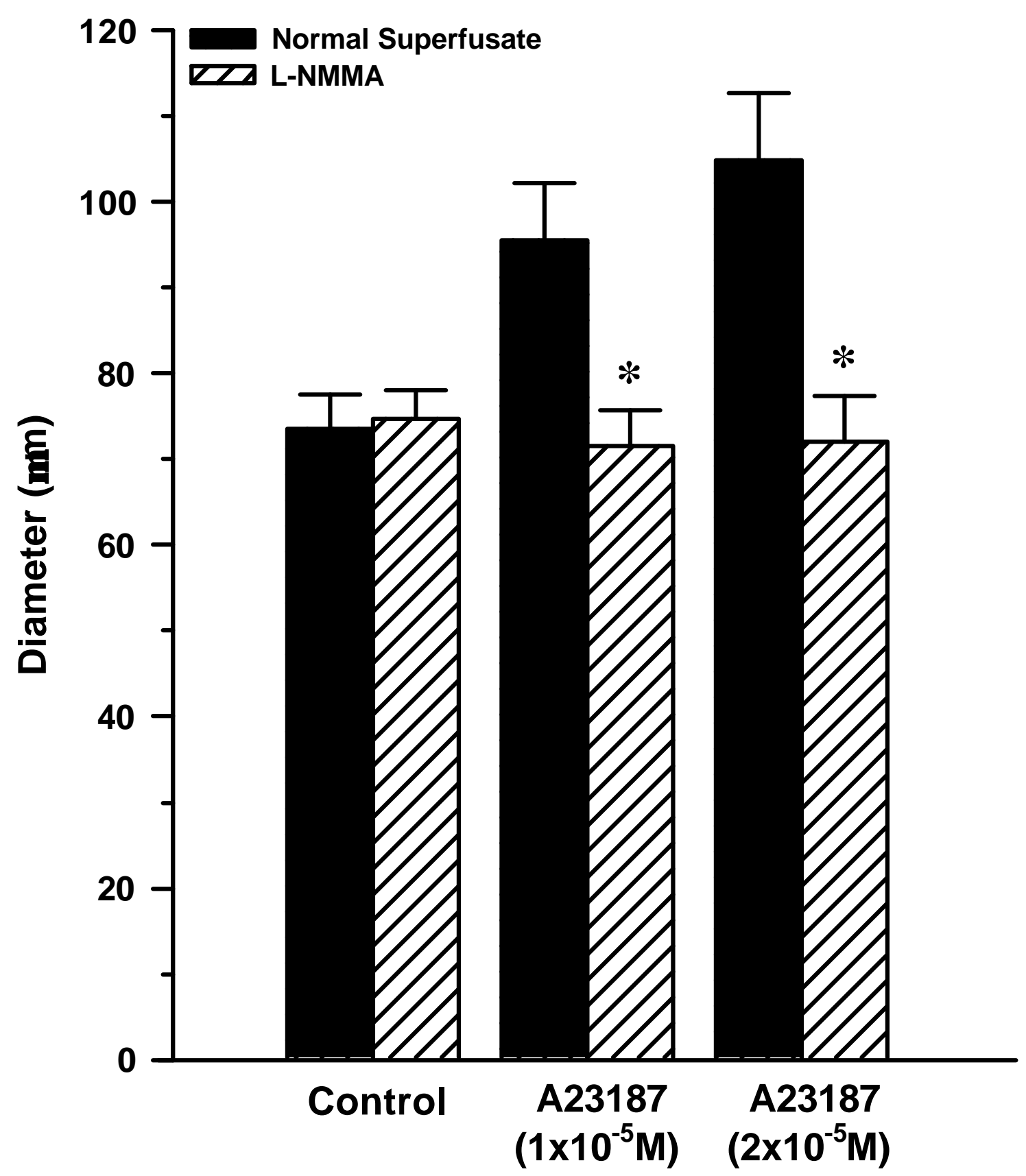

Figure 5. First-order arteriole diameters before and during application of $A 23187$ under normal superfusate (solid bars) and normal superfusate $+10^{-4} \mathrm{M}$ L-NMMA (hatched bars). $n=10$ vessels per group. ${ }^{*} \mathrm{P}<0.05$ vs. normal superfusate. 


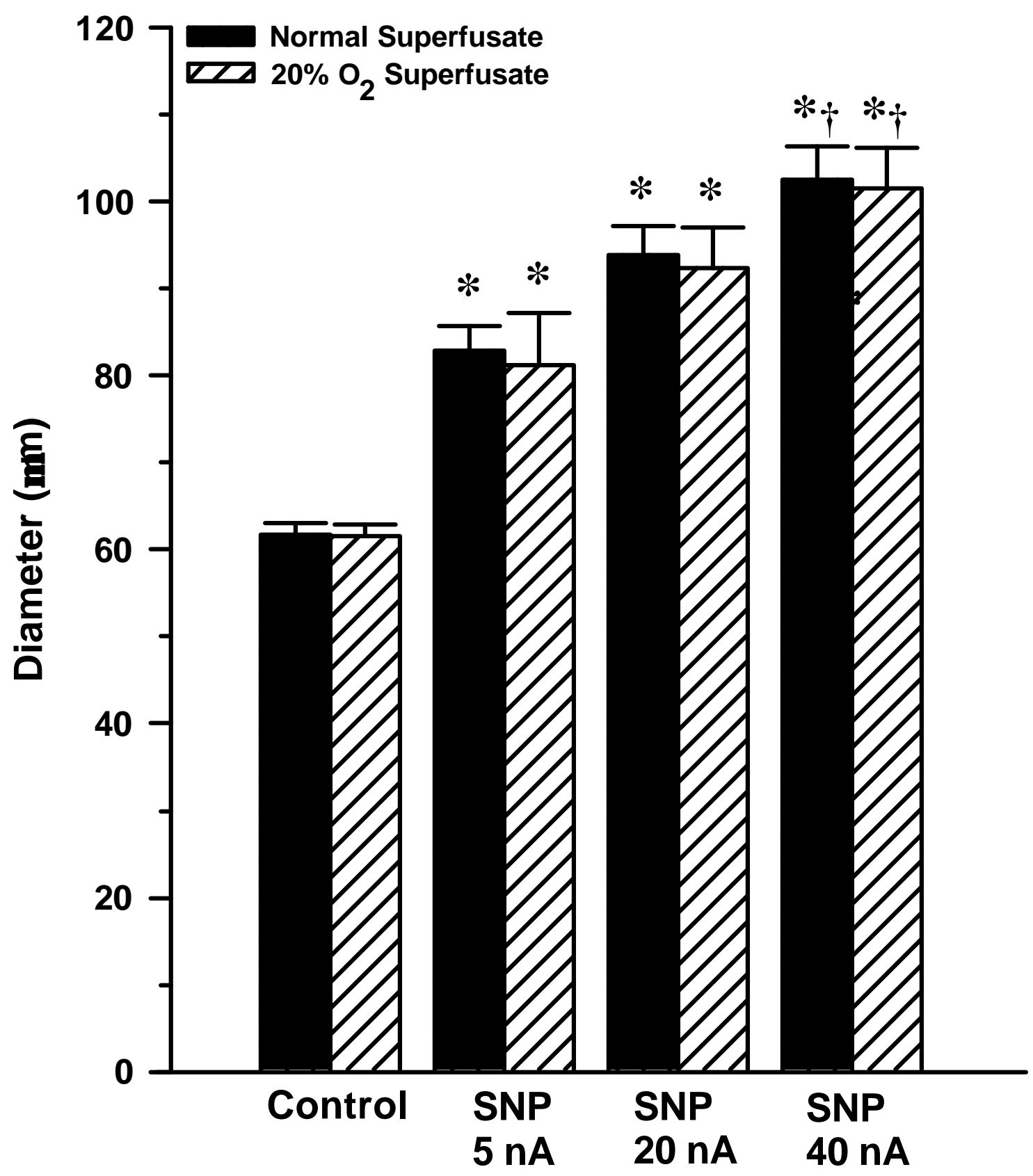

Figure 6. First-order arteriole diameter responses to iontophoretic application of sodium nitroprusside (SNP; 5, 20, and $40 \mathrm{nA}$ ejection currents) under normal superfusate (solid bars) and $20 \% \mathrm{O}_{2}$ superfusate (hatched bars). $\mathrm{n}=8$ vessels. * $\mathrm{P}<0.05$ vs. control diameter under same superfusate. ${ }^{\dagger} \mathrm{P}<0.05$ vs. diameter during 5nA application. 


\section{DISCUSSION}

A reduction in $\mathrm{O}_{2}$ availability can decrease arteriolar tone through a direct effect on the vessel wall and/or indirectly via changes in the metabolic state of nearby parenchymal cells $(13,16,29)$. The mechanism(s) by which resistance vessels are directly sensitive to reduced $\mathrm{O}_{2}$ can vary depending on the vascular bed. Harder et al. have reported that reduced $\mathrm{O}_{2}$ levels in rat renal and cremaster muscle microvessels may lead to reduced formation of 20-HETE, a constitutively-produced cytochrome p450 metabolite that normally acts as a potent vasoconstrictor (17). In other cases, a fall in local $\mathrm{PO}_{2}$ leads to increased release of one or more endothelium-derived vasodilator prostanoids. This has been demonstrated in vitro for resistance vessels in rat heart (27) and arterioles isolated from dog heart (22) and rat cremaster muscle (21). In contrast, a fall in $\mathrm{PO}_{2}$ increases the release of endothelium-derived $\mathrm{NO}$ from resistance vessels in the coronary circulation of the pig (18) and guinea pig (28), the diaphragm of the dog (35), and in the human forearm vasculature (1). There is also evidence of $\mathrm{O}_{2}$-sensitive $\mathrm{NO}$ release in some vascular beds of the rat. Pries et al (30) have reported an inverse correlation between elevated microvascular $\mathrm{O}_{2}$ levels and NO activity in the rat spinotrapezius muscle. The hypoxia-induced dilation of preconstricted rat aortic ring segments is also due to the release of endotheliumderived NO (16).

The results of our current study suggest that a reduction in arteriolar wall $\mathrm{PO}_{2}$ may serve as a major stimulus for arteriolar $\mathrm{NO}$ production during 
sympathetic vasoconstriction in the rat intestine. Resting arteriolar wall $\mathrm{PO}_{2}$ under the normal superfusate averaged $69 \pm 6 \mathrm{~mm} \mathrm{Hg}$, which is consistent with an earlier study in the rat intestine by Bohlen and Lash (7), who found that resting wall $\mathrm{PO}_{2}$ averages $65-70 \mathrm{~mm} \mathrm{Hg}$ in first-order arterioles and as low as $50 \mathrm{~mm} \mathrm{Hg}$ in more distal arterioles, indicating a marked precapillary oxygen loss from these downstream vessels. Under the normal superfusate, sympathetic nerve stimulation produced frequency-dependent arteriolar constriction and a significant reduction in arteriolar wall $\mathrm{PO}_{2}$ at stimulation frequencies of 8 and 16 $\mathrm{Hz}$ (Figs. 1 and 4). At all stimulation frequencies, the magnitude of sympathetic constriction was significantly increased in the presence of the NOS inhibitor LNMMA (Fig. 1), which is consistent with a previous report by this laboratory in which this effect of L-NMMA was also completely reversed by excess L-arginine (23). Although mean arteriolar wall $\mathrm{PO}_{2}$ was not significantly reduced during $3 \mathrm{~Hz}$ nerve stimulation under the normal superfusate (Fig. 4), wall $\mathrm{PO}_{2}$ did fall by an average of $13 \pm 4 \mathrm{~mm} \mathrm{Hg}$ in 6 of the 8 vessels studied, and in those vessels LNMMA significantly enhanced the sympathetic constriction. In the remaining 2 vessels where wall $\mathrm{PO}_{2}$ did not fall under these conditions, L-NMMA had no effect on sympathetic constriction. These observations strongly suggest that endogenous NO plays an important role in limiting the magnitude of sympathetic arteriolar constriction when arteriolar $\mathrm{O}_{2}$ levels fall in this vascular bed. We have more recently determined that this $\mathrm{NO}$ is of endothelial origin, based on the loss of this NO influence after functional disruption of the endothelium (24). 
In the current study, the high- $\mathrm{O}_{2}$ superfusate that we used did not significantly increase resting arteriolar wall $\mathrm{PO}_{2}$, but did limit the fall in wall $\mathrm{PO}_{2}$ that accompanies sympathetic nerve stimulation (Fig. 4). This is most likely because arteriolar wall $\mathrm{O}_{2}$ levels are predominantly influenced by blood $\mathrm{O}_{2}$ delivery during normal flow conditions, with extraluminal $\mathrm{O}_{2}$ delivery from the superfusate only becoming an important contributor to wall oxygenation as blood flow falls (4). Under the $\mathrm{O}_{2}$-enriched superfusate, arteriolar wall $\mathrm{PO}_{2}$ remained at resting levels throughout the $3 \mathrm{~Hz}$ sympathetic nerve stimulation (Fig. 4). Under these conditions, the magnitude of the sympathetic constriction was increased and no longer sensitive to L-NMMA (Figs. 2 and 3). Although arteriolar wall $\mathrm{PO}_{2}$ still fell during the 8 and $16 \mathrm{~Hz}$ stimulations under the high- $\mathrm{O}_{2}$ superfusate, sympathetic constriction was also increased and no longer sensitive to L-NMMA. Based on our hypothesis, we might have expected these decreases in wall $\mathrm{PO}_{2}$ to stimulate NO synthesis and thus make the arteriolar responses to sympathetic nerve stimulation sensitive to NOS inhibition. However, a closer inspection of the data reveals that while wall $\mathrm{PO}_{2}$ fell during the $8 \mathrm{~Hz}$ stimulation under increased superfusate $\mathrm{O}_{2}$, the level to which it fell was not below the resting value for these vessels measured under the normal superfusate (Fig. 4). This suggests that a fall in wall $\mathrm{O}_{2}$ levels may only promote $\mathrm{NO}$ release if $\mathrm{PO}_{2}$ falls below some critical level. Taken together, the observations for sympathetic nerve stimulation at 3 and $8 \mathrm{~Hz}$ suggest a causal link between reduced arteriolar wall $\mathrm{PO}_{2}$ and $\mathrm{NO}$ release during sympathetic constriction. However, the lack of an effect of 
L-NMMA on arteriolar responses to the $16 \mathrm{~Hz}$ nerve stimulation under the high$\mathrm{O}_{2}$ superfusate is inconsistent with this interpretation, since the level to which wall $\mathrm{PO}_{2}$ falls under these conditions is similar to that measured during $8 \mathrm{~Hz}$ stimulation under the normal superfusate (where constriction was enhanced by L-NMMA). It may be that the dramatic (and possibly maximal) constriction of these vessels during this supraphysiological level of nerve stimulation in a high$\mathrm{O}_{2}$ environment was so overwhelming that locally-released $\mathrm{NO}$ was simply unable to exert any modulating effect on the response.

In previous efforts to identify the stimulus for arteriolar NO release during sympathetic constriction in rat intestine, this laboratory ruled out the possibility that neurally-released norepinephrine was stimulating NO release by binding to endothelial $\alpha_{2}$ receptors (25). Another possible stimulus that could act in concert with reduced arteriolar wall $\mathrm{PO}_{2}$ is hemodynamic shear stress, which serves as an important trigger for continuous endothelial NO release during periods of normal and increased luminal flow $(2,8,15)$. However, sympathetic nerve stimulation at 3,8 and $16 \mathrm{~Hz}$ reduces average wall shear rate in first-order intestinal arterioles by $20 \%, 45 \%$ and $73 \%$, respectively (25), and Bohlen and Nase (8) have reported a linear relationship between wall shear rate and periarteriolar $[\mathrm{NO}]$ for these vessels, with each $10 \%$ change in shear rate causing a $6 \%$ change in [NO]. If flow-dependent shear stress remained the predominant stimulus for endothelial NO release in these arterioles during sympathetic constriction, then Bohlen and Nase's calculations would predict a reduction in NO 
release of $12 \%$ during $3 \mathrm{~Hz}$ stimulation, $23 \%$ during $8 \mathrm{~Hz}$ stimulation, and $37 \%$ during $16 \mathrm{~Hz}$ stimulation. Because arteriolar NO release appears to be well maintained throughout sympathetic nerve stimulation (Fig. 1; Refs. 23, 24), it appears unlikely that shear stress remains the primary stimulus for NO release under these conditions.

Instead of reflecting suppressed NO release, the enhanced sympathetic constriction and its resistance to L-NMMA under the hyperoxic superfusate could have been due to a reduction in arteriolar smooth muscle responsiveness to NO. However, our finding that arteriolar responses to the NO donor SNP were unchanged under the hyperoxic superfusate (Fig. 6) argues against this possibility. Alternatively, the apparent absence of arteriolar NO activity under the hyperoxic superfusate could have been due to accelerated NO breakdown by reactive oxygen species generated in the arteriolar wall (32). Although our direct measurements indicate that resting arteriolar wall $\mathrm{PO}_{2}$ was not significantly increased during exposure to the hyperoxic superfusate, there was a clear trend toward higher resting wall $\mathrm{PO}_{2}$ under these conditions (Fig. 4). We therefore used the TNBT reduction method to assess arteriolar oxidant activity in preparations exposed to either the normal or hyperoxic superfusate. This method has been previously used to demonstrate increased oxidative stress in arteriolar and venular walls of hypertensive Dahl rats (34) and normotensive rats fed a high salt diet (20). In the current study, exposure to the hyperoxic superfusate had no effect on arteriolar wall light absorption following TNBT 
exposure, arguing against increased oxidant activity in these vessels. Exposure to intravascular $\mathrm{HX} / \mathrm{XO}$ changed arteriolar wall light absorption by the same amount under the normal superfusate and the hyperoxic superfusate (64-68\%), indicating that the sensitivity of the TNBT reduction method is sufficient to detect increased oxidative stress under either superfusate.

The lack of an effect of L-NMMA on resting arteriolar tone in the intestine (Figs. 1 and 5) contrasts with findings in other vascular beds $(2,15,26,30)$, but is consistent with our previous findings in this preparation (24). In light of recent direct measurements verifying that $\mathrm{NO}$ is continuously released from these vessels in the resting state (8), local NOS inhibition would be expected to reduce arteriolar diameter. However, resting arteriolar tone is the result of vascular smooth muscle's integration of numerous simultaneous vasoactive signals, and the activity of local metabolic and myogenic control mechanisms may set vascular tone at some constant and optimal level for the tissue. These local regulatory mechanisms may be so highly developed in the intestine that the withdrawal of any single influence (such as NO in the presence of L-NMMA) is accompanied by a compensatory change in the activity of one or both of these systems, thereby preserving the level of tone. The lack of effect of increased superfusate $\mathrm{O}_{2}$ on resting arteriolar tone (Fig. 6), which also contrasts with findings in some other vascular beds $(3,4,13,30)$, could simply reflect the fact that the level of $\mathrm{O}_{2}$ in the superfusate was insufficient to significantly alter resting 
arteriolar wall $\mathrm{PO}_{2}$ (Fig. 4). Therefore, a direct effect of oxygen on the vessel wall would be unlikely under these conditions.

Since molecular $\mathrm{O}_{2}$ serves as a co-substrate for all isoforms of NOS (14, 37), one might expect a fall in arteriolar wall $\mathrm{PO}_{2}$ to limit arteriolar $\mathrm{NO}$ production instead of increasing it. This would undoubtedly be the case if the endothelial cell $\mathrm{O}_{2}$ concentration reached rate-limiting levels, but during our experiments arteriolar wall $\mathrm{PO}_{2}$ never fell to the level corresponding to the $\mathrm{K}_{\mathrm{m}}$ of $\mathrm{O}_{2}$ for either isolated eNOS (6 mm Hg) (31) or eNOS in intact endothelial cells $(38 \mathrm{~mm} \mathrm{Hg})$ (37). Therefore, we conclude that the reduction in arteriolar wall $\mathrm{PO}_{2}$ during sympathetic constriction was probably not sufficient to limit endothelial NO synthesis in the current study. Our observations suggest that as arteriolar wall $\mathrm{PO}_{2}$ falls, $\mathrm{NO}$ synthesis may in fact change in a biphasic manner. A fall in $\mathrm{PO}_{2}$ from resting levels could initially stimulate NO synthesis, whereas a continued fall to lower levels would begin to suppress $\mathrm{NO}$ synthesis as $\mathrm{O}_{2}$ becomes limited as a NOS co-substrate. The mechanism by which reduced arteriolar wall $\mathrm{O}_{2}$ tension could lead to increased NO synthesis has not been clearly established. Some investigators have reported that a fall in $\mathrm{O}_{2}$ tension increases cytosolic $\mathrm{Ca}^{+2}$ levels in endothelial cells, which would increase both basal and stimulated NO production $(12,15)$. Alternatively, Bryan and Marshall $(10,11)$ have suggested that a reduction in blood $\mathrm{PO}_{2}$ can promote the release of adenosine from the endothelium of resistance vessels, and that this adenosine acts in an autocrine 
fashion to hyperpolarize the endothelial cell membrane via activation of receptorcoupled $\mathrm{K}_{\mathrm{ATP}}$ channels.

In summary, we have shown that if the fall in arteriolar wall $\mathrm{PO}_{2}$ associated with neurogenic constriction is limited by increased superfusate $\mathrm{O}_{2}$ delivery, sympathetic neurogenic vasoconstriction is enhanced and no longer sensitive to NOS inhibition. This effect can not be explained by reduced vascular smooth muscle responsiveness to NO or by oxidative degradation of NO. These results suggest that during periods of increased sympathetic nerve activity, a flowdependent fall in arteriolar wall $\mathrm{PO}_{2}$ may serve as a stimulus for the release of endothelial NO that in turn limits arteriolar neurogenic constriction. 


\section{REFERENCES}

1. Blitzer, M. L., L. Lee, and M. A. Creager. Endothelium-derived nitric oxide mediates hypoxic vasodilation of resistance vessels in humans. Am. J. Physiol. 271 (Heart Circ. Physiol. 40): H1182-H1185, 1996.

2. Boegehold, M. A. Flow-dependent arteriolar dilation in normotensive rats fed low or high salt diets. Am. J. Physiol. 269 (Heart Circ. Physiol. 38): H1407H1414, 1995.

3. Boegehold, M. A. and P. C. Johnson. Response of arteriolar network of skeletal muscle to sympathetic nerve stimulation. Am. J. Physiol. 254 (Heart Circ. Physiol. 23): H919-H928, 1988a.

4. Boegehold, M. A. and P. C. Johnson. Periarteriolar and tissue $\mathrm{PO}_{2}$ during sympathetic escape in skeletal muscle. Am. J. Physiol. 254 (Heart Circ. Physiol. 23): H929-H936, 1988b.

5. Bohlen, H. G. Intestinal tissue $\mathrm{PO}_{2}$ and microvascular responses during glucose exposure. Am. J. Physiol. 238 (Heart Circ. Physiol. 7): H164-H171, 1980. 
6. Bohlen, H. G. Determinants of resting and passive intestinal vascular pressures in rat and rabbit. Am. J. Physiol. 253 (Gastrointest. Liver Physiol. 16): G587-G595, 1987.

7. Bohlen, H. G. and J. M. Lash. Resting oxygenation of rat and rabbit intestine: arteriolar and capillary contributions. Am. J. Physiol. 269 (Heart Circ. Physiol. 38): H1342-H1348, 1995.

8. Bohlen, H. G. and G. P. Nase. In vivo intestinal arteriolar nitric oxide concentration is altered by blood flow velocity. (Abstract) FASEB J. 13.4: A26, 1999.

9. Bohlen, H. G., H. Henrich, R. W. Gore, and P. C. Johnson. Intestinal muscle and mucosal blood flow during direct sympathetic stimulation. Am. J. Physiol. 235 (1): H40-H45, 1978.

10. Bryan, P. T. and J. M. Marshall. Adenosine receptor subtypes and vasodilatation in rat skeletal muscle during systemic hypoxia: a role for $A_{1}$ receptors. J. Physiol. 514.1: 151-162, 1999. 
11. Bryan, P. T. and J. M. Marshall. Cellular mechanisms by which adenosine induces vasodilatation in rat skeletal muscle: significance for systemic hypoxia. J. Physiol. 514.1: 163-175, 1999.

12. Busse, R., A. Mulsch, I. Fleming, and M. Hecker. Mechanisms of nitric oxide release from the vascular endothelium. Circulation 87: v18-v25, 1993.

13. Duling, B. R. and R. N. Pittman. Oxygen tension: dependent or independent variable in local control of blood flow? Federation Proc. 34: 2012-2019, 1975.

14. Förstermann, U., E. I. Closs, J. S. Pollock, M. Nakane, P. Schwarz, I. Garth, and H. Kleinert. Nitric oxide synthase isozymes characterization, purification, molecular cloning, and function. Hypertension. 23 (part 2): 11211131, 1994.

15. Friebel, M., K. F. Klotz, K. Ley, P. Gaehtgens, and A. R. Pries. Flowdependent regulation of arteriolar diameter in rat skeletal muscle in situ: role of endothelim-derived relaxing factor and prostanoids. J. Physiol. 483.15 (pt 3): 715-726, 1995. 
16. Gräser, T. and G. M. Rubanyi. Different mechanisms of hypoxic relaxation in canine coronary arteries and rat abdominal aortas. J. Cardiovascular Pharm. (Suppl. 12): S117-S119, 1992.

17. Harder, D. R., J. Narayanan, E. K. Birks, J. F. Liard, J. D. Imig, J. H. Lombard, A. R. Lange, and R. J. Roman. Identification of a putative microvascular oxygen sensor. Circ. Res. 79: 54-61, 1996.

18. Jimenez, A. H., M. A. Tanner, W. M. Caldwell, and P. R. Myers. Effects of oxygen tension on flow-induced vasodilation in porcine coronary resistance arterioles. Microvasc. Res. 51: 365-377, 1996.

19. Jones, C. J. H., D. V. DeFily, J. L. Patterson, and W. M. Chilian. Endothelium-derived relaxation competes with $\alpha_{1}$ - and $\alpha_{2}$-adrenergic constriction in the canine epicardial coronary microcirculation. Circulation 87: 1264-1274, 1993.

20. Lenda, D., B. Sauls, and M. A. Boegehold. Local production of superoxide anion may contribute to reduced arteriolar nitric oxide in rats fed high salt. (Abstract) FASEB J. 13.4: A31, 1999. 
21. Messina, E. J., D. Sun, A. Koller, M. S. Wolin, and G. Kaley. Role of endothelium-derived prostaglandins in hypoxia-elicited arteriolar dilation in rat skeletal muscle. Circ. Res. 71: 790-796, 1992.

22. Myers, P. R., J. M. Muller, and M. A. Tanner. Effects of oxygen tension on endothelium dependent responses in canine coronary microvessels. Cardiovasc. Res. 25: 885-894, 1991.

23. Nase, G. P. and M. A. Boegehold. Nitric oxide modulates arteriolar responses to increased sympathetic nerve activity. Am. J. Physiol. 271 (Heart Circ. Physiol. 40): H860-H869, 1996.

24. Nase, G. P. and M. A. Boegehold. Endothelium-derived nitric oxide limits sympathetic neurogenic constriction in intestinal microcirculation. Am. J. Physiol. 273 (Heart Circ. Physiol. 42): H426-H433, 1997.

25. Nase, G. P. and M. A. Boegehold. Postjunctional $\alpha_{2}$-adrenoceptors are not present in proximal arterioles of rat intestine. Am. J. Physiol. 274 (Heart Circ. Physiol. 43): H202-H208, 1998. 
26. Ohyanagi, M., K. Nishigaki, and J. E. Faber. Interaction between microvascular $\alpha_{1^{-}}$and $\alpha_{2}$-adrenoceptors and endothelium-derived relaxing factor. Circ. Res. 71: 188-200, 1992.

27. Okada, T. Hypoxia-induced change in prostanoids production and coronary flow in isolated rat heart. J. Mol. Cell Cardiol. 23: 939-948, 1991.

28. Park, K. H., L. E. Rubin, S. S. Gross, and R. Levi. Nitric oxide is a mediator of hypoxic coronary vasodilatation. Circ. Res. 71: 992-1001, 1992.

29. Pohl, U. and R. Busse. Hypoxia stimulates release of endothelium-derived relaxant factor. Am. J. Physiol. 256 (Heart Circ. Physiol. 25): H1595-H1600, 1989.

30. Pries, A. R., J. Heide, K. Ley, K. F. Klotz, and P. Gaehtgens. Effect of oxygen tension on regulation of arteriolar diameter in skeletal muscle in situ. Microvascular Res. 49: 289-299, 1995.

31. Rengasamy, A. and R. A. Johns. Determination of $K_{m}$ for oxygen of nitric oxide synthase isoforms. JPET. 276: 30-33, 1996. 
32. Rubanyi, G. M. and P. M. Vanhoutte. Superoxide anions and hyperoxia inactivate endothelium-derived relaxing factor. Am. J. Physiol. 250 (Heart Circ. Physiol. 19): H822-H827, 1986.

33. Stewart, A. G. and P. J. Piper. Vasodilator actions of acetylcholine, A23187 and bradykinin in the guinea-pig isolated perfused heart are independent of prostacyclin. Br. J. Pharmacol. 95: 379-384, 1988.

34. Swei, A., F. Lacy, F. A. DeLano, and G. W. Schmid-Schönbein. Oxidative stress in the Dahl hypertensive rat. Hypertension. 30: 1628-1633, 1997.

35. Ward, M. E. Effect of inhibition of nitric oxide synthesis on the diaphragmatic microvascular response to hypoxia. J. Appl. Physiol. 81(4): 1633-1641, 1996.

36. Whalen, W. J., J. Riley, and P. Nair. A microelectrode for measuring intracellular $\mathrm{PO}_{2}$. J. Appl. Physiol. 23(5): 798-801, 1967.

37. Whorton, A. R., D. B. Simonds, and C. A. Piantadosi. Regulation of nitric oxide synthesis by oxygen in vascular endothelial cells. Am. J. Physiol. 272 (Lung Cell. Mol. Physiol. 16): L1161-L1166, 1997. 
Study II: Reduced $\mathrm{PO}_{2}$ and adenosine formation preserve arteriolar nitric oxide synthesis during sympathetic constriction in the rat intestine 


\section{SUMMARY}

Previous reports by this laboratory have indicated that a flow-dependent fall in arteriolar wall $\mathrm{PO}_{2}$ may be a stimulus for the sustained release of endothelial nitric oxide (NO) during sympathetic vasoconstriction in the superfused rat intestine. In this study, we tested the hypothesis that locally-formed adenosine serves as the link between the fall in local $\mathrm{PO}_{2}$ and $\mathrm{NO}$ synthesis under these conditions. Adenosine applied via pressurized micropipettes directly onto the wall or at a distance of $25 \mu \mathrm{m}$ from the wall of first-order arterioles (resting diameter $=54 \pm 1 \mu \mathrm{m})$ elicited dose-dependent dilations of $15-46 \%$ that were significantly reduced by the NO synthase inhibitor $N^{a}$-monomethyl-L-arginine (LNMMA, $\left.10^{-4} \mathrm{M}\right)$. Arteriolar responses to sympathetic nerve stimulation were enhanced by $57-66 \%$ in the presence of L-NMMA or when tissue $\mathrm{PO}_{2}$ was prevented from falling under a high $\mathrm{O}_{2}$ superfusate. Adenosine deaminase (2.0 $\mathrm{U} / \mathrm{ml}$ ) or the selective $A_{1}$ receptor antagonist 8-cyclopentyl-1,3-dipropylxanthine $\left(4 \times 10^{-4} \mathrm{M}\right)$ completely blocked the enhancing effect of L-NMMA on sympathetic constriction. These results are consistent with the hypothesis that the fall in arteriolar wall and/or tissue $\mathrm{PO}_{2}$ that accompanies sympathetic arteriolar constriction in the rat intestine can lead to local adenosine production, which in turn preserves endothelial NO release. 


\section{INTRODUCTION}

Previous studies by this laboratory have demonstrated that endotheliumderived nitric oxide (NO) normally limits arteriolar responses to increased sympathetic nerve activity in the intestine [1,2]. Hemodynamic shear stress and activation of endothelial $\alpha_{2}$-adrenoceptors have been ruled out as stimuli for NO release under these conditions [3]. In contrast, we have recently reported that the limiting influence of NO on sympathetic constriction is lost when the flowdependent fall in arteriolar wall $\mathrm{PO}_{2}$ is minimized under a hyperoxic superfusate, implicating reduced local oxygen levels as a possible stimulus for endothelial NO release [4].

Some investigators have reported that the vascular endothelium itself is sensitive to local oxygen levels, and that reduced $\mathrm{PO}_{2}$ directly increases the release of endothelial NO [5-7]. Alternatively, a local decrease in oxygen tension may indirectly stimulate NO release through adenosine formation. It is well established that reductions in oxygen tension lead to increased adenosine levels [8-10], and adenosine has been shown to stimulate NO synthesis in some vascular beds [11, 12]. In this study, we tested the hypothesis that locallyproduced adenosine serves as the link between reduced local oxygen levels and arteriolar NO synthesis during sympathetic constriction in the rat intestine. We evaluated the effects of NO synthase (NOS) inhibition, enhanced tissue oxygen delivery, and pharmacological manipulation of adenosine activity on arteriolar responses to sympathetic nerve stimulation. Nitric oxide synthesis was inhibited 
with the NOS inhibitor $\mathrm{N}^{a}$-monomethyl-L-arginine (L-NMMA), and local oxygen delivery was enhanced with a hyperoxic superfusate to maintain tissue oxygen tension at resting levels during sympathetic constriction. Endogenous adenosine activity was manipulated with adenosine deaminase or the $A_{1}$ receptor antagonist 8-cyclopentyl-1,3-dipropylxanthine (DPCPX). Tissue $\mathrm{PO}_{2}$ was directly measured with oxygen sensitive microelectrodes to verify the effects of sympathetic nerve stimulation and increased superfusate oxygen content on local oxygen levels.

\section{METHODS}

All surgical and experimental procedures were approved by the West Virginia University Animal Care and Use Committee. Male Sprague-Dawley rats aged 8-9 wk (Harlan Sprague Dawley, Indianapolis, IN) were anesthetized with sodium thiopental (100 mg/kg ip) and placed on a heating mat to maintain a $37^{\circ} \mathrm{C}$ rectal temperature. To ensure adequate gas exchange, rats were intubated and ventilated by a rodent ventilator (Harvard Apparatus, South Natick, MA). Arterial pressure was measured directly with a Gould P23 ID pressure transducer (Cleveland, $\mathrm{OH}$ ) connected to a cannula inserted into the right carotid artery.

The small intestine was prepared for microscopic observation as previously described [1], and continuously superfused with a physiological electrolyte solution (in $\mathrm{mM}$ : $119 \mathrm{NaCl}, 25 \mathrm{NaHCO}_{3}, 6 \mathrm{KCl}$, and $3.6 \mathrm{CaCl}_{2}$ ) that was warmed to $37^{\circ} \mathrm{C}$ and equilibrated with $5 \% \mathrm{O}_{2}-5 \% \mathrm{CO}_{2}-90 \% \mathrm{~N}_{2}$ to mimic normal in-vivo conditions [13] or $20 \% \mathrm{O}_{2}-5 \% \mathrm{CO}_{2}-75 \% \mathrm{~N}_{2}$ to create a hyperoxic environment. 
Isoproterenol (10 mg/l; Sigma, St. Louis, MO) and phenytoin (20 mg/l; ParkeDavis, Morris Plains, NJ) were added to the superfusate to suppress intestinal motility. At these concentrations, neither agent alters resting arteriolar tone in this vascular bed [14]. With most of the preparation covered by polyvinyl film, and superfusate flow directed beneath the film, solution $\mathrm{PO}_{2}$ above the tissue is maintained at $40-50 \mathrm{mmHg}$ under normal conditions [15].

After surgery, the rat was transferred to the stage of an Olympus BHTU intravital microscope (Hyde Park, NY) fitted with a CCD video camera (Dage MTI, Michigan City, IN). Video images were displayed on a Panasonic highresolution video monitor and stored on videotape for off-line analysis. Observations were made with a x10 eyepiece and Nikon x10 water immersion objective (final video magnification $=x 730$ ). The theoretical resolution of this system is $1-1.5 \mu \mathrm{m}$, with the actual resolution under experimental conditions slightly diminished due to light scattering by the tissue. Arteriolar inner diameters were measured with a video caliper (Microcirculation Research Institute, Texas A \& M University) during videotape replay.

Tissue $\mathrm{PO}_{2}$ was measured with Whalen-type $\mathrm{O}_{2}$ microelectrodes (tip diameter $=2-3 \mu \mathrm{m}$, Diamond General, Ann Arbor, Ml) that were calibrated immediately before and after each experiment. Data from electrodes exhibiting more than a $5 \%$ change in gain from pre- to postexperimental calibrations were discarded. For calibration, electrodes were placed in a tonometer (model 1251, Diamond General), and current output was recorded in superfusates equilibrated 
with $10 \%$ and $20 \% \mathrm{O}_{2}$ gas mixtures $\left(\mathrm{PO}_{2}=71\right.$ and $142 \mathrm{~mm} \mathrm{Hg}$, respectively). Zero-level $\mathrm{PO}_{2}$ was determined by placing the electrode tip in an actively respiring yeast mixture as described by Whalen et al [16].

A bipolar platinum electrode was used to stimulate the sympathetic postganglionic efferents running along a mesenteric artery-vein pair upstream from the arteriole under study. The electrode and artery-vein pair were briefly raised above the superfusate, and the nerves were stimulated with square-wave pulses at supramaximal voltage $(5-6 \mathrm{~V})$ and a pulse duration of $10 \mathrm{~ms}$. These stimulation parameters elicit frequency-dependent arteriolar constrictions that are abolished by the non-selective $\alpha$-receptor antagonist phentolamine [1] and the selective $\alpha_{1}$-receptor antagonist prazosin [3], verifying that these responses are due to sympathetic nerve activation.

Experimental Protocols. In the first series of experiments, we assessed adenosine's ability to stimulate arteriolar NO synthesis in this preparation. A Picospritzer II pressure ejection system (General Valve, Fairfield, NJ) was used to eject adenosine from glass micropipettes positioned at the vessel wall or 25 and $50 \mu \mathrm{m}$ away from the wall. The micropipettes (2-3 $\mu \mathrm{m}$ inner tip diameter) were filled with $4.7 \times 10^{-7} \mathrm{M}$ adenosine in superfusion solution. After a 1-min control period, adenosine was applied using an ejection pressure of 10,20 , or 30 psi for $1 \mathrm{~min}$. Following a 3-min recovery, this sequence was repeated two more times so that the arteriole was challenged with all 3 levels of adenosine, 
delivered in random order. These applications were then repeated during continuous exposure of the vasculature to the NOS inhibitor L-NMMA at a superfusate concentration of $1 \times 10^{-4} \mathrm{M}$.

The second series of experiments was designed to define the relationship between tissue oxygenation and NO activity during periods of increased sympathetic nerve activity. During superfusion with either the normal $\left(5 \% \mathrm{O}_{2}\right)$ or hyperoxic $\left(20 \% \mathrm{O}_{2}\right)$ solution, a single first-order arteriole was selected for study and an $\mathrm{O}_{2}$ microelectrode was positioned with the tip at the same tissue depth as the arteriole and $25 \mu \mathrm{m}$ from the vessel wall. A site $25 \mu \mathrm{m}$ from the wall was chosen because the results of our first series of experiments indicated that adenosine released from distances within $25 \mu \mathrm{m}$ of the arteriolar wall elicited dilations that were due largely to NO release (see Fig. 1). After a 1-min control period, the sympathetic nerves were stimulated for 1 min at either 3 or $8 \mathrm{~Hz}$, followed by a 3-min recovery period. This sequence was then repeated for stimulation at the other frequency so that the arteriole was subjected to both levels of increased sympathetic nerve activity, delivered in random order. The superfusate was then changed (from normal to hyperoxic or from hyperoxic to normal), and the sequence of nerve stimulations was repeated. The nerve stimulation sequences under both the normal and hyperoxic superfusates were then repeated in the presence of $10^{-4} \mathrm{M} \mathrm{L-NMMA}$.

A third series of experiments was designed to determine if locally-produced adenosine acting on microvascular $A_{1}$ receptors could serve as the link between 
the fall in local $\mathrm{PO}_{2}$ and $\mathrm{NO}$ synthesis during periods of increased sympathetic nerve activity. Experiments were performed on two groups of rats, with the protocol identical to that used in the second series of experiments except that in the first group, the vasculature was continuously exposed to $2.0 \mathrm{U} / \mathrm{ml}$ adenosine deaminase (Sigma) and in the second group, the vasculature was continuously exposed to the selective $A_{1}$ receptor antagonist DPCPX $\left(4 \times 10^{-4} \mathrm{M}\right.$, Sigma). In pilot experiments, $2.0 \mathrm{U} / \mathrm{ml}$ adenosine deaminase maximally reduced arteriolar responses to $10^{-3} \mathrm{M}$ adenosine (dilations reduced by $88 \pm 13 \%$ ). Both adenosine deaminase and DPCPX were added directly to the superfusate via syringe pump. DPCPX was initially dissolved in 50\% DMSO/50\% $0.1 \mathrm{M} \mathrm{NaOH}$. Control measurements verified that DMSO at its final superfusate concentration (1.3\%) had no direct effect on arteriolar tone.

In a fourth series of experiments, we evaluated the effectiveness of DPCPX in blocking arteriolar responses to adenosine. Adenosine was applied directly to the arteriolar wall via pressurized micropipettes as described above. After a 1min control period, adenosine was applied for $1 \mathrm{~min}$ at ejection pressures of 10 , 20, and 30 psi (in random order). Each application was followed by a 3-min recovery period. These applications were then repeated in the presence of $4 x$ $10^{-4} \mathrm{M}$ DPCPX.

In a fifth series of experiments, the specificity of DPCPX for $A_{1}$ receptors was assessed by evaluating its effect on arteriolar responses to the selective $A_{1}$ agonist 2-chloro- $\mathrm{N}^{6}$-cylclopentyl-adenosine (CCPA). CCPA was initially 
dissolved in DMSO (0.3\% final bath concentration) and then added to the superfusate at concentrations of $10^{-7}$ and $10^{-6} \mathrm{M}$ (random application order, 7-min recovery period between applications).

A sixth series of experiments was designed to determine if treatment with either adenosine deaminase or DPCPX alters the inherent responsiveness of arteriolar smooth muscle to NO. Arteriolar responses to the NO-donor sodium nitroprusside (SNP, Sigma) were assessed before and then during exposure to each agent. Glass micropipettes were filled with 0.5 M SNP in distilled water and connected to an iontophoresis current programmer (model 260, World Precision Instruments, Sarasota, FL). A retaining current of $40 \mathrm{nA}$ was used to prevent diffusion of SNP from the pipette tip, and net ejection currents of 5,20 , and $40 \mathrm{nA}$ (in random order) were used to deliver SNP to the vessel wall. Each vessel was observed during a 2-min control period, a 2-min application period, and a 2-min recovery period. To avoid potential complications related to acute changes in endogenous NO production, these experiments were conducted in the presence of $10^{-4} \mathrm{M}$ L-NMMA.

At the end of all experiments, adenosine was added to the superfusate $\left(10^{-3}\right.$ M final concentration), and passive arteriolar diameter was measured.

Data and Statistical Analysis. For each arteriole, the level of resting tone (T) was calculated as follows: $T=\left[\left(D_{\max }-D_{c} / D_{\max }\right] \times 100\right.$ where $D_{\max }$ is passive 
diameter under adenosine, and $D_{c}$ is the diameter measured during the control period.

All data are expressed as means \pm SE. Statistical analysis was carried out using commercially available software (Sigma Stat, Jandel Scientific, San Rafael, CA). ANOVA for repeated measures was used to compare arteriolar dilations to adenosine, CCPA, and SNP before and after treatment with L-NMMA, DPCPX, or adenosine deaminase. ANOVA for repeated measures was also used to compare arteriolar constrictions to sympathetic nerve stimulation before and after L-NMMA under the low and high- $\mathrm{O}_{2}$ superfusates in the presence and absence of DPCPX and adenosine deaminase, as well as for comparison of tissue $\mathrm{PO}_{2}$ values under the high and low- $\mathrm{O}_{2}$ superfusate. For all ANOVA procedures, the Student Newman-Keuls multiple range procedure for post hoc analysis was used to identify differences among specific groups. Significance was assessed at $\mathrm{P}<$ 0.05 for all statistical tests.

\section{RESULTS}

In all protocols combined, a total of 78 first-order arterioles were observed in 47 rats. The rats averaged $273 \pm 4 \mathrm{~g}$ in body weight at $57 \pm 1$ days of age, with a mean arterial pressure under anesthesia of $98 \pm 1 \mathrm{~mm} \mathrm{Hg}$. Arteriolar resting and passive diameters averaged $54 \pm 1$ and $87 \pm 1 \mu \mathrm{m}$, respectively, with an average calculated arteriolar tone of $37 \pm 1 \%$. 
Twenty-six first-order arterioles were studied to evaluate adenosine's ability to stimulate arteriolar NO synthesis in this preparation. Although L-NMMA had no significant effect on resting arteriolar diameters $(50 \pm 2 \mu \mathrm{m}$ under control conditions vs. $52 \pm 1 \mu \mathrm{m}$ during L-NMMA exposure), arteriolar responses to directly applied adenosine were significantly inhibited by L-NMMA. Adenosine applied to the arteriolar wall at micropipette ejection pressures of 10,20 and 30 psi caused dilations of $7 \pm 1,11 \pm 1$, and $15 \pm 2 \mu \mathrm{m}$ under control conditions (average dilations of 14,22 , and $30 \%$ above resting diameter), vs. $1 \pm 1,3 \pm 1$, and $3 \pm 1 \mu \mathrm{m}$ in the presence of L-NMMA (dilations of 2,6 , and $6 \%$ above resting diameter) (Fig. 1, top panel). When adenosine was applied to a tissue site $25 \mu \mathrm{m}$ from the vascular wall, arteriolar responses to adenosine were still sensitive to NOS inhibition, with respective dilations of $8 \pm 1,14 \pm 1$, and $22 \pm 3 \mu \mathrm{m}$ under control conditions $(16,28$, and $44 \%$ above resting diameter) vs. $0.3 \pm 0.3,5 \pm 2$, and $6 \pm 1$ $\mu \mathrm{m}$ in the presence of L-NMMA $(1,10$, and 12\% above resting diameter) (Fig. 1, middle panel). However, when adenosine was applied to a site $50 \mu \mathrm{m}$ from the vascular wall, the arteriolar responses were no longer sensitive to L-NMMA (dilations of $9 \pm 2,14 \pm 2$, and $21 \pm 3 \mu \mathrm{m}$, or 18,28 , and $42 \%$ above resting diameter vs. $9 \pm 3,12 \pm 3$ and $18 \pm 1 \mu \mathrm{m}$, or 18,24 , and $35 \%$ above resting diameter in the presence of L-NMMA) (Fig.1, bottom panel).

Ten first-order arterioles were studied to define the relationship between tissue oxygenation and NO activity during periods of increased sympathetic nerve activity. Under the normal superfusate, sympathetic nerve stimulation 
induced frequency-dependent constrictions, with arteriolar diameters reduced from $62 \pm 1 \mu \mathrm{m}$ at rest to $50 \pm 1$ and $44 \pm 1 \mu \mathrm{m}$ (average diameter reductions of 19 and 29\%) during stimulation at 3 and $8 \mathrm{~Hz}$, respectively (Fig. 2). In the presence of L-NMMA, resting arteriolar diameters were unchanged $(63 \pm 2 \mu \mathrm{m})$, but responses to each level of sympathetic nerve stimulation were significantly enhanced. During L-NMMA exposure, stimulation at 3 and $8 \mathrm{~Hz}$ reduced arteriolar diameters to $41 \pm 1$ and $30 \pm 1 \mu \mathrm{m}$ (average diameter reductions of 35 and $52 \%$ ), respectively.

Figure 3 illustrates the effect of L-NMMA on steady-state arteriolar responses to sympathetic nerve stimulation under the normal and high-oxygen superfusates. As stated above, exposure to L-NMMA significantly enhanced the maximal arteriolar constrictions under the normal superfusate by 48 to $83 \%$ (an increase in constriction magnitude from $12 \pm 1$ to $22 \pm 1 \mu \mathrm{m}$ for $3 \mathrm{~Hz}$ stimulation, and from $21 \pm 1$ to $31 \pm 2 \mu \mathrm{m}$ for $8 \mathrm{~Hz}$ stimulation). Under the high-oxygen superfusate, resting arteriolar diameters were unchanged $(63 \pm 2 \mu \mathrm{m})$, but control responses to nerve stimulation were significantly greater than those under the normal superfusate (constrictions of $22 \pm 1 \mu \mathrm{m}$, or $35 \%$ from resting diameter, at 3 $\mathrm{Hz}$ and $31 \pm 2 \mu \mathrm{m}$, or $49 \%$ from resting diameter, at $8 \mathrm{~Hz}$ ). L-NMMA did not alter resting arteriolar diameters $(61 \pm 1 \mu \mathrm{m})$ under the high-oxygen superfusate. However, in contrast to the normal superfusate, L-NMMA did not enhance arteriolar responses to sympathetic nerve stimulation under the high-oxygen 
superfusate (constrictions of $21 \pm 1 \mu \mathrm{m}$, or $33 \%$ from resting diameter, at $3 \mathrm{~Hz}$ and $33 \pm 2 \mu \mathrm{m}$, or $52 \%$ from resting diameter, at $8 \mathrm{~Hz}$ ).

Under the normal superfusate, resting tissue $\mathrm{PO}_{2}$ measured $25 \mu \mathrm{m}$ from the arteriolar wall averaged $41 \pm 1 \mathrm{~mm} \mathrm{Hg}$ (Fig. 4). During sympathetic nerve stimulation at $3 \mathrm{~Hz}$, tissue $\mathrm{PO}_{2}$ fell by $32 \%$ to $28 \pm 3 \mathrm{~mm} \mathrm{Hg}$, and at $8 \mathrm{~Hz}$, tissue $\mathrm{PO}_{2}$ fell by $46 \%$ to $22 \pm 2 \mathrm{~mm} \mathrm{Hg}$. Under the high-oxygen superfusate, resting tissue $\mathrm{PO}_{2}$ was not significantly changed $(44 \pm 1 \mathrm{~mm} \mathrm{Hg})$, but there was no significant fall in tissue $\mathrm{PO}_{2}$ during sympathetic constriction. During 3 and $8 \mathrm{~Hz}$ stimulation, steady-state $\mathrm{PO}_{2}$ averaged $41 \pm 1 \mathrm{~mm} \mathrm{Hg}$ and $40 \pm 1 \mathrm{~mm} \mathrm{Hg}$, respectively.

Fifteen first-order arterioles were studied to evaluate the contribution of locally-produced adenosine and microvascular $A_{1}$ receptors to NO synthesis during periods of increased sympathetic nerve activity. Similar to the results described above, exposure to L-NMMA did not alter the resting tone of the arterioles observed during this protocol (resting diameter $=56 \pm 2 \mu \mathrm{m}$ under control conditions and in the presence of L-NMMA). However, in contrast to the above results, in the presence of adenosine deaminase, arteriolar responses to sympathetic nerve stimulation were not enhanced by L-NMMA under either the normal or high-oxygen superfusate (Fig. 5). Under the normal superfusate, 3 and $8 \mathrm{~Hz}$ stimulation induced arteriolar constrictions of $15 \pm 1$ and $31 \pm 2 \mu \mathrm{m}(27$ and $55 \%$ from resting diameter) under control conditions vs. $15 \pm 1$ and $24 \pm 2 \mu \mathrm{m}$ (27 and $43 \%$ from resting diameter) in the presence of L-NMMA. Under the 
high-oxygen superfusate, 3 and $8 \mathrm{~Hz}$ stimulation induced arteriolar constrictions of $14 \pm 1$ and $27 \pm 3 \mu \mathrm{m}$ ( 28 and $48 \%$ from resting diameter) under control conditions vs. $14 \pm 1$ and $22 \pm 2 \mu \mathrm{m}$ ( 28 and $39 \%$ from resting diameter) in the presence of L-NMMA. Similarly, in the presence of DPCPX, arteriolar responses to sympathetic nerve stimulation were not enhanced by L-NMMA under either superfusate (Fig. 6). Under the normal superfusate, 3 and $8 \mathrm{~Hz}$ stimulation induced arteriolar constrictions of $8 \pm 1$ and $21 \pm 3 \mu \mathrm{m}$ (14 and $38 \%$ from resting diameter) under control conditions vs. $9 \pm 1$ and $20 \pm 2 \mu \mathrm{m}$ (16 and $36 \%$ from resting diameter) in the presence of L-NMMA. Under the high-oxygen superfusate, 3 and $8 \mathrm{~Hz}$ stimulation induced arteriolar constrictions of $8+1$ and $23 \pm 2 \mu \mathrm{m}$ ( 14 and $41 \%$ from resting diameter) under control conditions vs. $9 \pm 1$ and $20 \pm 2 \mu \mathrm{m}$ (16 and $36 \%$ from resting diameter) in the presence of L-NMMA.

The ability of DPCPX to block arteriolar responses to adenosine was verified in seven first-order arterioles. The $A_{1}$ receptor antagonist DPCPX had no significant effect on the resting diameter of arterioles studied in these experiments $(51 \pm 5 \mu \mathrm{m}$ under control conditions vs. $54 \pm 5 \mu \mathrm{m}$ during DPCPX exposure). As shown in Figure 7 (top panel), arteriolar responses to adenosine were virtually abolished in the presence of DPCPX, with application of adenosine at 10,20 , and 30 psi inducing dilations of $9 \pm 2,13 \pm 3$, and $18 \pm 1 \mu \mathrm{m}(18,25$, and $35 \%$ above resting diameter) under control conditions and $0,1 \pm 1$, and $1 \pm 1 \mu \mathrm{m}(0$, 2 , and $2 \%$ above resting diameter) in the presence of DPCPX. 
The specificity of DPCPX for $A_{1}$ receptors was evaluated in six arterioles. Similar to the preceding protocol, the $A_{1}$ receptor antagonist DPCPX had no significant effect on the resting diameter of arterioles studied in these experiments $(49 \pm 2 \mu \mathrm{m}$ under control conditions vs. $51 \pm 2 \mu \mathrm{m}$ during DPCPX exposure). As shown in Figure 7 (bottom panel), the arteriolar dilations induced by the $A_{1}$ receptor agonist CCPA at concentrations of $10^{-7}$ and $10^{-6} \mathrm{M}$ were significantly reduced in the presence of DPCPX (dilations of $14 \pm 2$ and $23 \pm 2 \mu \mathrm{m}$, or 29 and $47 \%$, under control conditions vs. dilations of $2 \pm 1$ and $7 \pm 1 \mu \mathrm{m}$, or 4 and $14 \%$, in the presence of DPCPX).

Fourteen first-order arterioles were studied to evaluate the effect of adenosine deaminase and DPCPX on vascular smooth muscle responsiveness to NO. Similar to the above protocols, neither adenosine deaminase nor DPCPX altered the resting diameter of the arterioles observed in these experiments (resting diameter of $57 \pm 2 \mu \mathrm{m}$ under control conditions, $59 \pm 2 \mu \mathrm{m}$ in the presence of adenosine deaminase, and $56 \pm 2 \mu \mathrm{m}$ in the presence of DPCPX). Application of SNP resulted in dilations that were not significantly altered by either adenosine deaminase or DPCPX (Fig. 9). For the adenosine deaminase experiments, SNP applied with ejection currents of 5,20 , and $40 \mathrm{nA}$ induced respective dilations of $10 \pm 2,19 \pm 2$, and $31 \pm 2 \mu \mathrm{m}(18,33$, and $54 \%$ above resting diameter) under control conditions and $12 \pm 2,22 \pm 2$, and $26 \pm 4 \mu \mathrm{m}(20,37$, and $44 \%$ above resting diameter) during exposure to adenosine deaminase. For the DPCPX experiments, application of SNP induced dilations of $11 \pm 2,20 \pm 2$, and $30 \pm 3 \mu \mathrm{m}$ 
$(19,35$, and $53 \%$ above resting diameter) under control conditions and $12 \pm 2$, $22 \pm 2$, and $31 \pm 2 \mu \mathrm{m}(21,39$, and $55 \%$ above resting diameter) during DPCPX exposure. 

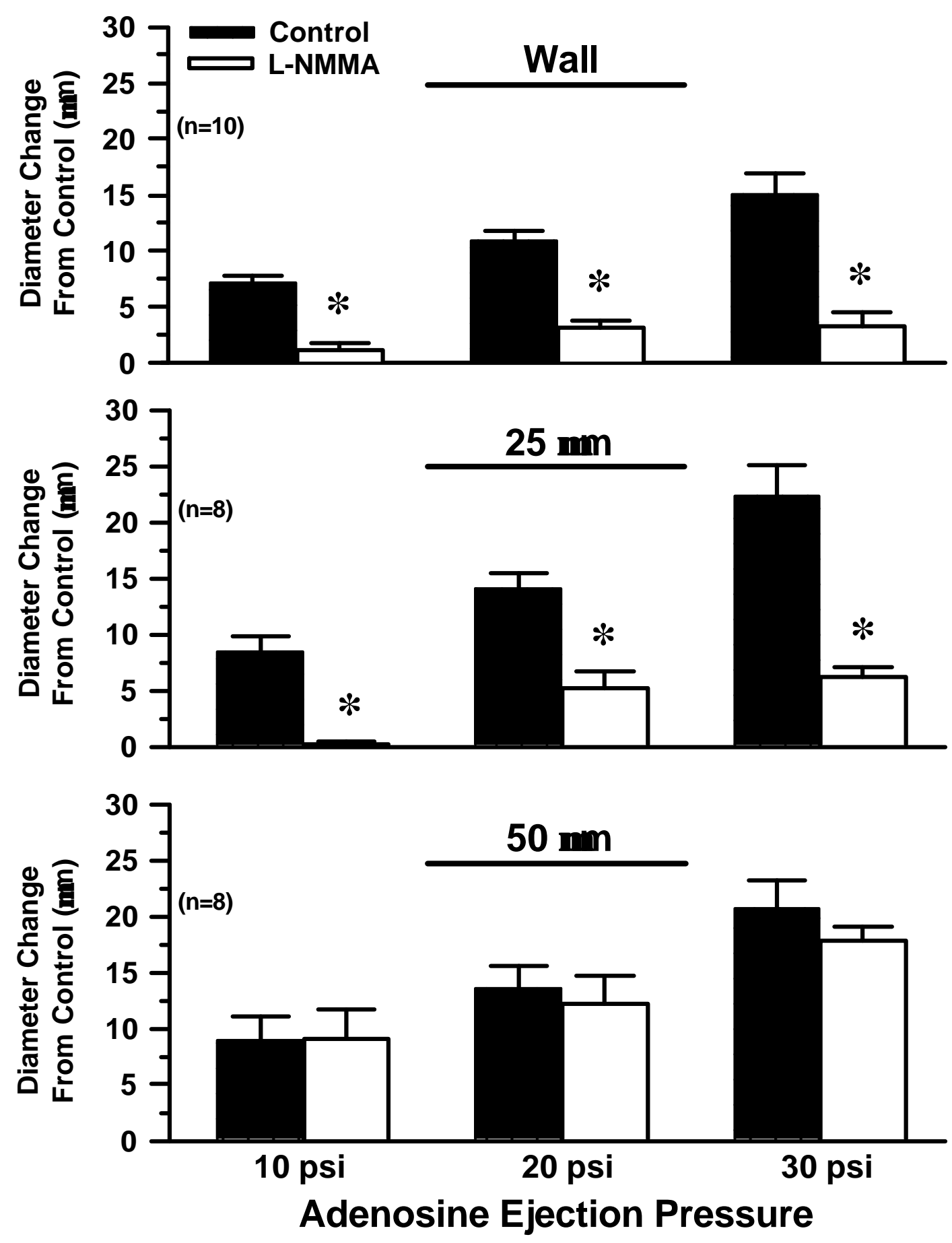

Figure 1. Arteriolar diameter responses to adenosine applied via pressurized micropipette directly to the arteriolar wall (top panel), $25 \mu \mathrm{m}$ from the wall (middle panel), and $50 \mu \mathrm{m}$ from the wall (bottom panel) under the normal superfusate, before (closed bars) and then during (open bars) exposure to $10^{-4} \mathrm{M} \mathrm{L-NMMA.} \mathrm{n}$ $=$ number of vessels. ${ }^{*} \mathrm{P}<0.05$ vs. control. 


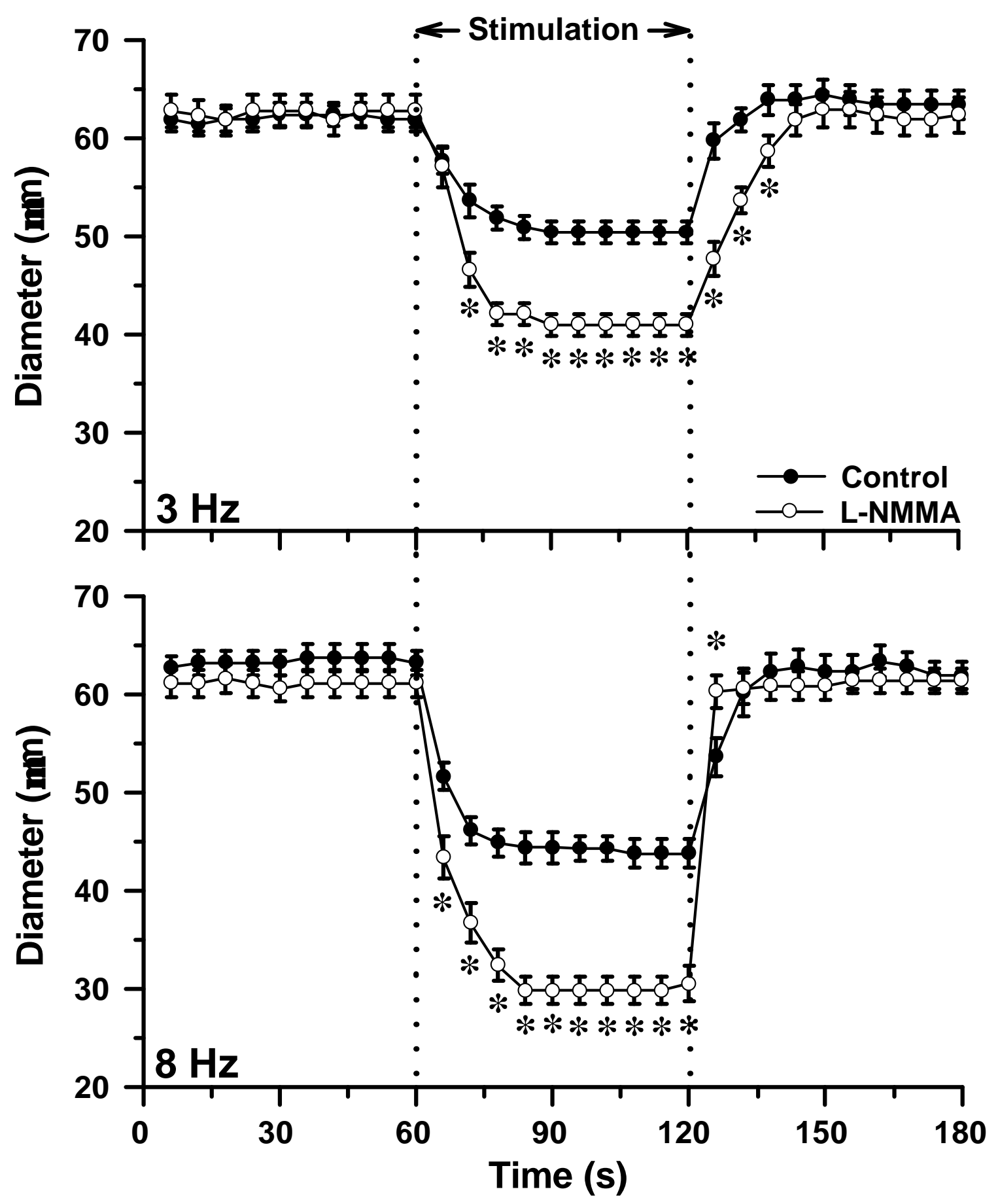

Figure 2. Arteriolar diameter responses to sympathetic nerve stimulation at frequencies of 3 and $8 \mathrm{~Hz}$ under normal superfusate, before (closed circles) and during (open circles) exposure to $10^{-4} \mathrm{M} \mathrm{L-NMMA}$. All data are paired. $\mathrm{n}=10$ vessels. ${ }^{*} \mathrm{P}<0.05$ vs. control. 


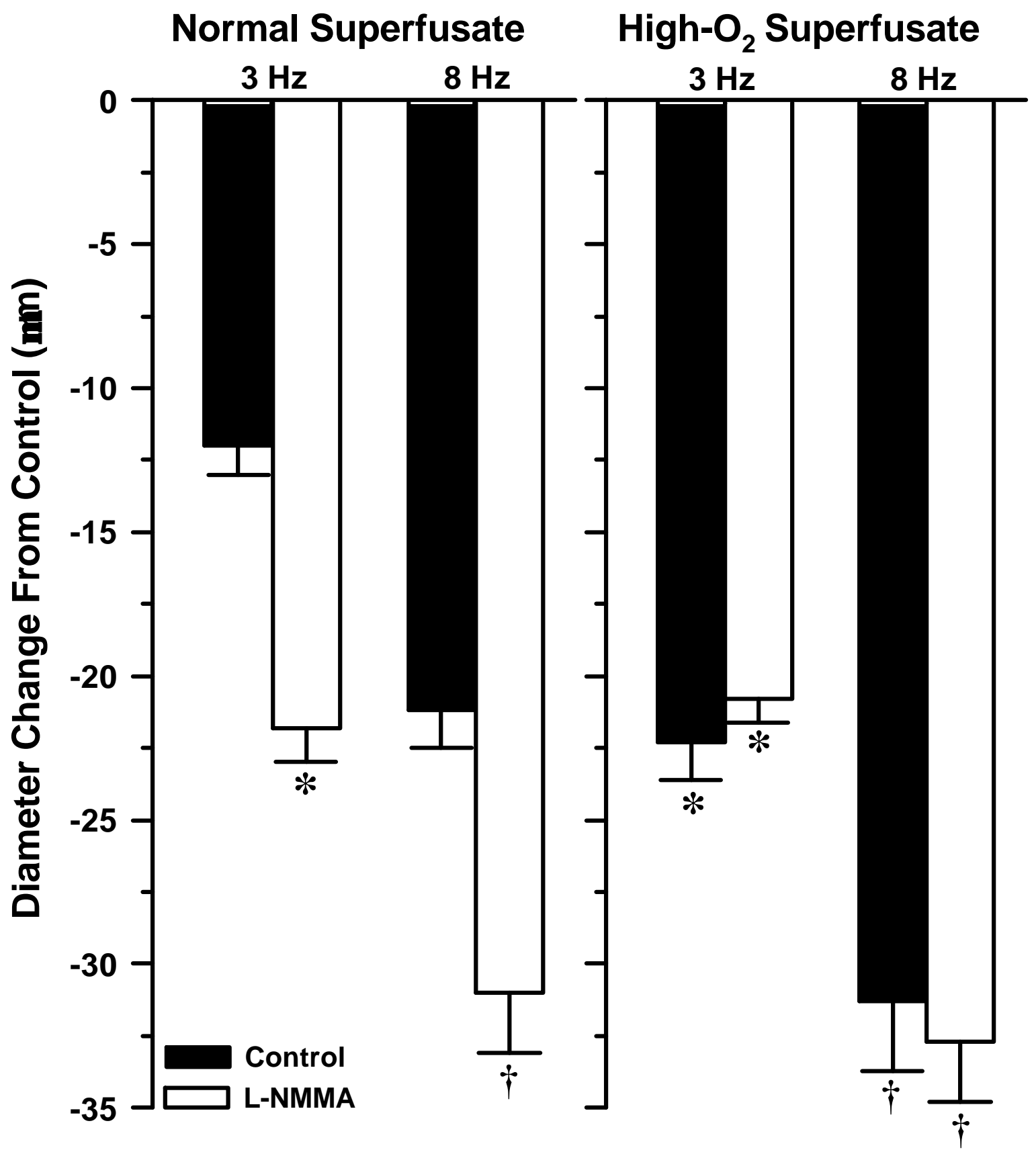

Figure 3. Effect of L-NMMA on arteriolar diameter responses to 3 and $8 \mathrm{~Hz}$ sympathetic nerve stimulation under normal superfusate (left panel) and high- $\mathrm{O}_{2}$ superfusate (right panel). All data are paired. $n=10$ vessels. ${ }^{*} \mathrm{P}<0.05$ vs. control response to $3 \mathrm{~Hz}$ stimulation under normal superfusate; $\dagger \mathrm{P}<0.05$ vs. control response to $8 \mathrm{~Hz}$ stimulation under normal superfusate. 


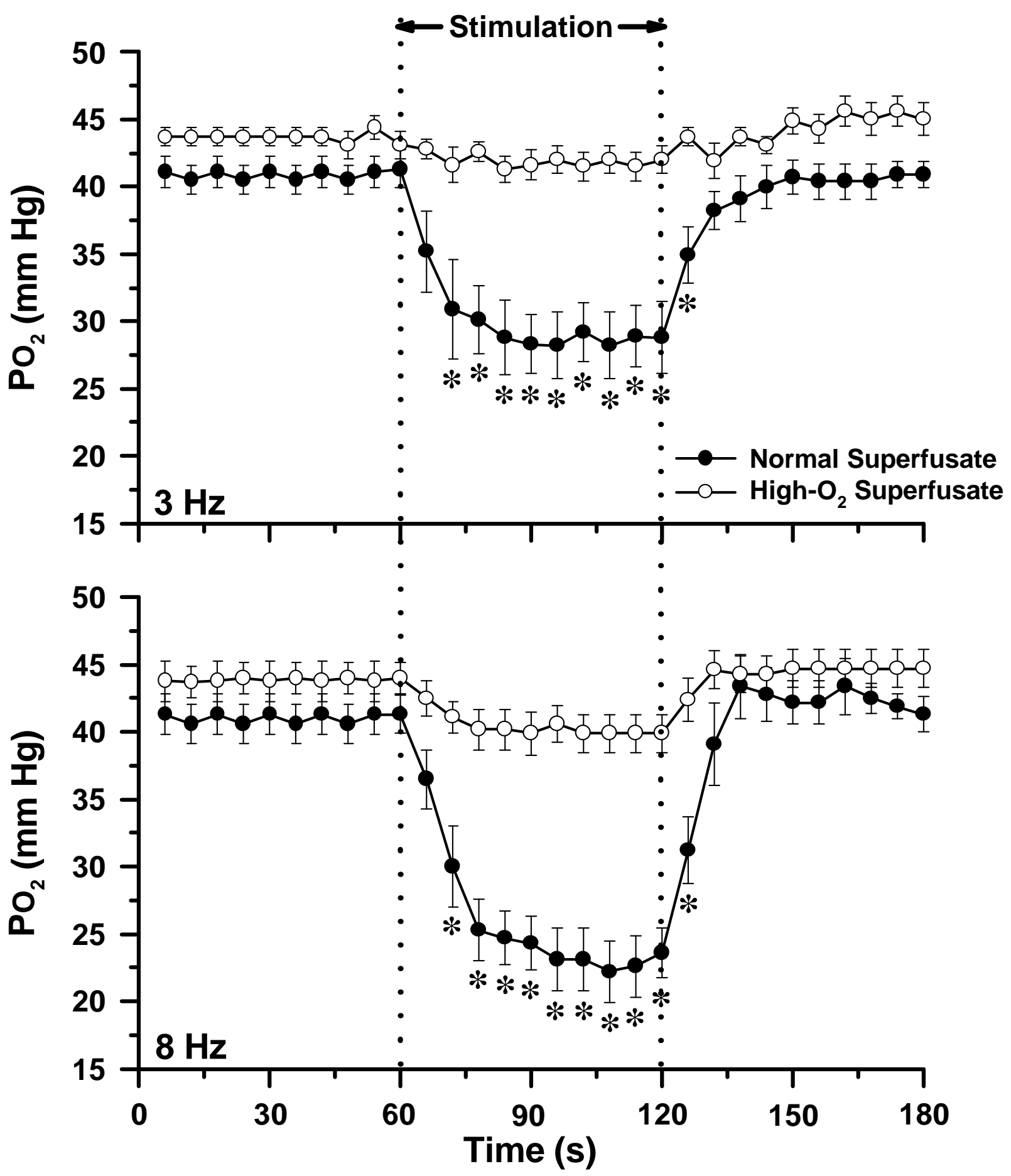

Figure 4. Tissue $\mathrm{PO}_{2}$ measured $25 \mu \mathrm{m}$ from the arteriolar wall during 3 and $8 \mathrm{~Hz}$ sympathetic nerve stimulation under normal superfusate (closed circles) and high- $\mathrm{O}_{2}$ superfusate (open circles). All data are paired. $\mathrm{n}=7$ measurements. ${ }^{*} \mathrm{P}<0.05$ vs. pre-stimulation value. 


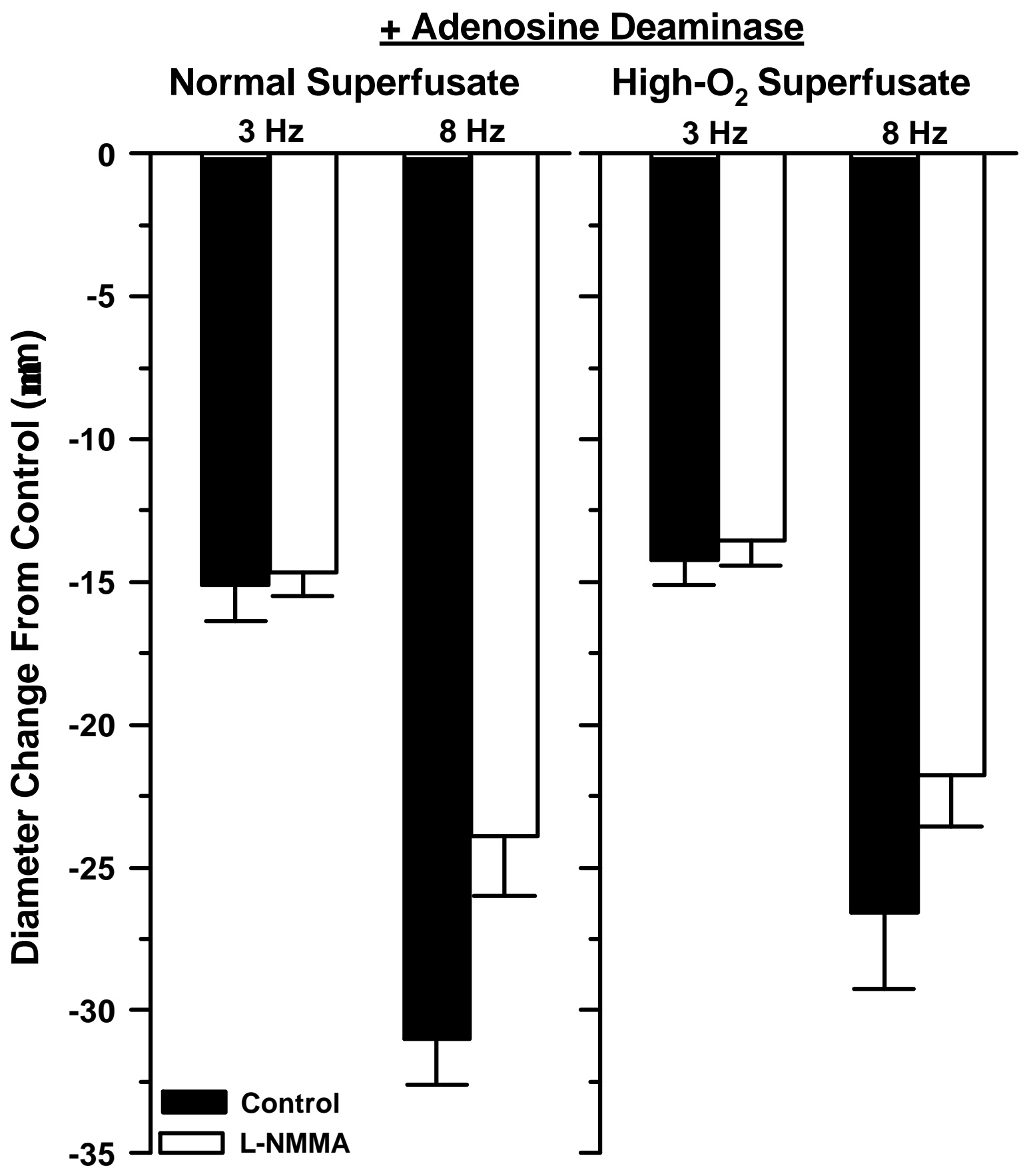

Figure 5. Effect of L-NMMA on arteriolar diameter responses to 3 and $8 \mathrm{~Hz}$ sympathetic nerve stimulation during continuous exposure to $2.0 \mathrm{U} / \mathrm{ml}$ adenosine deaminase under normal superfusate (left panel) and high- $\mathrm{O}_{2}$ superfusate (right panel). All data are paired. $\mathrm{n}=9$ vessels. 


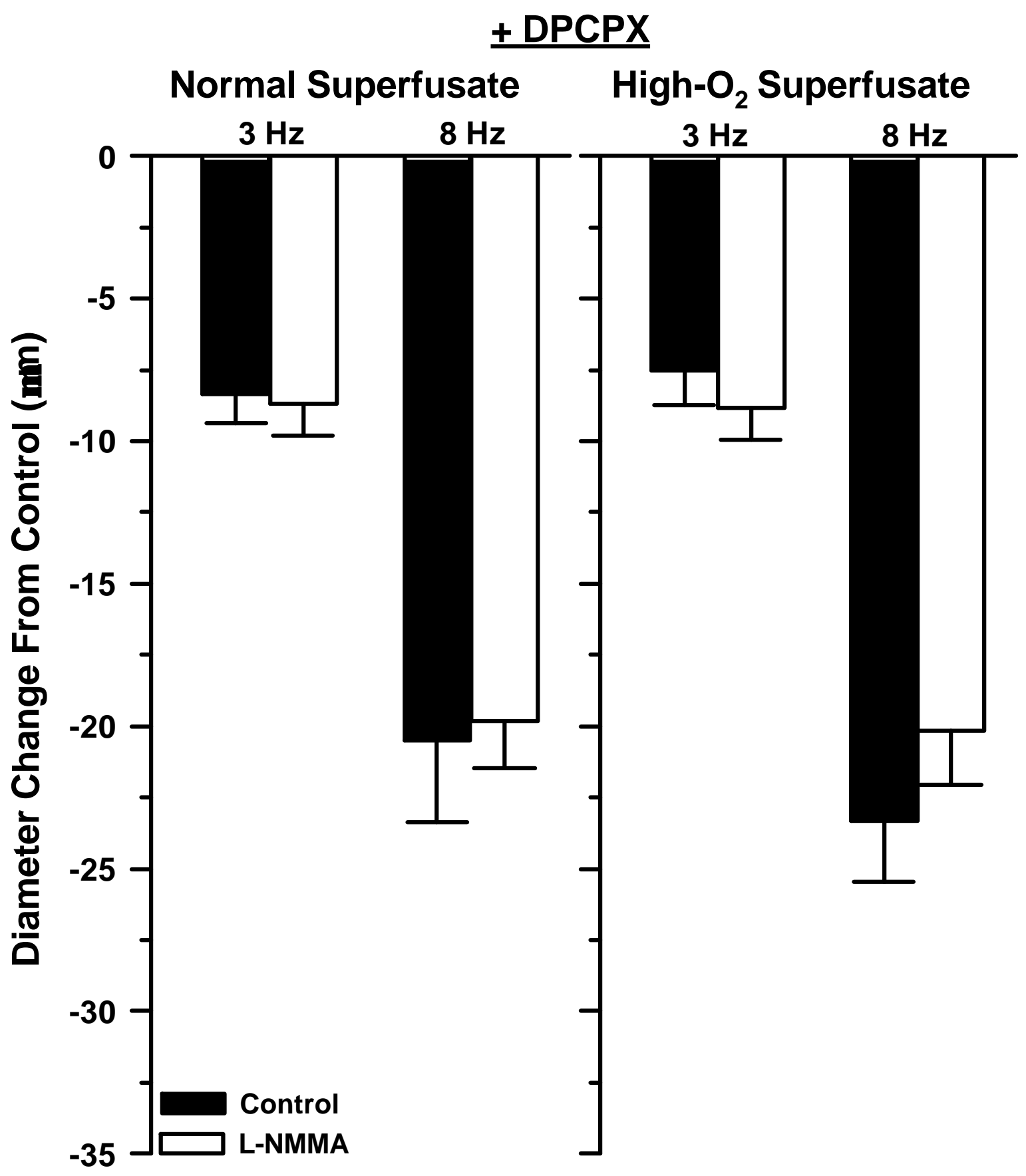

Figure 6. Effect of L-NMMA on arteriolar diameter responses to 3- and 8- $\mathrm{Hz}$ sympathetic nerve stimulation during continuous exposure to $4 \times 10^{-4} \mathrm{M}$ DPCPX under normal superfusate (left panel) and high- $\mathrm{O}_{2}$ superfusate (right panel). All data are paired. $\mathrm{n}=6$ vessels. 


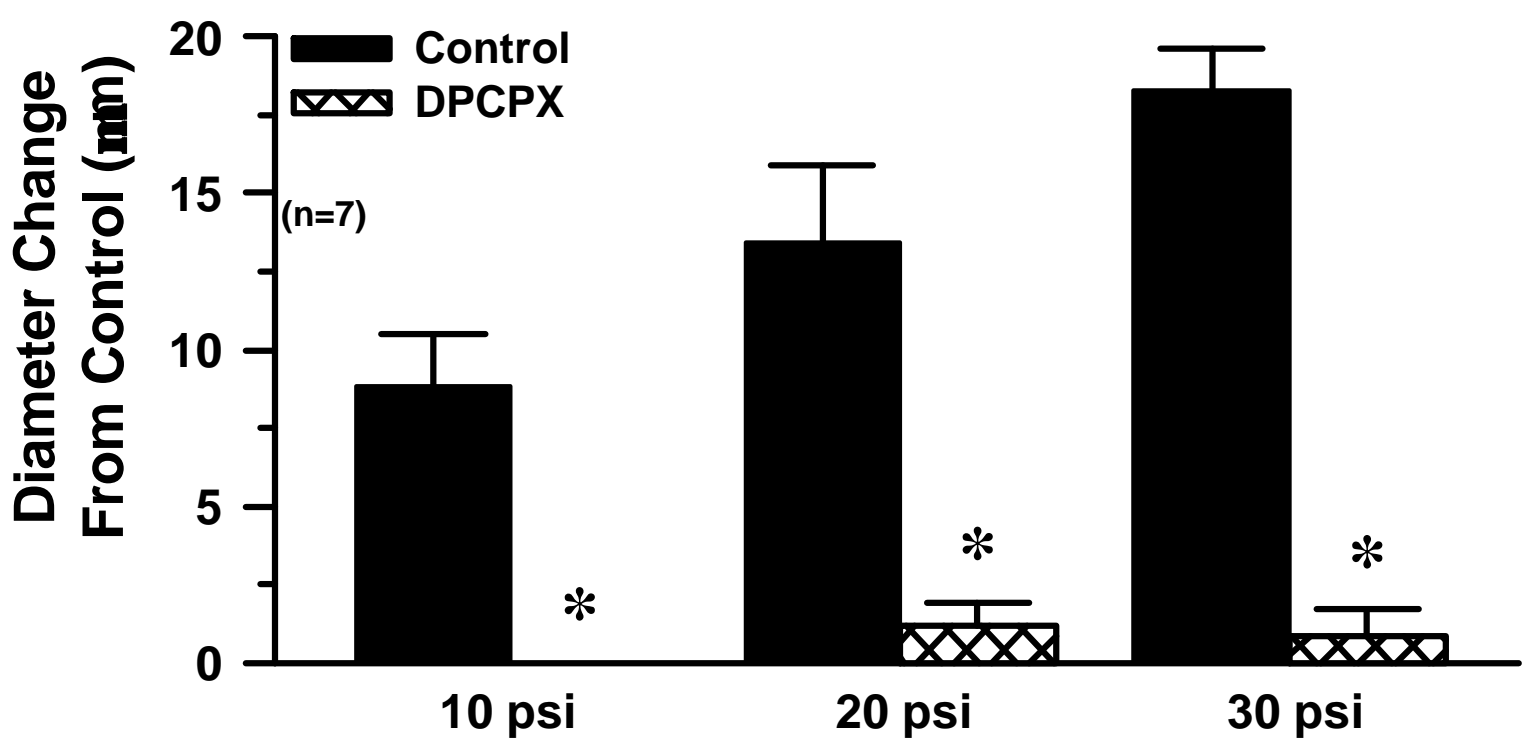

Adenosine Ejection Pressure

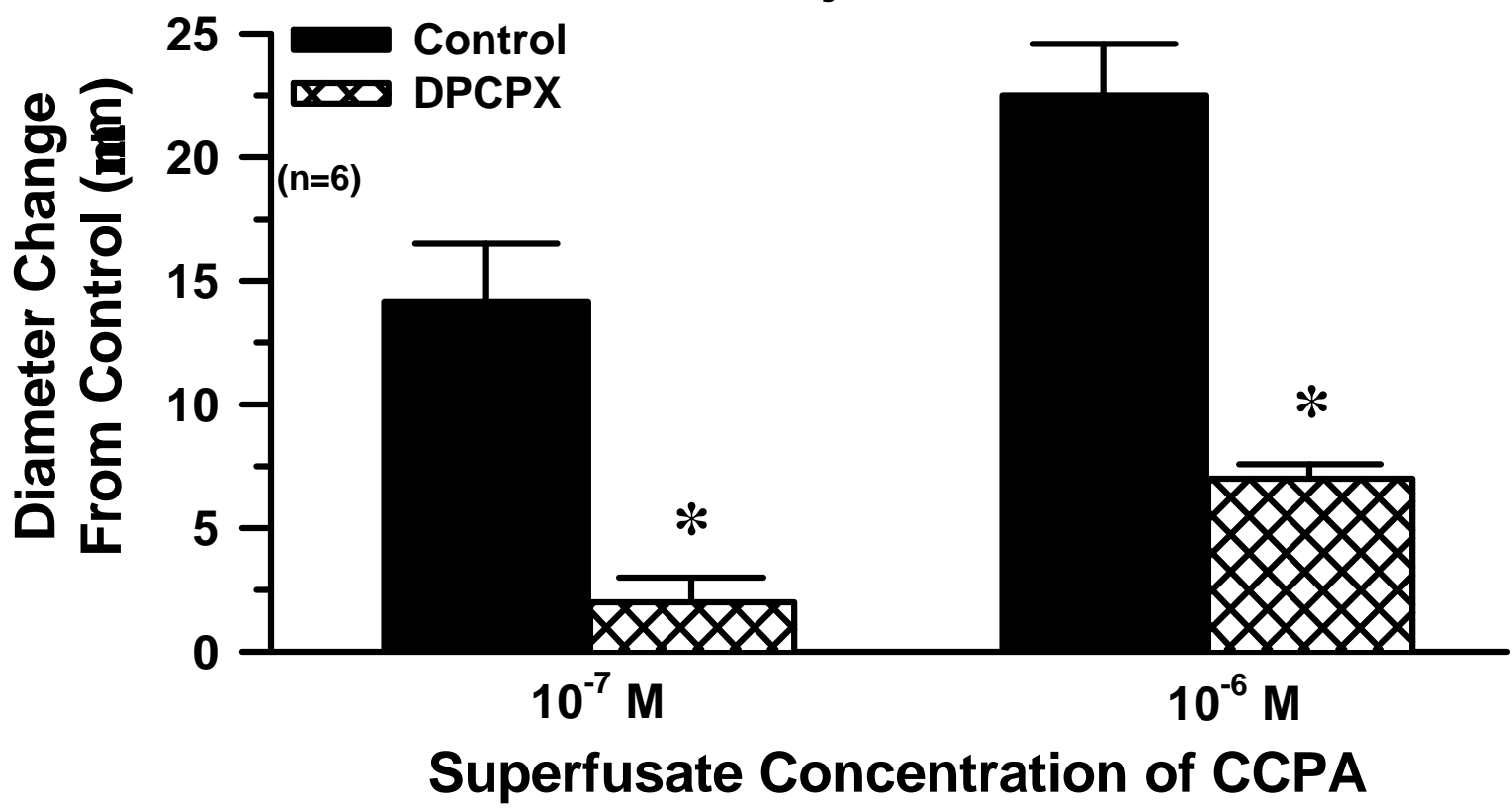

Figure 7. Arteriolar diameter responses to adenosine applied directly to the arteriolar wall via pressurized micropipette (top panel; closed bars) and to topically applied CCPA (bottom panel; closed bars) before and during (both panels; crosshatched bars) exposure to $4 \times 10^{-4} \mathrm{M}$ DPCPX. $\mathrm{n}=$ number of vessels. ${ }^{*} \mathrm{P}<0.05$ vs. control. 

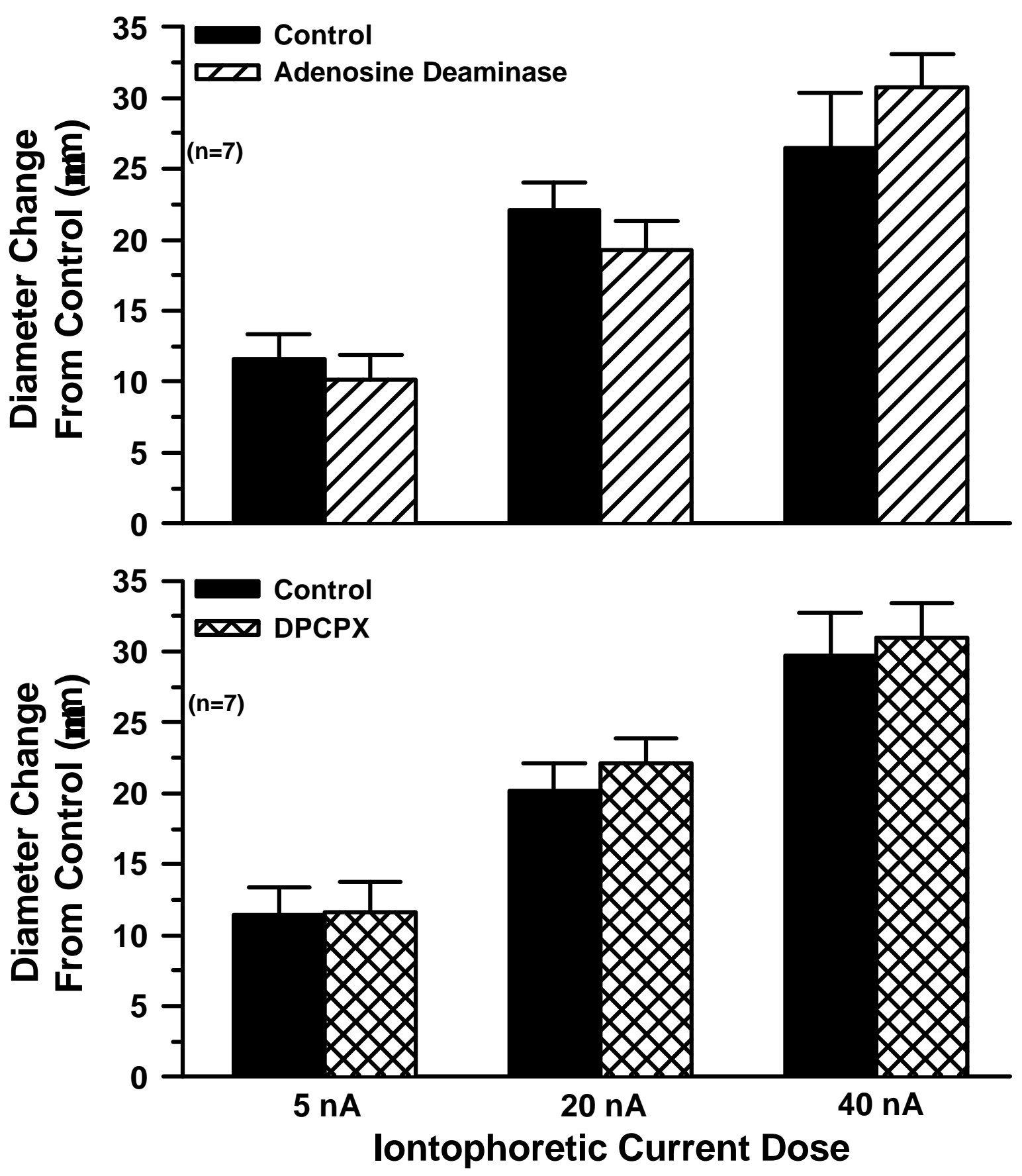

Figure 8. Arteriolar diameter responses to iontophoretically applied SNP under normal superfusate before (closed bars) and during exposure to adenosine deaminase (hatched bars) or DPCPX (crosshatched bars). $\mathrm{n}=$ number of vessels. 


\section{DISCUSSION}

Our finding that NOS inhibition greatly enhanced arteriolar responses to sympathetic nerve stimulation (Fig. 2) is consistent with our earlier reports that endothelium-derived NO normally limits arteriolar responses to increased sympathetic nerve activity in the rat intestine $[1,2,4]$. We have recently reported that a flow-dependent fall in arteriolar wall $\mathrm{PO}_{2}$ may be an important stimulus for sustained endothelial NO synthesis under these conditions [4], but that study did not allow us to determine if a reduction in local tissue $\mathrm{PO}_{2}$ could also contribute to this process. In the current study, sympathetic constriction caused a fall in tissue $\mathrm{PO}_{2}$ that was greater than the recently reported fall in arteriolar wall $\mathrm{PO}_{2}[4]$. Furthermore, the limiting influence of NO on sympathetic constriction was lost when tissue $\mathrm{PO}_{2}$ was prevented from falling during sympathetic nerve stimulation (Figs. 3 and 4), or when local adenosine activity was abolished via accelerated adenosine metabolism (Fig. 5) or blockade of microvascular $A_{1}$ receptors (Fig. 6). Furthermore, abolition of adenosine activity had no effect on sympathetic constriction when tissue $\mathrm{PO}_{2}$ did not fall during sympathetic constriction. It is unlikely that any of our experimental manipulations simply changed vascular smooth muscle responsiveness to NO because arteriolar responses to the NO donor SNP were unaltered by either adenosine deaminase or DPCPX (Fig. 8), and we have previously shown that exposure to the hyperoxic superfusate also does not alter arteriolar responsiveness to SNP [4]. Based on our direct assessments of arteriolar wall oxidant activity [4] it is also unlikely that the 
absence of arteriolar NO activity under the hyperoxic superfusate is due to accelerated NO breakdown by locally-generated reactive oxygen species. The current results, in combination with these previous findings, suggest that locallyformed adenosine serves as the link between reduced local oxygen tension and NO synthesis during neurogenic constriction in the rat intestine.

Our results also suggest that endothelial $A_{1}$ receptors mediate adenosineinduced NO synthesis in rat intestinal arterioles (Fig. 7). Similarly, Danialou et al. [17] reported that whereas activation of both $A_{1}$ and $A_{2}$ adenosine receptors can stimulate arteriolar NO synthesis in the rat diaphragm, $\mathrm{A}_{1}$-mediated responses are predominant. More recently, Bryan and Marshall [5] reported that activation of both $A_{1}$ and $A_{2}$ receptors by systemically-administered adenosine increases rat femoral vascular conductance through a NO-dependent mechanism, but only the $A_{1}$ receptor subtype mediates increased vascular NO synthesis during systemic hypoxia. However, there appears to be some heterogeneity among vascular beds in the adenosine receptor subtype that mediates this effect. For example, adenosine induces NO synthesis through the activation of endothelial $A_{2}$ receptors in the rat liver [12] and porcine coronary microvessels [11].

In addition to stimulating NO synthesis, adenosine could theoretically limit sympathetic constriction by presynaptic inhibition of norepinephrine (NE) release, as has been demonstrated in some canine vascular beds [18, 19]. However, endogenous adenosine does not decrease NE release in the rat mesentery [20], and although we did not directly evaluate this possibility in the current study, our 
results suggest that local adenosine also does not limit NE release in the rat intestine either. If adenosine were inhibiting NE release in addition to stimulating NO synthesis, then the magnitude of sympathetic constriction during exposure to adenosine deaminase (Fig. 5) should have been greater than that during exposure to L-NMMA (Fig. 2). Instead, arteriolar constriction in the presence of adenosine deaminase (15 \pm 1 and $31 \pm 2 \mu \mathrm{m}$ at 3 and $8 \mathrm{~Hz}$, respectively) was not significantly greater than that in the presence of L-NMMA $(22 \pm 1$ and $31 \pm 2 \mu \mathrm{m}$ at 3 and $8 \mathrm{~Hz}$, respectively). Although these data were obtained in different groups of rats, resting arteriolar tone and diameter were similar in these groups.

This study did not permit us to determine the exact origin of the adenosine that links the fall in local $\mathrm{PO}_{2}$ to endothelial $\mathrm{NO}$ release. However, based on $\mathrm{L}$ NMMA's effect on arteriolar responses to exogenous adenosine (Fig. 1), we conclude that the adenosine involved in stimulating NO release must come from sites less than $50 \mu \mathrm{m}$ from the vessel wall. Although arteriolar responses to adenosine applied $50 \mu \mathrm{m}$ from the wall were not dependent on NO synthesis, an interpolation of our findings suggests that $\mathrm{NO}$ becomes increasingly more important in this response as adenosine is released from closer sites, until it mediates nearly all of the response to adenosine released within $25 \mu \mathrm{m}$ of the wall. This "gradient" in the involvement of NO may reflect the existence of 2 different receptor subtypes in the arteriolar wall with different affinities for adenosine. Bryan and Marshall [5] have recently reported that in rat hindlimb resistance vessels, high-affinity $A_{1}$ receptors are primarily located on the 
endothelium whereas low-affinity $A_{2}$ receptors predominate on the vascular smooth muscle. In this case, if adenosine is applied at relatively low doses in close proximity to the arteriolar wall (e.g., within $25 \mu \mathrm{m}$ ), the action of $A_{1}$ receptors would be expected to prevail and a largely NO-dependent response should occur. Responses to adenosine released $50 \mu \mathrm{m}$ from the wall may induce a NO-independent dilation (i.e., a direct effect on smooth muscle) simply because adenosine is not reaching the endothelium in sufficient quantities to stimulate NO synthesis.

We have recently reported that arteriolar wall $\mathrm{PO}_{2}$ declines by $14-28 \%$ during 3-8 $\mathrm{Hz}$ sympathetic nerve stimulation in this vascular bed [4]. As in the current study, arteriolar responses to nerve stimulation were enhanced and no longer sensitive to L-NMMA when we used a high-oxygen superfusate to limit this fall in $\mathrm{PO}_{2}$ [4], suggesting that the arteriolar wall could also be a source of adenosine under these conditions. Closely-paired venules represent another potential source of adenosine during sympathetic nerve stimulation. Because first-order venular $\mathrm{PO}_{2}$ is typically $20-30 \%$ less than first-order arteriolar $\mathrm{PO}_{2}$ under normal flow conditions [21], minimum venular $\mathrm{PO}_{2}$ should be lower than minimum arteriolar $\mathrm{PO}_{2}$ during sympathetic nerve stimulation. Furthermore, adenosine can freely diffuse from the venular lumen to nearby arterioles in vasoactive amounts [22]. In addition to these possibilities, erythrocytes within the vessel lumen may also indirectly serve as a source of adenosine. Erythrocytes 
can release ATP in response to decreased oxygen tension [23-25], and this ATP can be degraded by membrane-bound nucleotidases to adenosine [26].

Another issue germane to this study is that of "critical $\mathrm{PO}_{2}$ ". During sympathetic nerve stimulation, tissue $\mathrm{PO}_{2}$ did not typically fall to the level where one might expect a large increase in adenosine formation (Fig. 4). A study in rat skeletal muscle provides compelling evidence that the critical extracellular $\mathrm{PO}_{2}$ at which there is a large-scale shift from aerobic to anaerobic metabolism is less than $3 \mathrm{~mm} \mathrm{Hg}$ [27]. However, because cellular concentrations of adenosine and AMP are in dynamic equilibrium, one would expect the more moderate reduction in $\mathrm{PO}_{2}$ that we observed to shift this balance toward adenosine formation. Furthermore, a recent report by Decking et al. [28] suggests that even a modest reduction in oxygen tension suppresses cellular adenosine kinase activity, thereby reducing the re-phosphorylation of adenosine to AMP. As a result, a modest increase in adenosine formation can be amplified into a relatively large increase (up to 17-fold) in local adenosine concentration [28]. This effect of reduced oxygen on adenosine kinase may be an important mechanism for the close matching of blood flow to oxygen consumption over a wide range of metabolic activities $[28,29]$. Most relevant to this study, previous studies in the rat intestine have implicated adenosine as a mediator of reactive and absorptive hyperemia under conditions where tissue $\mathrm{PO}_{2}$ may not ever fall to "critical" levels $[30,31]$. 
The lack of an effect of L-NMMA on resting arteriolar tone in the intestine (e.g., Fig. 2) is consistent with our previous findings in this preparation [2, 4]. In light of recent direct measurements verifying that $\mathrm{NO}$ is continuously released from these vessels in the resting state [32], local NOS inhibition would be expected to reduce arteriolar diameter. However, resting arteriolar tone is the result of vascular smooth muscle's integration of numerous simultaneous vasoactive signals, and the activity of local metabolic and myogenic control mechanisms may set vascular tone at some constant and optimal level for the tissue. These local regulatory mechanisms may be so highly developed in the intestine that the withdrawal of any single influence (such as NO in the presence of L-NMMA) is accompanied by a compensatory change in the activity of one or both of these systems, thereby preserving the level of tone.

In summary, our results suggest that as arterioles constrict in response to sympathetic nerve stimulation, a flow-dependent fall in local $\mathrm{PO}_{2}$ leads to an increase in extracellular adenosine, which, through its interaction with endothelial $A_{1}$ receptors, stimulates $N O$ synthesis that in turn limits the arteriolar constriction. 


\section{REFERENCES}

1. Nase GP, Boegehold MA: Nitric oxide modulates arteriolar responses to increased sympathetic nerve activity. Am J Physiol 1996; 271: H860-H869.

2. Nase GP, Boegehold MA: Endothelium-derived nitric oxide limits sympathetic neurogenic constriction in intestinal microcirculation. Am J Physiol 1997; 273: $\mathrm{H} 426-\mathrm{H} 433$.

3. Nase GP, Boegehold MA: Postjunctional $\alpha_{2}$-adrenoceptors are not present in proximal arterioles of rat intestine. Am J Physiol 1998; 274: H202-H208.

4. Sauls BA, Boegehold MA: Arteriolar wall $\mathrm{PO}_{2}$ and nitric oxide release during sympathetic vasoconstriction in the rat intestine. Am. J Physiol 2000; 279:H484-H491.

5. Bryan PT, Marshall JM: Adenosine receptor subtypes and vasodilatation in rat skeletal muscle during systemic hypoxia: a role for $A_{1}$ receptors. J Physiol 1999; 514.1: 151-162.

6. Park KH, Rubin LE, Gross SS, Levi R: Nitric oxide is a mediator of hypoxic coronary vasodilatation. Circ Res 1992; 71: 992-1001. 
7. Xu X, Pollock JS, Tanner MA, Myers PR: Hypoxia activates nitric oxide synthase and stimulates nitric oxide production in porcine coronary resistance arteriolar endothelial cells. Cardiovasc Res 1995; 30: 841-847.

8. Cohen MV, Walsh RS, Goto M, Downey JM: Hypoxia preconditions rabbit myocardium via adenosine and catecholamine release. J Mol Cell Cardiol $1995 ; 27: 1527-1534$.

9. Decking UKM, Schlieper G, Kroll K, Schrader J: Hypoxia-induced inhibition of adenosine kinase potentiates cardiac adenosine release. Circ Res 1997; $81: 154-164$.

10. Raatikainen MJP, Peuhkurinen KJ, Hassinen IE: Contribution of endothelium and cardiomyocytes to hypoxia-induced adenosine release. J Mol Cell Cardiol 1994; 26:1069-1080.

11. Hein TW, Belardinelli L, Kuo L: Adenosine $A_{2 A}$ receptors mediate coronary microvascular dilation to adenosine: role of nitric oxide and ATP-sensitive potassium channels. JPET 1999; 291:655-664. 
12. Peralta C, Hotter G, Closa D, Prats N, Xaus C, Gelpi E, Roselló-Catafau J: The protective role of adenosine in inducing nitric oxide synthesis in rat liver ischemia preconditioning is mediated by activation of adenosine $A_{2}$ receptors. Hepatology 1999; 29:126-132.

13. Bohlen HG: Intestinal tissue $\mathrm{PO}_{2}$ and microvascular responses during glucose exposure. Am J Physiol 1980; 238: H164-H171.

14. Bohlen HG, Henrich H, Gore RW, Johnson PC: Intestinal muscle and mucosal blood flow during direct sympathetic stimulation. Am J Physiol 1978; 235 (1): H40-H45.

15. Bohlen HG: Determinants of resting and passive intestinal vascular pressures in rat and rabbit. Am J Physiol 1987; 253: G587-G595.

16. Whalen WJ, Riley J, Nair P: A microelectrode for measuring intracellular $\mathrm{PO}_{2}$. J Appl Physiol 1967; 23(5): 798-801.

17. Danialou G, Vicaut E, Sambe A, Aubier M, Boczkowski J: Predominant role of $A_{1}$ receptors in mediating adenosine induced vasodilatation of rat diaphragmatic arterioles: involvement of nitric oxide and the ATP-dependent $\mathrm{K}^{+}$channels. Br. J. Pharmacol. 1997; 121(7):1355-1363. 
18. Abe T, Morgan DA, Gutterman DD: Role of adenosine receptor subtypes in neural stunning of sympathetic coronary innervation. Am. J Physiol 1997; 272:H25-H34.

19. Tamaoki J, Tagaya E, Chiyotani A, Takemura H, Nagai A, Konno K, Onuki T, Nitta S: Effect of adenosine on adrenergic neurotransmission and modulation by endothelium in canine pulmonary artery. Am. J Physiol 1997; 272:H1100H1105.

20. Kuan C, Jackson EK: Role of adenosine in noradrenergic neurotransmission. Am. J Physiol 1988; 255:H386-H393.

21. Sinaasappel M, Donkersloot C, Van Bommel J, Ince C: $\mathrm{PO}_{2}$ measurements in the rat intestinal microcirculation. Am. J Physiol 1999; 276:G1515-G1520.

22. Hester RL: Venular-arteriolar diffusion of adenosine in hamster cremaster microcirculation. AM J Physiol 1990; 258:H1918-H1924.

23. Bergfeld GR, Forrester T: Release of ATP from human erythrocytes in response to a brief period of hypoxia and hypercapnia. Cardiovasc Res 1992; 26:40-47. 
24. Dietrich HH, Ellsworth ML, Sprague RS, Dacey RG: Red blood cell regulation of microvascular tone through adenosine triphosphate. Am J Physiol 2000; I278:H1294-H1298.

25. Ellsworth ML, Forrester T, Ellis CG, Dietrich $\mathrm{HH}$ : The erythrocyte as a regulator of vascular tone. Am J Physiol 1995; 269:H2155-H2161.

26. Shryock JC, Belardinelli L: Adenosine and adenosine receptors in the cardiovascular system: biochemistry, physiology, and pharmacology. Am J Cardiol 1997; 79(12A):2-10.

27. Richmond KN, Shonal RD, Lynch RM, Johnson PC: Critical $\mathrm{PO}_{2}$ of skeletal muscle in vivo. Am J Physiol 1999; 277:H1831-H1840.

28. Decking KM, Schlieper G, Kroll K, Schrader J: Hypoxia-induced inhibition of adenosine kinase potentiates cardiac adenosine release. Circ Res 1997; 81; 154-164.

29. Arch JRS, Newsholme EA: Activities and some properties of 5'-nucleotidase, adenosine kinase and adenosine deaminase in tissues from vertebrates and invertebrates in relation to the control of the concentration and the physiological role of adenosine. Biochem J 1978; 965-977. 
30. Pawlik WW, Hottenstein OD, Palen TE, Pawlik T, Jacobson ED: Adenosine modulates reactive hyperemia in rat gut. J Physiol Pharm 1993; 44,2:119137.

31. Proctor KG: Possible role for adenosine in local regulation of absorptive hyperemia in rat intestine. Circ Res 1986; 59:474-481.

32. Bohlen HG, Nase GP: Dependence of intestinal arteriolar regulation on flowdependent nitric oxide formation. Am J Physiol 2000; 279:H2249-H2258. 
Study III: Adenosine Linking Reduced Oxygen to Arteriolar Nitric Oxide Release in the Intestine Is Not Formed From Extracellular ATP 


\section{SUMMARY}

We have previously reported that adenosine formed in response to reduced arteriolar and/or tissue $\mathrm{PO}_{2}$ preserves endothelial nitric oxide (NO) synthesis during sympathetic vasoconstriction in the rat intestine. To more precisely identify the site and mechanism of adenosine formation under these conditions, we tested the hypothesis that ATP released in response to reduced $\mathrm{O}_{2}$ levels serves as a source of adenosine. Direct application of ATP to the wall of firstorder arterioles elicited dose-dependent dilations of $15-33 \%$ above resting diameter that were reduced by $71-80 \%$ by the 5 '-ectonucleotidase inhibitor $\alpha, \beta$ methyleneadenosine 5 -diphosphate (AOPCP, $4.5 \times 10^{-5} \mathrm{M}$ ) or by $\mathrm{A} 1$ adenosine receptor antagonism via 8-cyclopentyl-1,3-dipropylxanthine (DPCPX $4 \times 10^{-4} \mathrm{M}$ in superfusate) and completely abolished by $\mathrm{N}^{\mathrm{a}}$-monomethyl-L-arginine (L-NMMA, $\left.10^{-4} \mathrm{M}\right)$. Under control conditions, sympathetic nerve stimulation at 3 and $8 \mathrm{~Hz}$ induced arteriolar constrictions of $11 \pm 1$ and $19 \pm 1 \mu \mathrm{m}$, respectively. These responses were enhanced by $58-69 \%$ in the presence of L-NMMA or when local $\mathrm{PO}_{2}$ was maintained at resting levels. However, in the presence of AOPCP, the enhancing effects of L-NMMA and the high- $\mathrm{O}_{2}$ superfusate on sympathetic constriction were preserved. These results suggest that although exogenouslyapplied ATP can stimulate arteriolar NO release in the intestine largely through its sequential extracellular hydrolysis to adenosine, this process does not contribute to adenosine formation and sustained NO release during sympathetic constriction in this vascular bed. 


\section{INTRODUCTION}

Nitric oxide (NO) contributes importantly to the regulation of arteriolar tone and blood flow in the intestine $(8,9,24)$. Under normal resting conditions, there is continuous NO release from the arteriolar endothelium that is due in large part to the shear stress associated with blood flow (9). However, we have obtained considerable evidence that during periods of increased sympathetic nerve activity, the constriction of intestinal arterioles is limited by sustained endothelial NO release despite a precipitous fall in shear stress $(25,26,33,34)$. Moreover, this modulating influence of NO on sympathetic constriction can be prevented by minimizing the fall in microvascular and/or tissue $\mathrm{PO}_{2}$ that normally accompanies the decrease in network blood flow $(33,34)$, suggesting that a reduction in local $\mathrm{O}_{2}$ levels becomes the main stimulus for endothelial NO release under these lowshear conditions. Direct measurement with NO-sensitive microelectrodes have verified that a reduction in blood $\mathrm{O}_{2}$ delivery is a potent stimulus for arterial NO release in the intestine (9), and reduced $\mathrm{O}_{2}$ levels lead to increased endothelial NO production in other vascular beds as well $(1,11,28,29)$.

We have recently determined that during sympathetic constriction in the intestine, the fall in microvascular and/or tissue $\mathrm{PO}_{2}$ is linked to endothelial $\mathrm{NO}$ release through the local formation of adenosine, which then binds to endothelial $A_{1}$ receptors that are coupled to the NO synthesis pathway. Our findings also suggest that this adenosine is most likely formed within $50 \mu \mathrm{m}$ of the arteriolar wall (34). In addition to the possible release of adenosine from periarteriolar 
parenchymal cells or from cells within the arteriolar wall itself, recent studies raise the possibility that adenosine could also be formed extracellularly via the breakdown of ATP that is released from circulating erythrocytes when luminal $\mathrm{O}_{2}$ levels fall in either the arterioles or nearby venules $(13,15,16)$. Consistent with this possibility, microvascular endothelial cells have a high activity of extracellular membrane ectonucleotidase, which readily degrade adenine nucleotides to adenosine (35). The purpose of the current study was to determine if this latter mechanism contributes to local adenosine formation, and therefore sustained endothelial NO release, during sympathetic vasoconstriction in the intestine.

\section{METHODS}

All surgical and experimental procedures were approved by the West Virginia University Animal Care and Use Committee. Male Sprague-Dawley rats aged 8-9 wk (Harlan Sprague Dawley, Indianapolis, IN) were anesthetized with sodium thiopental (100 mg/kg ip) and placed on a heating mat to maintain a $37^{\circ} \mathrm{C}$ rectal temperature. To ensure adequate gas exchange, rats were intubated and ventilated with a rodent ventilator (Harvard Apparatus, South Natick, MA). Arterial pressure was measured from the cannulated right carotid artery with a Gould P23 ID pressure transducer (Cleveland, $\mathrm{OH}$ ). The small intestine was prepared for microscopic observation as previously described (25), and continuously superfused with a physiological electrolyte solution (in mM: $119 \mathrm{NaCl}, 25$ $\mathrm{NaHCO}_{3}, 6 \mathrm{KCl}$, and $3.6 \mathrm{CaCl}_{2}$ ) that was warmed to $37^{\circ} \mathrm{C}$ and equilibrated with 
either $5 \% \mathrm{O}_{2}-5 \% \mathrm{CO}_{2}-90 \% \mathrm{~N}_{2}$ to mimic normal in-vivo conditions (3) or $20 \% \mathrm{O}_{2^{-}}$ $5 \% \mathrm{CO}_{2}-75 \% \mathrm{~N}_{2}$ to create an $\mathrm{O}_{2}$-enriched environment. Isoproterenol $(10 \mathrm{mg} / \mathrm{l}$; Sigma, St. Louis, MO) and phenytoin (20 mg/l; Parke-Davis, Morris Plains, NJ) were added to the superfusate to suppress intestinal motility. At these concentrations, neither agent alters resting arteriolar tone in this vascular bed (10). With most of the preparation covered by polyvinyl film, and superfusate flow directed beneath the film, solution $\mathrm{PO}_{2}$ immediately above the tissue is maintained at $40-50 \mathrm{mmHg}$ under normal conditions (6).

After surgery, the rat was transferred to the stage of an Olympus BHTU intravital microscope (Hyde Park, NY) fitted with a CCD video camera (Dage MTI, Michigan City, IN). Video images were displayed on a Panasonic highresolution video monitor and stored on videotape for off-line analysis. Arteriolar inner diameters were measured with a video caliper (Microcirculation Research Institute, Texas A \& M University) during videotape replay.

A bipolar platinum electrode was used to stimulate the sympathetic postganglionic efferents running along a mesenteric artery-vein pair upstream from the arteriole under study. The electrode and artery-vein pair were briefly raised above the superfusate, and the nerves were stimulated with square-wave pulses at supramaximal voltage $(5-6 \mathrm{~V})$ and a pulse duration of $10 \mathrm{~ms}$. These stimulation parameters elicit frequency-dependent arteriolar constrictions that are abolished by the selective $\alpha_{1}$-receptor antagonist prazosin (27), verifying that these responses are due to sympathetic nerve activation. 
Experimental Protocols. The overall aim of this study was to evaluate the hypothesis that during sympathetic arteriolar constriction in the intestine, the adenosine that links reduced local $\mathrm{O}_{2}$ levels to endothelial $\mathrm{NO}$ release is formed by the sequential hydrolysis of extracellular ATP that has been released from erythrocytes. The framing of this hypothesis gives rise to a number of testable predictions. First, increased extracellular ATP levels in the immediate vicinity of the arteriolar wall must reduce arteriolar tone by the same mechanism through which endogenous adenosine acts during sympathetic constriction, i.e., the activation of $A_{1}$ adenosine receptors and stimulation of arteriolar NO release (34). Second, this vasoactive effect of ATP must depend on the activity of 5ectonucleotidase, the extracellular membrane-bound enzyme that converts AMP to adenosine (the final step of the postulated adenosine formation pathway). Third, inhibition of 5 -ectonucleotidase activity should abolish the NO-mediated modulation of arteriolar constriction during sympathetic nerve stimulation. Fourth, inhibition of $5^{\prime}$-ectonucleotidase activity should disrupt the relationship between reduced luminal $\mathrm{O}_{2}$ levels and $\mathrm{NO}$ activity that we have previously documented during sympathetic nerve stimulation (33). These predictions were tested in the experiments described below.

The $5^{\prime}$-ectonucleotidase inhibitor $\alpha, \beta$-methyleneadenosine 5 -diphosphate (AOPCP) was used in this study. For continuous localized delivery of AOPCP to the intestinal vasculature, the inhibitor was added to the superfusate at a concentration of $4.5 \times 10^{-5} \mathrm{M}$, which maximally inhibits $5^{\prime}$-ectonucleotidase in 
other systems $(22,23)$. The first series of experiments was designed to verify that this superfusate concentration of AOPCP was sufficient to maximally inhibit 5 '-ectonucleotidase in our intestinal preparation. This was accomplished by evaluating the effect of AOPCP on arteriolar responses to exogenous AMP, which exerts most of its vasodilator influence only after its extracellular conversion to adenosine via $5^{\prime}$-ectonucleotidase (20). A Picospritzer II ejection system (General Valve, Fairfield, NJ) was used to apply AMP to individual firstorder arterioles. Glass micropipettes (2-3 $\mu \mathrm{m}$ inner tip diameter) were filled with superfusate containing $10^{-3} \mathrm{M} \mathrm{AMP}$ and positioned with the tip lightly touching the arteriolar wall. After a 1-min control period, AMP was applied for 1 min using an ejection pressure of 10,20 , or 30 psi. After a 3-min recovery, this sequence was repeated two more times so that the arteriole was challenged with all three quantities of AMP, delivered in random order. These applications were then repeated 10 min after addition of AOPCP to the superfusate.

The second series of experiments was designed to assess ATP's ability to elicit a NO-dependent reduction in arteriolar tone, and the importance of adenosine $A_{1}$ receptors in this effect. Micropipettes filled with $10^{-3} \mathrm{M}$ ATP in superfusate were positioned in contact with the arteriolar wall, and after a 1-min control period, ATP was applied using ejection pressures of 10,20 , or 30 psi for $1 \mathrm{~min}$. After a 3-min recovery, this sequence was repeated two more times so that the arteriole was challenged with all three quantities of ATP, delivered in random order. These applications were then repeated during continuous 
exposure of the vasculature to either the NO synthase inhibitor $N^{G}$-monomethylL-arginine (L-NMMA, $1 \times 10^{-4} \mathrm{M}$ in superfusate), or the selective adenosine $A_{1}$ receptor antagonist 8-cyclopentyl-1,3-dipropylxanthine (DPCPX, $4 \times 10^{-4} \mathrm{M}$ in superfusate). We have recently reported that DPCPX at this concentration virtually abolishes the responses of intestinal arterioles to directly applied adenosine (34), verifying its effectiveness as an $A_{1}$ receptor antagonist in this preparation.

A third series of experiments was designed to determine if the vasoactive effect of ATP can be blocked by inhibition of 5 -ectonucleotidase. As described above, ATP was applied to the arteriolar wall by pressurized micropipette. The arteriole was first subjected to all three quantities of ATP delivered in random order under the normal superfusate, and then the sequence of ATP applications was repeated in presence of $4.5 \times 10^{-5} \mathrm{M}$ AOPCP. Finally, a third series of applications was performed during continuous exposure to both AOPCP and $10^{-4}$ M L-NMMA.

A fourth series of experiments was designed to determine (1) the relationship between $5^{\prime}$-ectonucleotidase activity and arteriolar NO during periods of increased sympathetic nerve activity, and (2) the importance of $5^{\prime}$ ectonucleotidase in the relationship between arteriolar $\mathrm{O}_{2}$ levels and NO availability under these conditions. Experiments were performed on two groups of rats. In the first group, during superfusion with either the normal $\left(5 \% \mathrm{O}_{2}\right)$ or high- $\mathrm{O}_{2}\left(20 \% \mathrm{O}_{2}\right)$ solution, a single first-order arteriole was selected for study. 
We have previously demonstrated that increased $\mathrm{O}_{2}$ delivery to these arterioles from the high $-\mathrm{O}_{2}$ superfusate either completely prevents or greatly reduces the fall in arteriolar $\mathrm{O}_{2}$ levels that normally accompanies sympathetic constriction (33). After a 1-min control period, the sympathetic nerves innervating the vessel were stimulated for $1 \mathrm{~min}$ at either 3 or $8 \mathrm{~Hz}$. After a 3-min recovery period and a second control period, the nerves were stimulated at the remaining frequency. The superfusate was then changed (from normal to high- $\mathrm{O}_{2}$ or from high- $\mathrm{O}_{2}$ to normal), and the sympathetic nerves were again stimulated at 3 and $8 \mathrm{~Hz}$. Finally, the nerve stimulations under the normal and high- $\mathrm{O}_{2}$ superfusates were repeated in the presence of $10^{-4} \mathrm{M} \mathrm{L-NMMA.} \mathrm{For} \mathrm{the} \mathrm{second} \mathrm{group} \mathrm{of} \mathrm{rats,} \mathrm{the}$ same protocol was followed except that all of the nerve stimulations were performed in the additional presence of $4.5 \times 10^{-5} \mathrm{M}$ AOPCP.

A fifth series of experiments was designed to determine if AOPCP alters the inherent responsiveness of arteriolar smooth muscle to NO. Arteriolar responses to the NO-donor sodium nitroprusside (SNP, Sigma) were assessed before and then during exposure to AOPCP. Glass micropipettes were filled with $0.5 \mathrm{M} \mathrm{SNP}$ in distilled water and connected to an iontophoresis current programmer (model 260, World Precision Instruments, Sarasota, FL). A retaining current of $40 \mathrm{nA}$ was used to prevent diffusion of SNP from the pipette tip, and net ejection currents of 5,20 , and $40 \mathrm{nA}$ (in random order) were used to deliver SNP to the vessel wall. Each vessel was observed during a 2-min control period, a 2-min application period, and a 2-min recovery period. To avoid potential complications 
related to acute changes in endogenous NO production, these experiments were conducted in the presence of $10^{-4} \mathrm{M} \mathrm{L-NMMA}$.

At the end of all experiments, adenosine was added to the superfusate $\left(10^{-3}\right.$ M final concentration), and passive arteriolar diameter was measured.

Data and Statistical Analysis. For each arteriole, the level of resting tone (T) was calculated as follows: $T=\left[\left(D_{\max }-D_{c} / D_{\max }\right] \times 100\right.$ where $D_{\max }$ is passive diameter under adenosine, and $D_{c}$ is the diameter measured during the control period.

All data are expressed as means \pm SE. Statistical analysis was carried out using commercially available software (Sigma Stat, Jandel Scientific, San Rafael, CA). ANOVA for repeated measures was used to compare arteriolar dilations to AMP, ATP, and SNP before and after AOPCP, L-NMMA, or DPCPX. ANOVA for repeated measures was also used to compare arteriolar constrictions to sympathetic nerve stimulation before and after L-NMMA under the low and high$\mathrm{O}_{2}$ superfusates in the presence and absence of AOPCP. For all ANOVA procedures, the Student Newman-Keuls multiple range procedure for post hoc analysis was used to identify differences among specific groups. Significance was assessed at $P<0.05$ for all statistical tests. 


\section{RESULTS}

In all protocols combined, a total of 58 first-order arterioles were observed in 36 rats. The rats averaged $264 \pm 4 \mathrm{~g}$ in body weight at $56 \pm 1$ days of age, with a mean arterial pressure under anesthesia of $100 \pm 1 \mathrm{~mm} \mathrm{Hg}$. Arteriolar resting and passive diameters averaged $54 \pm 1$ and $90 \pm 1 \mu \mathrm{m}$, respectively, with an average calculated arteriolar tone of $39 \pm 1 \%$.

Eight first-order arterioles were studied to evaluate AOPCP's effectiveness as a 5 -ectonucleotidase inhibitor in the rat intestine. AOPCP did not have a significant effect on resting arteriolar diameter $(55 \pm 2 \mu \mathrm{m}$ under control conditions vs. $57 \pm 2 \mu \mathrm{m}$ during AOPCP exposure), but it completely abolished arteriolar responses to directly applied AMP. AMP applied at ejection pressures of 10, 20 and 30 psi caused dilations of $6 \pm 1,13 \pm 1$, and $18 \pm 1 \mu \mathrm{m}$ under control conditions vs. $0 \pm 0,0 \pm 0$, and $1 \pm 1 \mu \mathrm{m}$ in the presence of AOPCP (Fig. 1).

To assess ATP's ability to stimulate arteriolar NO synthesis in this vascular bed, we evaluated the effect of L-NMMA on arteriolar responses to directly applied ATP ( $\mathrm{n}=8$ vessels). L-NMMA had no significant effect on resting arteriolar diameters $(47 \pm 3 \mu \mathrm{m}$ under control conditions vs. $48 \pm 2 \mu \mathrm{m}$ during LNMMA exposure), but it completely abolished arteriolar responses to ATP. ATP applied to the arteriolar wall at 10,20 , and 30 psi induced dilations of $7 \pm 1,12 \pm 1$, and $16 \pm 2 \mu \mathrm{m}$ under control conditions vs. $0 \pm 0,1 \pm 1$, and $1 \pm 1 \mu \mathrm{m}$ in the presence of L-NMMA (Fig. 2, top panel). Eight additional vessels were studied to determine the importance of adenosine $A_{1}$ receptors in ATP's effect on arteriolar 
tone. DPCPX had no significant effect on resting arteriolar diameter $(49 \pm 3 \mu \mathrm{m}$ under control conditions and during DPCPX exposure), but significantly reduced arteriolar responses to ATP. In these experiments, ATP application at 10, 20 and 30 psi induced dilations of $8 \pm 1,14 \pm 1$, and $16 \pm 2 \mu \mathrm{m}$ under control conditions, vs. $1 \pm 1,2 \pm 1$ and $4 \pm 1 \mu \mathrm{m}$ in the presence of DPCPX, a reduction of $75-88 \%$ (Fig. 2, bottom panel).

Eight arterioles were studied to determine if the activity of $5^{\prime}$ ectonucleotidase is necessary for arteriolar responsiveness to ATP (Fig. 3). In these experiments, neither AOPCP nor L-NMMA had an effect on resting arteriolar diameters $(50 \pm 2 \mu \mathrm{m}$ under control conditions vs. $51 \pm 2 \mu \mathrm{m}$ with AOPCP and $52 \pm 1$ with AOPCP + L-NMMA). ATP application at 10, 20 and 30 psi induced dilations of $10 \pm 1,14 \pm 1$, and $17 \pm 1 \mu \mathrm{m}$. In the presence of AOPCP, these responses were reduced to $2 \pm 1,3 \pm 1$ and $5 \pm 1 \mu \mathrm{m}$, respectively (reductions of 70 $80 \%$ ). With the subsequent addition of L-NMMA, these residual responses were virtually abolished (dilations of $0 \pm 0,0 \pm 1$, and $1 \pm 1 \mu \mathrm{m}$, respectively).

Seventeen arterioles were studied to explore the relationship between $5^{\prime}$ ectonucleotidase activity and NO activity during periods of increased sympathetic nerve activity. Under the normal superfusate, resting arteriolar diameter averaged $62 \pm 1 \mu \mathrm{m}$ and sympathetic nerve stimulation at 3 and $8 \mathrm{~Hz}$ induced frequency-dependent constrictions of $11 \pm 1$ and $19 \pm 1 \mu \mathrm{m}$, respectively (Fig. 4). With the addition of L-NMMA, resting arteriolar diameters were unchanged $(60 \pm 1$ $\mu \mathrm{m})$, but responses to each level of sympathetic nerve stimulation were 
significantly enhanced (constrictions of $19 \pm 1$ and $29 \pm 2 \mu \mathrm{m}$ at 3 and $8 \mathrm{~Hz}$, respectively). Under the high- $\mathrm{O}_{2}$ superfusate, resting arteriolar diameters were unchanged $(61 \pm 1 \mu \mathrm{m})$, but control responses to nerve stimulation were significantly greater than those under the normal superfusate (constrictions of $18 \pm 1 \mu \mathrm{m}$ at $3 \mathrm{~Hz}$ and $30 \pm 2 \mu \mathrm{m}$ at $8 \mathrm{~Hz}$ ). L-NMMA did not alter resting arteriolar diameters $(62 \pm 1 \mu \mathrm{m})$ under the high- $\mathrm{O}_{2}$ superfusate. However, in contrast to the normal superfusate, L-NMMA did not enhance arteriolar responses to sympathetic nerve stimulation under the high- $\mathrm{O}_{2}$ superfusate (constrictions of $20 \pm 1 \mu \mathrm{m}$ at $3 \mathrm{~Hz}$ and $30 \pm 2 \mu \mathrm{m}$ at $8 \mathrm{~Hz}$.

Figure 5 illustrates the effect of L-NMMA on arteriolar responses to sympathetic nerve stimulation under the normal and high- $\mathrm{O}_{2}$ superfusates in the presence of AOPCP. As in the other experiments, neither AOPCP nor L-NMMA altered resting arteriolar diameters in these experiments $(60 \pm 1 \mu \mathrm{m}$ under control conditions vs. $60 \pm 1 \mu \mathrm{m}$ in the presence of $\mathrm{AOPCP}$, and $58 \pm 1 \mu \mathrm{m}$ in the presence of L-NMMA). Similar to the above findings, in the presence of AOPCP, arteriolar responses to sympathetic nerve stimulation were enhanced by L-NMMA under the normal superfusate, but not under the high- $\mathrm{O}_{2}$ superfusate. Under the normal superfusate, 3 and $8 \mathrm{~Hz}$ stimulation induced arteriolar constrictions of $10 \pm 1$ and $17 \pm 1 \mu \mathrm{m}$ under control conditions vs. $17 \pm 1$ and $30 \pm 1 \mu \mathrm{m}$ in the presence of L-NMMA. Under the high- $\mathrm{O}_{2}$ superfusate, 3 and $8 \mathrm{~Hz}$ stimulation induced arteriolar constrictions of $19 \pm 1$ and $30 \pm 1 \mu \mathrm{m}$ under control conditions vs. $16 \pm 1$ and $30 \pm 1 \mu \mathrm{m}$ in the presence of L-NMMA. 
To explore the possibility that erythrocytes in nearby first-order venules may be a significant source of ATP and/or adenosine during increased sympathetic nerve activity, we determined if proximity to a venule was a critical factor in the limitation of arteriolar constriction by reduced $\mathrm{PO}_{2}$ or $\mathrm{NO}$. Figure 6 , which is derived from the data shown in Figures 4 and 5, illustrates the lack of a relationship between arteriolar-venular separation distance and the effect of either L-NMMA or increased $\mathrm{O}_{2}$ availability on arteriolar responses to sympathetic nerve stimulation. For either treatment, there was no significant correlation between the magnitude of the response enhancement and arteriolevenule separation distance (see figure legend for line equations, correlation coefficients, and $p$ values).

Seven first-order arterioles were studied to evaluate the effect of AOPCP on vascular smooth muscle responsiveness to NO (Fig. 7). As in the other experiments, AOPCP did not alter resting arteriolar diameter $(57 \pm 2 \mu \mathrm{m}$ under control conditions vs. $58 \pm 2 \mu \mathrm{m}$ in the presence of AOPCP). Under control conditions, SNP induced dilations of $11 \pm 2,23 \pm 2$, and $35 \pm 3 \mu \mathrm{m}$ at ejection currents of 5, 20, and $40 \mathrm{nA}$, respectively. Exposure to AOPCP did not significantly alter these responses (dilations of $12 \pm 2,22 \pm 3$, and $32 \pm 3 \mu \mathrm{m}$ at ejection currents of 5,20 , and $40 \mathrm{nA})$. 


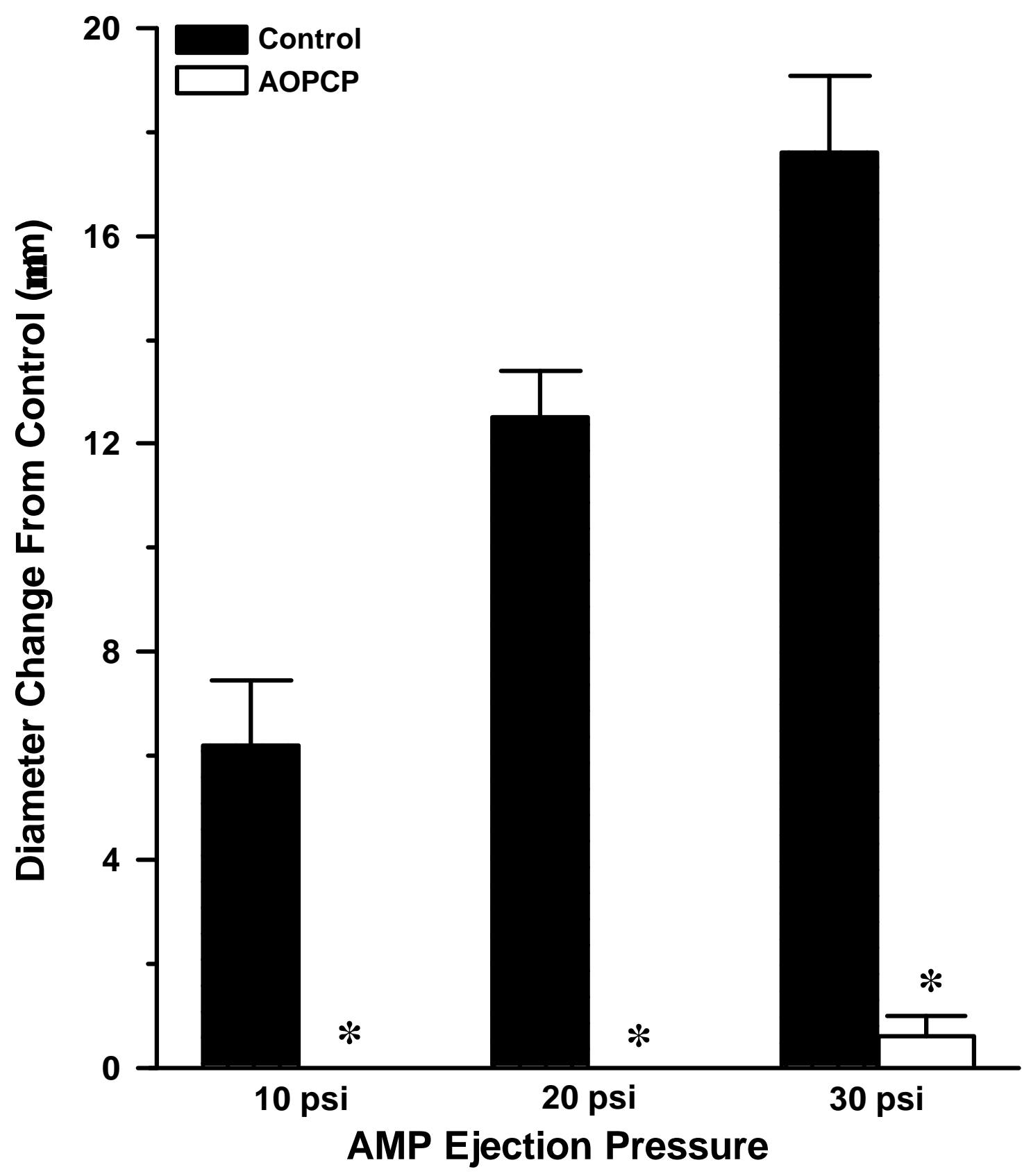

Figure 1. Arteriolar responses to AMP applied via pressurized micropipette directly to the arteriolar wall under the normal superfusate, before (closed bars) and then during (open bars) exposure to $4.5 \times 10^{-5} \mathrm{M}$ AOPCP. All data are paired. $n=10$ vessels. ${ }^{*} P<0.05$ vs. control. 

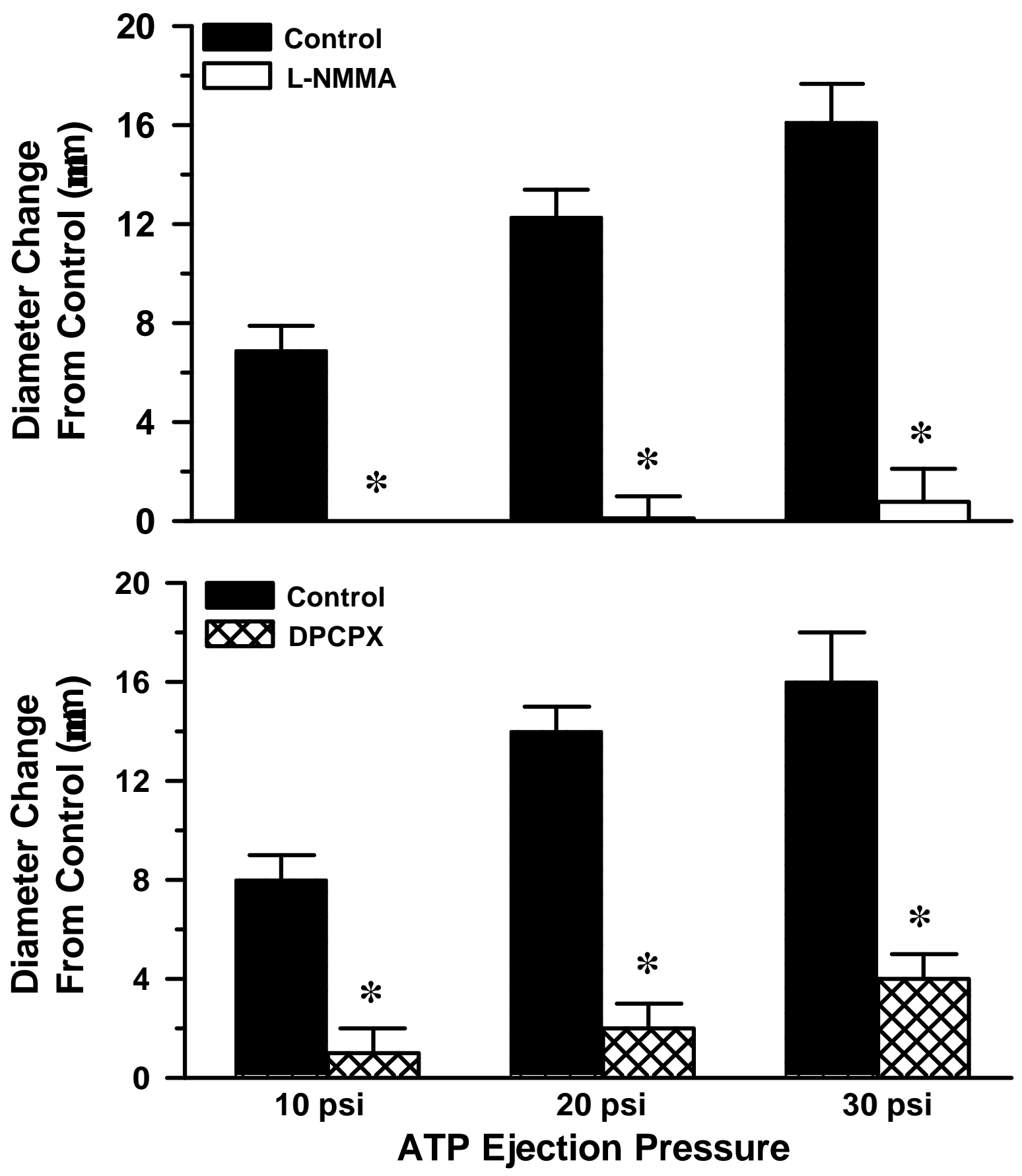

Figure 2. Arteriolar responses to ATP applied via pressurized micropipette, before (closed bars; both panels) and then during exposure to $10^{-4} \mathrm{M}$ L-NMMA (open bars) or $4 \times 10^{-4} \mathrm{M}$ DPCPX (hatched bars). Data within each group of experiments ( $n=8$ vessels) are paired. ${ }^{*} P<0.05$ vs. control. 


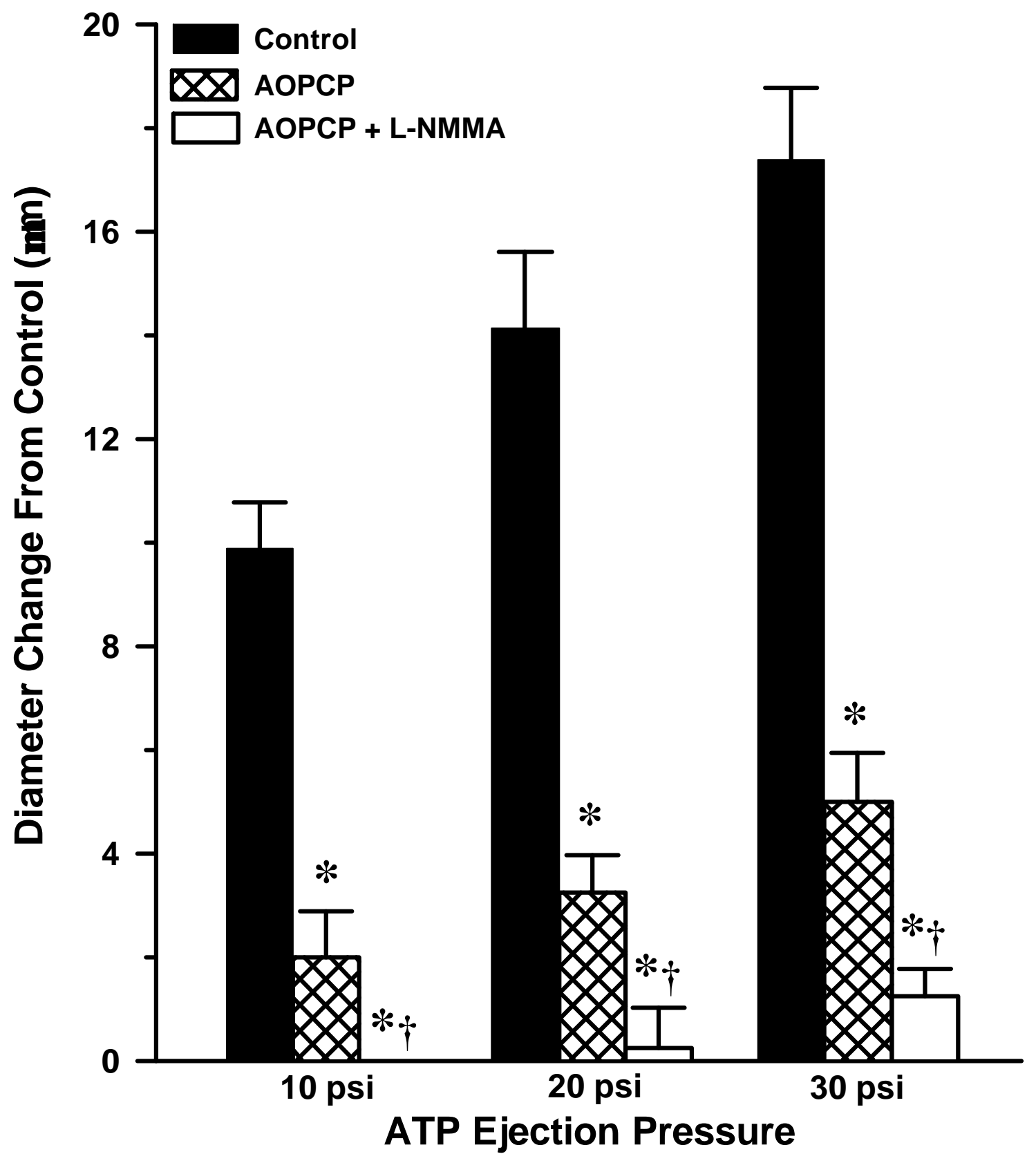

Figure 3. Arteriolar responses to ATP applied via pressurized micropipette under the normal superfusate, before (closed bars) and then during exposure to $4.5 \times 10^{-5} \mathrm{M}$ AOPCP (hatched bars) and then during exposure to $4.5 \times 10^{-5} \mathrm{M}$ AOPCP $+10^{-4} \mathrm{M}$ L-NMMA (open bars). All data are paired. $\mathrm{n}=8$ vessels. ${ }^{*} \mathrm{P}<0.05$ vs. control; $\uparrow \mathrm{P}<0.05$ vs. AOPCP. 


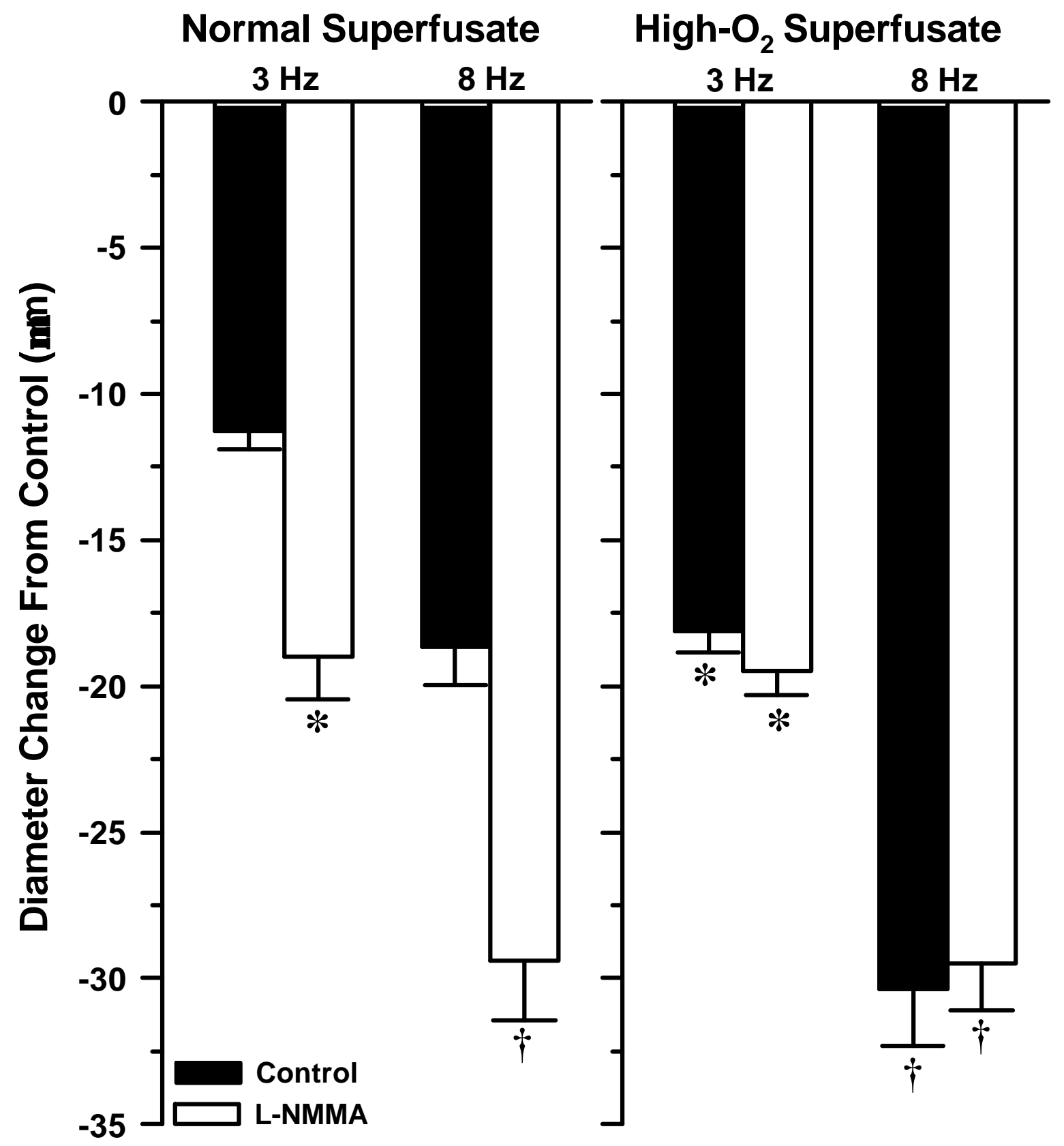

Figure 4. Effect of L-NMMA on arteriolar responses to 3 and $8 \mathrm{~Hz}$ sympathetic nerve stimulation under normal superfusate (left panel) and high- $\mathrm{O}_{2}$ superfusate (right panel). All data are paired. $\mathrm{n}=8$ vessels. ${ }^{*} \mathrm{P}<0.05 \mathrm{vs}$. control response to $3 \mathrm{~Hz}$ stimulation under normal superfusate; $\nmid \mathrm{P}<0.05$ vs. control response to $8 \mathrm{~Hz}$ stimulation under normal superfusate. 


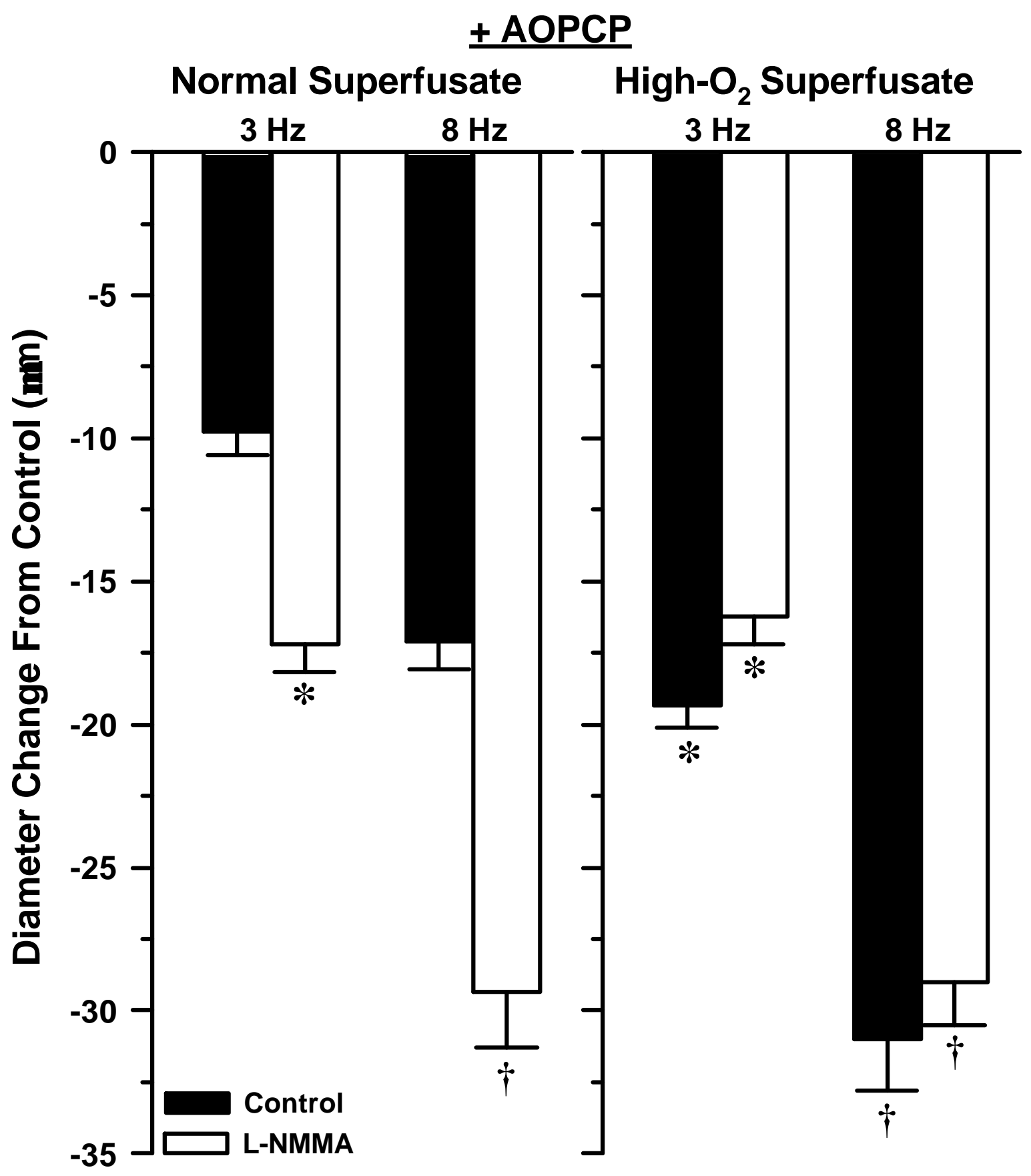

Figure 5. Effect of L-NMMA on arteriolar responses to 3 and $8 \mathrm{~Hz}$ sympathetic nerve stimulation during continuous exposure to $4.5 \times 10^{-5} \mathrm{M}$ AOPCP under normal superfusate (left panel) and high- $\mathrm{O}_{2}$ superfusate (right panel). All data are paired. $n=9$ vessels. 

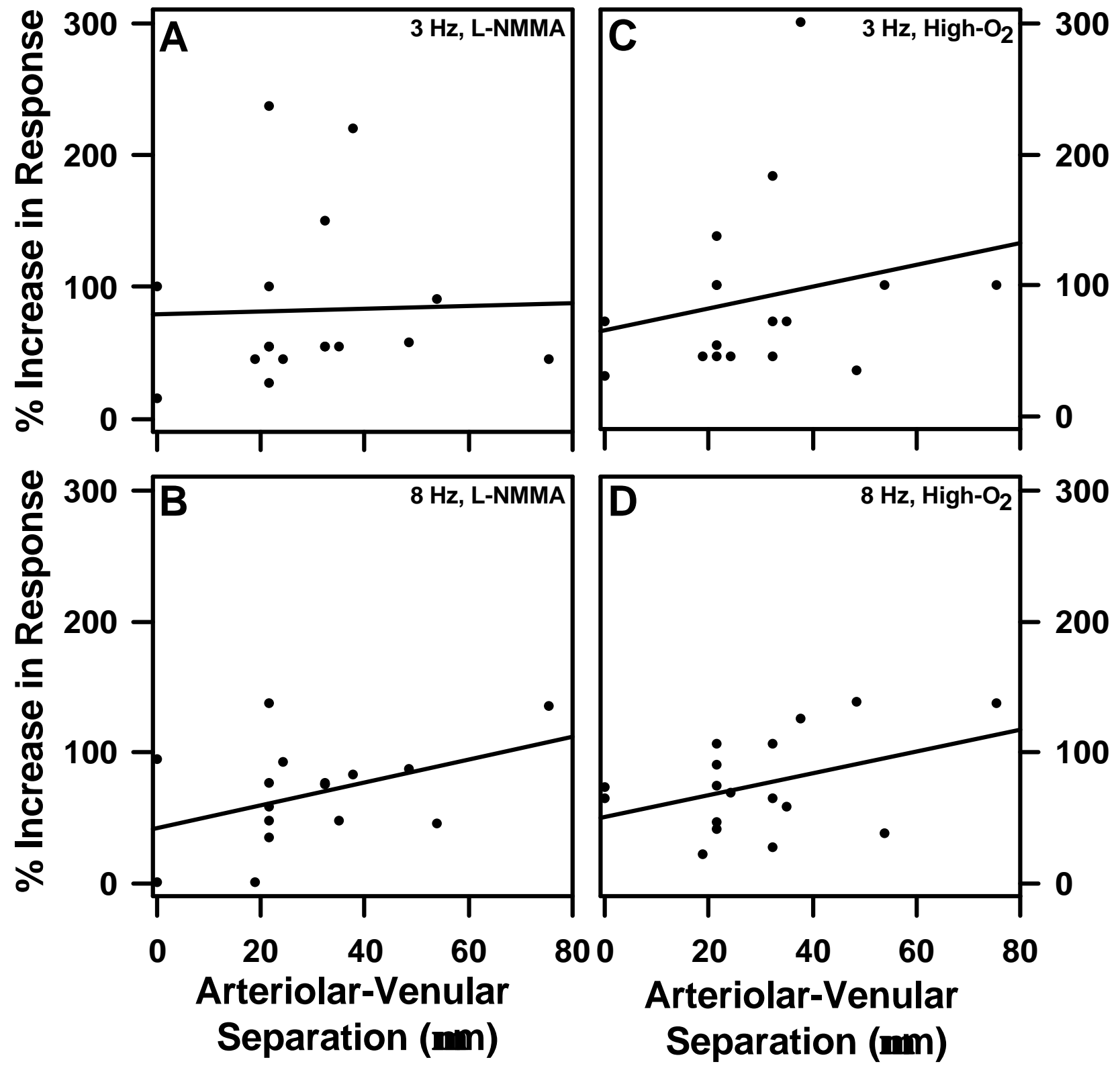

Figure 6. First-order linear regression plots of the increase in arteriolar sympathetic constriction vs. arteriole-venule separation distance at nerve stimulation frequencies of $3 \mathrm{~Hz}$ (panels $A$ and $C$ ) or $8 \mathrm{~Hz}$ (panels $B$ and $D$ ) during exposure to L-NMMA (panels $A$ and $B$ ) or to the high- $\mathrm{O}_{2}$ superfusate (panels $C$ and $D$ ). $r=0.03, P=0.91$, and $f=79.3+.11 x$ for panel $A ; r=0.42, P=0.09$, and $f=42.9+.87 x$ for panel $B ; r=0.23, P=0.38$, and $f=65.8+.83 x$ for panel $C ; r=0.42, P=0.10$, and $f=50.7+.83 x$ for panel $D$. All data are paired. $n=17$ vessels. 


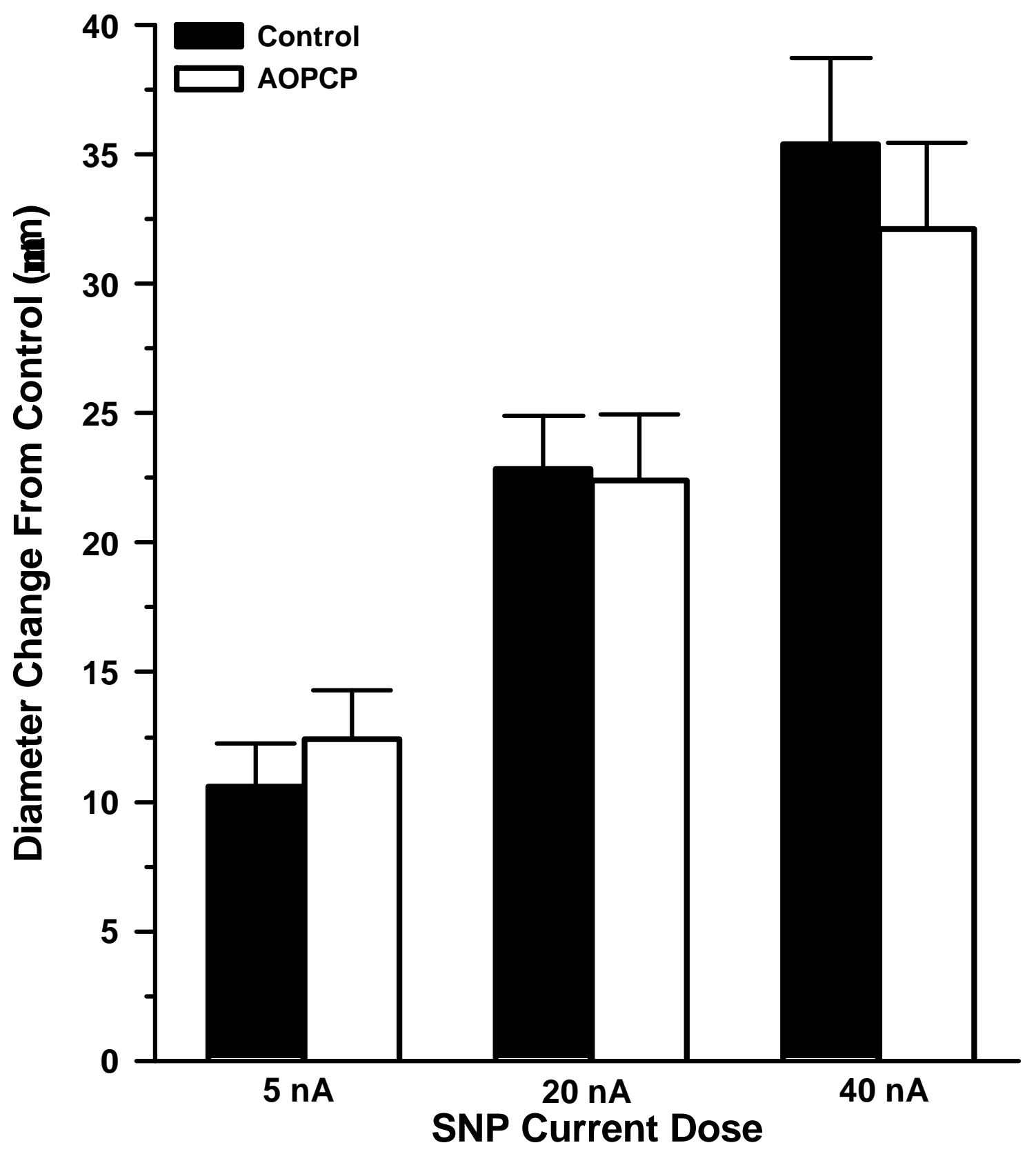

Figure 7. Arteriolar responses to iontophoretically applied SNP under normal superfusate before (closed bars) and during exposure to AOPCP (open bars). All data are paired. $n=7$ vessels. 


\section{DISCUSSION}

Our recent investigations of this vascular bed have led us to conclude that during periods of increased sympathetic outflow to the arterioles, a flowdependent fall in local $\mathrm{PO}_{2}$ leads to local formation of adenosine, which in turn maintains arteriolar NO synthesis in the face of reduced shear stress via activation of endothelial $A_{1}$ receptors (34). In an attempt to determine the site of adenosine formation under these conditions, we sought in this study to test the hypothesis that ATP, released from erythrocytes in response to reduced $\mathrm{O}_{2}$ levels, is sequentially hydrolyzed to adenosine via extracellular nucleotidase activity.

Recently, Ellsworth has reported that a reduction in $\mathrm{PO}_{2}$ from 85 to $35 \mathrm{~mm}$ $\mathrm{Hg}$ increases ATP release from rat erythrocytes by more than $75 \%$ (15). We have found that $3-8 \mathrm{~Hz}$ sympathetic nerve stimulation reduces blood flow in the intestine by $33-66 \%$ (23), which causes first-order arteriolar wall $\mathrm{PO}_{2}$ to fall from $67 \pm 3 \mathrm{~mm} \mathrm{Hg}$ to as low as $41 \pm 6 \mathrm{~mm} \mathrm{Hg}$ (33). Since arteriolar wall $\mathrm{PO}_{2}$ is almost identical to luminal $\mathrm{PO}_{2}(14)$, it seems possible that under our experimental conditions, there could have been an increase in erythrocyte ATP release similar to that reported by Ellsworth. Erythrocytes in nearby venules could also be the source of ATP under these conditions. We have not measured first-order venular $\mathrm{PO}_{2}$ in the rat intestine during sympathetic nerve stimulation, but measurements made by others in this preparation under similar experimental conditions $(7,36)$ suggest that the resting $\mathrm{PO}_{2}$ of these venules is probably around $50 \mathrm{~mm} \mathrm{Hg}$, or 
roughly $25 \%$ below that of the paired first-order arterioles. Therefore, during sympathetic nerve stimulation, we would expect venular lumen $\mathrm{PO}_{2}$ to fall as low as if not lower than the minimum $\mathrm{PO}_{2}$ we measured in the nearby arterioles. Chemical communication can occur between paired arterioles and venules (17, $21,37)$, and adenosine in particular can readily diffuse from venules to arterioles in vasoactive amounts, even when the vessels are separated by more than 150 $\mu \mathrm{m}$ (21). In the current experiments, the adenosine responsible for stimulating endothelial NO synthesis is most likely formed within $50 \mu \mathrm{m}$ of the arteriolar wall (34). Because most of the arterioles we studied were within $50 \mu \mathrm{m}$ of a paired venule (mean separation distance $=29 \pm 5 \mu \mathrm{m}$ ), it is possible that at least some of the adenosine responsible for stimulating arteriolar NO synthesis during sympathetic constriction could have either diffused from the venular blood or have been formed from ATP at the venular wall. However, we found no correlation between arteriole-venule separation distance and the effect of either L-NMMA or the high- $\mathrm{O}_{2}$ superfusate on arteriolar sympathetic constriction (Fig. 6). Therefore, it appears unlikely that a significant fraction of the vasoactive pool of adenosine (or its hypothesized precursor, ATP) originated within the venules.

Consistent with the possibility that ATP from arteriolar erythrocytes serves as an extracellular source of adenosine in this preparation, we found that ATP applied to the arteriolar wall causes a NO-dependent dilation (Fig. 2, top panel) that is largely due to $A_{1}$ receptor activation (Fig. 2, bottom panel) and that largely depends on 5'-ectonucleotidase activity (Fig. 3). Taken together, these findings 
suggest that in the intestine, extracellular ATP in the immediate vicinity of the arteriolar wall can stimulate arteriolar NO release through the ultimate conversion of AMP to adenosine. The smooth muscle of intestinal and mesenteric arterioles contains $\mathrm{P}_{2 x}$ purinergic receptors that should elicit vasoconstriction when stimulated by ATP $(19,31)$. However, the amounts of ATP that we applied to the arteriolar wall were relatively low (the highest amount causing only about $35 \%$ of maximal dilation) and did not cause even a transient constriction. Since most of that ATP was quickly hydrolyzed to adenosine (Figure 3), the amount of unhydrolyzed ATP was presumably insufficient to activate the $P_{2 x}$ receptors. Consistent with this interpretation, we found in preliminary experiments that application of ATP in higher quantities did cause arteriolar constriction (unpublished results).

If endogenous ATP were sequentially hydrolyzed to adenosine as local $\mathrm{O}_{2}$ levels fell during sympathetic constriction, then inhibition of 5'-ectonucleotidase should have abolished the limiting influence of NO on arteriolar constriction because, as mentioned above, adenosine serves to link the fall in $\mathrm{O}_{2}$ to $\mathrm{NO}$ production (34). A comparison of Figures 4 and 5 reveals that AOPCP had no effect on the ability of L-NMMA to enhance arteriolar responses to sympathetic nerve stimulation, or on the abrogation of L-NMMA's effect under the high- $\mathrm{O}_{2}$ superfusate. Therefore, these results suggest that extracellular ATP, regardless of its origin, probably does not serve as a significant source of the adenosine that sustains arteriolar NO release under the current experimental conditions. 
For the correct interpretation of our findings, it was critical that we verify the specificity of our antagonists and also demonstrate that vascular smooth muscle responsiveness to NO was not altered by any of our treatments. Our finding that AOPCP completely abolished arteriolar responses to AMP (Fig. 1) confirms the efficacy of AOPCP as a 5'-ectonucleotidase inhibitor in the intestinal microcirculation, and is consistent with studies conducted in other vascular beds $(22,23)$. In addition, we have previously demonstrated that $4 \times 10^{-4} \mathrm{M}$ DPCPX completely abolishes arteriolar responses to $A_{1}$ receptor agonists in this preparation (34). The preservation of normal arteriolar responses to SNP in the presence of AOPCP (Fig. 7) argues against the possibility that AOPCP alters the vascular smooth muscle responsiveness to NO under our experimental conditions. Finally we have previously demonstrated that neither the high- $\mathrm{O}_{2}$ superfusate nor DPCPX has any effect on vascular smooth muscle responsiveness to NO $(33,34)$.

Another important observation in this study is the lack of an effect of LNMMA on steady-state arteriolar tone, which contrasts with findings in skeletal muscle $(1,24)$, but is consistent with our previous findings in this vascular bed $(26,33,34)$. In light of recent direct measurements verifying that $\mathrm{NO}$ is continuously released from these vessels in the resting state (9), local NOS inhibition would be expected to reduce arteriolar diameter. In fact, we routinely did see a transient reduction in arteriolar diameter within the first few minutes of L-NMMA exposure, but then these vessels regained their initial resting diameter. 
This inability of L-NMMA to produce a sustained reduction in arteriolar diameter may reflect the fact that resting arteriolar tone results from the integration of numerous simultaneous vasoactive signals by the vascular smooth muscle. Local vascular regulatory mechanisms may be so highly developed in the intestine that the removal of any single influence (such as NO in the presence of L-NMMA) is accompanied by a compensatory change in the activity of any of these systems, thereby re-establishing the initial level of resting tone.

We also found that resting arteriolar diameters were not altered by exposure to the high- $\mathrm{O}_{2}$ superfusate, which is consistent with our earlier findings in this preparation $(33,34)$. This may be due to the fact that the high- $\mathrm{O}_{2}$ superfusate, which minimizes the fall in both arteriolar wall and local tissue $\mathrm{PO}_{2}$ during sympathetic constriction, does not have any significant effect on these $\mathrm{PO}_{2}$ values under resting conditions $(33,34)$. This is because $\mathrm{O}_{2}$ levels in the arteriolar wall and immediately adjacent parenchymal tissue are overwhelmingly influenced by luminal blood $\mathrm{O}_{2}$ delivery during normal flow conditions, with extraluminal $\mathrm{O}_{2}$ delivery from the superfusate only becoming important when luminal blood flow falls during sympathetic (4). Since resting wall and periarteriolar $\mathrm{PO}_{2}$ 's were not changed under the high- $\mathrm{O}_{2}$ superfusate, it is understandable that no arteriolar constriction occurred under these conditions.

Since molecular $\mathrm{O}_{2}$ is a co-substrate for all NOS isoforms $(18,38)$, the reduction in arteriolar wall $\mathrm{PO}_{2}$ that accompanies sympathetic constriction (33) might have been expected to limit arteriolar NO production despite increased 
local adenosine levels. However, our previous measurements indicate that during sympathetic stimulation at the frequencies used here, arteriolar wall $\mathrm{PO}_{2}$ never approaches the level reflecting the $\mathrm{K}_{\mathrm{m}}$ of $\mathrm{O}_{2}$ for either isolated eNOS (6 $\mathrm{mm} \mathrm{Hg})(32)$ or eNOS in intact endothelial cells $(38 \mathrm{~mm} \mathrm{Hg})(38)$. Therefore, the reduction in arteriolar wall $\mathrm{PO}_{2}$ during sympathetic constriction was probably not sufficient to limit endothelial NO synthesis in the current study. Our observations suggest that as arteriolar wall $\mathrm{PO}_{2}$ falls, $\mathrm{NO}$ synthesis may in fact change in a biphasic manner. A fall in $\mathrm{PO}_{2}$ from resting levels could initially stimulate $\mathrm{NO}$ synthesis through adenosine formation, whereas a continued fall to lower levels would begin to suppress NO synthesis as $\mathrm{O}_{2}$ becomes limited as a NOS cosubstrate.

Although the current results do not suggest a contribution of extracellular ATP hydrolysis to adenosine formation during sympathetic nerve stimulation in the intestine, they do provide important, albeit indirect, information about the nature of adenosine release under our experimental conditions. Based on our previous investigations, we concluded that the adenosine involved in stimulating NO release during sympathetic stimulation must come from a site within $50 \mu \mathrm{m}$ of the vessel wall (34). As reported here, ATP released from arteriolar and/or venular erythrocytes does not appear to contribute importantly to the formation of adenosine under the current experimental conditions, nor is there any evidence of the venular blood or venular wall cells serving as direct sources of adenosine. 
This leaves the arteriolar wall and/or the periarteriolar parenchymal cells as the most likely sources of adenosine under these conditions $(11,12)$. 


\section{REFERENCES}

1. Blitzer, ML, L Lee, and MA Creager. Endothelium-derived nitric oxide mediates hypoxic vasodilation of resistance vessels in humans. Am J Physiol Heart Circ. Physiol 271: H1182-H1185, 1996.

2. Boegehold MA. Flow-dependent arteriolar dilation in normotensive rats fed low or high salt diets. Am J Physiol Heart Circ Physiol 269: H1407-H1414, 1995.

3. Boegehold MA. Shear-dependent release of venular nitric oxide: effect on arteriolar tone in rat striated muscle. Am J Physiol Heart Circ Physiol 271:H387-H395, 1996.

4. Boegehold, MA and $P C$ Johnson. Periarteriolar and tissue $\mathrm{PO}_{2}$ during sympathetic escape in skeletal muscle. Am J Physiol Heart Circ Physiol 254: H929-H936, 1988.

5. Bohlen HG. Intestinal tissue $\mathrm{PO}_{2}$ and microvascular responses during glucose exposure. Am J Physiol Heart Circ Physiol 238: H164-H171, 1980. 
6. Bohlen HG. Determinants of resting and passive intestinal vascular pressures in rat and rabbit. Am J Physiol Gastrointest Liver Physiol 253: G587-G595, 1987.

7. Bohlen HG and JM Lash. Resting oxygenation of rat and rabbit intestine: arteriolar and capillary contributions. Am J Physiol Heart Circ Physiol 269:H1342-H1348, 1995.

8. Bohlen HG, Lash JM. Intestinal absorption of sodium and nitric oxidedependent vasodilation interact to dominate resting vascular resistance. Circ Res 78:231-237, 1996.

9. Bohlen HG, Nase GP. Dependence of intestinal arteriolar regulation on flowdependent nitric oxide formation. Am J Physiol Heart Circ Physiol 279:H2249-H2258, 2000.

10. Bohlen HG, H Henrich, RW Gore, and PC Johnson. Intestinal muscle and mucosal blood flow during direct sympathetic stimulation. Am J Physiol Heart Circ Physiol 235(1):H40-H45, 1978. 
11.Bryan PT and JM Marshall. Adenosine receptor subtypes and vasodilatation in rat skeletal muscle during systemic hypoxia: a role for $A_{1}$ receptors. J Physiol 514.1: 151-162, 1999.

12. Deussen A, M Stappert, S Schafer, and M Kelm. Quantification of extracellular and intracellular adenosine production: understanding the transmembranous concentration gradient. Circulation 20,99(15):20412047,1999 .

13. Dietrich HH, ML Ellsworth, RS Sprague, and RG Dacey. Red blood cell regulation of microvascular tone through adenosine triphosphate. $A m \mathrm{~J}$ Physiol Heart Circ Physiol 278:H1294-H1298, 2000.

14. Duling BR and RM Berne. Longitudinal gradients in periarteriolar oxygen tension. A possible mechanism for the participation of oxygen in local regulation of blood flow. Circ Res 27:669-678,1970.

15. Ellsworth ML. The red blood cell as an oxygen sensor: what is the evidence? Acta Physiol Scand 168(4):551-9, 2000. 
16. Ellsworth ML, T Forrester, CG Ellis, and HH Dietrich. The erythrocyte as a regulator of vascular tone. Am J Physiol Heart Circ Physiol 269:H2155H2161, 1995.

17. Falcone JC and HG Bohlen. EDRF from rat intestine and skeletal muscle venules causes dilation of arterioles. Am J Physiol Heart Circ Physiol 258:H1515-H1523, 1990.

18. Förstermann, U, El Closs, JS Pollock, M Nakane, P Schwarz, I Garth, and H Kleinert. Nitric oxide synthase isozymes characterization, purification, molecular cloning, and function. Hypertension. 23 (part 2): 1121-1131, 1994.

19. Galligan JJ, A Herring, and T Harpstead. Pharmacological characterization of purinoceptor-mediated constriction of submucosal arterioles in guinea pig ileum. J Pharmacol Exp Ther274(3):1425-30, 1995.

20. Gordon JL and W Martin. Endothelium-dependent relaxation of the pig aorta: relationship to stimulation of $86 \mathrm{Rb}$ efflux from isolated endothelial cells. Br J Pharmacol 79:531-541, 1983.

21. Hester RL. Venular-arteriolar diffusion of adenosine in hamster cremaster microcirculation. Am J Physiol Heart Circ Physiol 258:H1918-H1924, 1990. 
22. Kitakaze M, T Minamino, K Node, K Komamura, M Inoue, and M Hori. Activation of ecto-5'-nucleotidase by protein kinase $\mathrm{C}$ attenuates irreversible cellular injury due to hypoxia and reoxygenation in rat cardiomyocytes. $J \mathrm{Mol}$ Cell Cardiol 28(9):1945-1955, 1996.

23. Lorbar M, RA Fenton, and JG Dobson. ATP as a source of interstitial adenosine in the rat heart. Can J Physiol Pharmacol 77(8):579-588, 1999.

24. Macedo MP, Lautt WW. Autoregulatory capacity in the superior mesenteric artery is attenuated by nitric oxide. Am J Physiol Gastrointest Liver Physiol 271: G400-G404, 1996.

25. Nase G P and MA Boegehold. Nitric oxide modulates arteriolar responses to increased sympathetic nerve activity. Am J Physiol Heart Circ Physiol 271: H860-H869, 1996.

26. Nase GP and MA Boegehold. Endothelium-derived nitric oxide limits sympathetic neurogenic constriction in intestinal microcirculation. $A m \mathrm{~J}$ Physiol Heart Circ Physiol 273: H426-H433, 1997. 
27. Nase GP and MA Boegehold. Postjunctional $\alpha_{2}$-adrenoceptors are not present in proximal arterioles of rat intestine. Am J Physiol Heart Circ Physiol 274:H202-H208, 1998.

28. Park, KH., LE Rubin, SS Gross, and R Levi. Nitric oxide is a mediator of hypoxic coronary vasodilatation. Circ Res 71: 992-1001, 1992.

29. Pohl, U and R Busse. Hypoxia stimulates release of endothelium-derived relaxant factor. Am J Physiol Heart Circ Physiol 256: H1595-H1600, 1989.

30. Pries AR, J Heide, K Ley, KF Klotz, and P Gaehtgens. Effect of oxygen tension on regulation of arteriolar diameter in skeletal muscle in situ. Microvascular Res 49: 289-299, 1995.

31. Ralevic V and G Burnstock. Actions mediated by P2-purinoceptor subtypes in the isolated perfused mesenteric bed of the rat. $\mathrm{Br} J$ Pharmacol 95(2):63745, 1988.

32. Rengasamy, A and RA Johns. Determination of $\mathrm{K}_{\mathrm{m}}$ for oxygen of nitric oxide synthase isoforms. JPET. 276: 30-33, 1996. 
33. Sauls BA and MA Boegehold. Arteriolar wall $\mathrm{PO}_{2}$ and nitric oxide release during sympathetic vasoconstriction in the rat intestine. Am J Physiol Heart Circ Physiol 279:H484-H491, 2000.

34. Sauls BA and MA Boegehold. Reduced $\mathrm{PO}_{2}$ and adenosine formation preserve arteriolar nitric oxide synthesis during sympathetic constriction in the rat intestine. J Vasc Res 38:104-112, 2001.

35. Shryock JC and L Belardinelli. Adenosine and adenosine receptors in the cardiovascular system: biochemistry, physiology, and pharmacology. Am $\mathrm{J}$ Cardiol 79(12A):2-10, 1997.

36. Sinaasappel M, C Donkersloot, J Van Bommel, C Ince. $\mathrm{PO}_{2}$ measurements in the rat intestinal microcirculation. Am J Physiol Gastrointest Liver Physiol 276:G1515-G1520, 1999.

37. Steenbergen JM, JM Lash, and HG Bohlen. Role of a lymphatic system in glucose absorption and the accompanying microvascular hyperemia. Am J Physiol Gastrointest Liver Physiol 267:G529-G535, 1994. 
38. Whorton, AR, DB Simonds, and CA Piantadosi. Regulation of nitric oxide synthesis by oxygen in vascular endothelial cells. Am J Physiol Lung Cell. Mol Physiol 272:L1161-L1166, 1997. 


\section{GENERAL DISCUSSION}

The overall objective of this dissertation project was to determine if reduced $\mathrm{O}_{2}$ tension serves as a stimulus for endothelial NO synthesis during neurogenic constriction in the rat intestine, and if so, to determine the mechanism by which reduced $\mathrm{O}_{2}$ tension promotes $\mathrm{NO}$ synthesis under these conditions.

In the first study, we evaluated the hypothesis that a flow-dependent fall in arteriolar wall $\mathrm{PO}_{2}$ serves as a stimulus for endothelial $\mathrm{NO}$ synthesis during periods of increased sympathetic outflow to the arteriolar network of the intestine. Numerous studies have found that reduced $\mathrm{O}_{2}$ tension can promote the release of endothelium-derived vasoactive factors (Busse et al., 1983; Pohl and Busse, 1989; Myers et al., 1991; Okada, 1991; Gräser and Rubanyi, 1992; Messina et al., 1992; Park et al., 1992; Busse et al., 1993; Fredricks et al., 1994; Blitzer et al., 1996; Jimenez, 1996; Ward, 1996; Bryan and Marshal, 1999a; Bryan and Marshall, 1999b). In isolated rat aorta, Pohl and Busse (1989) demonstrated that hypoxia stimulates endothelial NO release. Similarly, hypoxia has been shown to increase NO synthesis in a variety of vessels and vascular beds, including rat aorta (Gräser and Rubanyi, 1992), guinea pig heart (Park et al., 1992), bovine pulmonary artery (Hampl et al., 1995), pig heart (Xu et al., 1995; Jimenez et al., 1996), human forearm (Blitzer et al., 1996), dog diaphragm (Ward, 1996), and rat intestine (Bohlen and Nase, 2000; Bohlen and Nase, 2001). In accordance with these studies, we found that limiting the flow-dependent fall in arteriolar wall $\mathrm{PO}_{2}$ that normally accompanies neurogenic constriction significantly enhances the 
arteriolar response to sympathetic nerve stimulation and renders this response no longer sensitive to NOS inhibition. Furthermore, the high- $\mathrm{O}_{2}$ superfusate had no effect on vascular smooth muscle responsiveness to NO or on arteriolar wall oxidant activity. Taken together, these results suggest that a flow-dependent fall in arteriolar wall $\mathrm{PO}_{2}$ promotes endogenous $\mathrm{NO}$ synthesis during periods of increased sympathetic nerve activity in the rat intestine.

Equipped with the results of the first study, we sought to evaluate the mechanism by which reduced $\mathrm{O}_{2}$ tension promotes $\mathrm{NO}$ synthesis. Some investigators have reported that the vascular endothelium is itself sensitive to local $\mathrm{O}_{2}$ levels, and that reduced $\mathrm{PO}_{2}$ directly increases the release of endothelial NO (Park et al., 1992; Xu et al., 1995). However, we chose to test an alternative hypothesis, namely, that a local decrease in oxygen tension indirectly stimulates endothelial NO release through adenosine formation. Many investigators have shown that reductions in $\mathrm{O}_{2}$ tension lead to increased adenosine levels (Raatikainen et al., 1994; Cohen et al., 1995; Decking et al., 1997), and adenosine has been shown to stimulate NO synthesis in some vascular beds (Hein et al., 1999; Peralta et al., 1999). Danialou et al. (1997) reported that activation of $A_{1}$ adenosine receptors stimulates arteriolar NO synthesis in the rat diaphragm. Similarly, Bryan and Marshall (1999a; 1999b) found that inspiration of $8 \% \mathrm{O}_{2}$ promotes adenosine release from the endothelium of resistance vessels, and that this adenosine then acts in an autocrine fashion to hyperpolarize the endothelial cell membrane via activation of $A_{1}$ receptor-coupled 
$\mathrm{K}_{\text {ATP }}$ channels. However, Bryan and Marshall's use of $8 \% \mathrm{O}_{2}$ to induce systemic hypoxia may have produced arteriolar wall $\mathrm{O}_{2}$ tensions that were considerably less than those achieved by sympathetic nerve stimulation in our first study. Furthermore, the interpretation of their findings may be complicated by reflex changes in sympathetic nerve activity due to decreased arterial $\mathrm{O}_{2}$ levels (Hoka et al., 1992). The second study was designed to avoid such influences by limiting the reduction in $\mathrm{O}_{2}$ tension to the intestine.

The "critical $\mathrm{PO}_{2}$ " that is traditionally considered necessary for the conversion from aerobic to anaerobic metabolism has been reported to be less than $3 \mathrm{~mm} \mathrm{Hg}$ in rat skeletal muscle (Richmond et al., 1999). Because our measured arteriolar wall $\mathrm{PO}_{2}$ remained well above this "critical $\mathrm{PO}_{2}$ " during sympathetic constriction, it seemed unlikely that the wall of these vessels could produce a significant amount of adenosine under the conditions of our study. However, cellular concentrations of adenosine and AMP are in dynamic equilibrium, and even a moderate reduction in $\mathrm{PO}_{2}$ could shift this balance toward adenosine formation. Recently Decking and colleagues (1997) reported that reductions in $\mathrm{O}_{2}$ tension suppress cellular adenosine kinase activity. As a result, a modest increase in adenosine formation can be amplified into a relatively large increase (up to 17-fold) in local adenosine concentration (Decking et al., 1997). This effect of reduced oxygen on adenosine kinase may be an important mechanism for the close matching of blood flow to oxygen consumption over a 
wide range of metabolic activities (Decking et al., 1997; Arch and Newsholme, 1978).

The results of the second study clearly indicate that adenosine serves as a link between reduced local $\mathrm{O}_{2}$ tension and arteriolar $\mathrm{NO}$ synthesis during neurogenic constriction in the rat intestine, and that the origin of this adenosine is most likely within $50 \mu \mathrm{m}$ of the arteriolar wall. To establish a link between tissue oxygenation and adenosine formation, I measured tissue $\mathrm{PO}_{2}$ at a site deemed capable of releasing adenosine that would yield NO-dependent arteriolar dilations, $25 \mu \mathrm{m}$ away from the arteriolar wall. Sympathetic constriction resulted in a fall in tissue $\mathrm{PO}_{2}$ that was significantly greater than that reported for the arteriolar wall in the first study. This significantly greater reduction in tissue $\mathrm{PO}_{2}$ could allow for more adenosine formation out in the parenchyma than within the arteriolar wall. Similar to the results of the first study, the limiting influence of NO on sympathetic constriction was lost in the presence of the high- $\mathrm{O}_{2}$ superfusate. However, unlike the first study, where the high- $\mathrm{O}_{2}$ superfusate only limited the fall in arteriolar wall $\mathrm{PO}_{2}$, the high- $\mathrm{O}_{2}$ superfusate completely abolished the flowdependent fall in tissue $\mathrm{PO}_{2}$ in the second study. These results suggest that tissues other than the arteriolar wall are more likely sites of adenosine formation under these conditions. Abolition of local adenosine activity via accelerated adenosine metabolism or blockade of microvascular $A_{1}$ receptors also enhanced arteriolar response to sympathetic nerve stimulation and rendered them insensitive to NOS inhibition in a manner that was not altered by tissue 
oxygenation. Collectively, the results of the first two studies suggest that a flowdependent fall in local $\mathrm{PO}_{2}$ leads to an increase in extracellular adenosine, which, through its interaction with endothelial $A_{1}$ receptors, stimulates NO synthesis that in turn limits the arteriolar response to sympathetic nerve activity.

Adenosine plays other important roles in this vascular bed, primarily in relation to local blood flow control. For instance, it has been suggested that adenosine is one of, perhaps, several mediators of intestinal functional hyperemia (Proctor, 1986). In his study, Proctor (1986) reported that treatment with either adenosine deaminase or the non-selective adenosine receptor antagonist theophylline significantly reduces, but does not eliminate, the intestinal vasodilation elicited by nutrient absorption. Furthermore, neither of these treatments affected basal hemodynamics, suggesting that resting intestinal blood flow is not influenced by adenosine. Pawlik and colleagues (1993) demonstrated that the use of either adenosine deaminase or theophylline also significantly reduces the dilatory response of intestinal arteries to brief periods of occlusion, suggesting that adenosine is a mediator of reactive hyperemia. Similarly, Buckley and coworkers (1988) reported that theophylline significantly reduced intestinal blood flow autoregulation in the pig. Finally, Kaminski and Proctor (1989) reported that topical application of adenosine to the serosa of partially isolated jejunal segments attenuates the intestinal no-reflow phenomenon, reduces a biochemical index of neutrophil activation, and limits the histological changes associated with reperfusion. 
The ubiquitous release of adenosine under low $\mathrm{O}_{2}$ conditions and its ability to stimulate NO synthesis in the intestinal vascular bed indicates that adenosine may also link reduced $\mathrm{PO}_{2}$ to $\mathrm{NO}$ synthesis during sympathetic nerve stimulation in other vascular beds. However, the intricate nature of this pathway suggests that it may be more prevalent in tissues where metabolic flow control mechanisms are well developed. For example, numerous investigators have reported a role for adenosine in the regulation of blood flow in tissues such as heart and brain, (Schrader et al., 1977; Olsson et al., 1979; Simpson and Phillis, $1991 ;)$. One likely exception to this postulate is the kidney, where adenosine has been shown to produce vasoconstriction and vasodilation at low and high concentrations, respectively (Inscho, 1996). In vascular beds where metabolic flow control mechanisms are not well developed, one or more key steps in this pathway may be absent. For instance, local NO activity does not limit arteriolar responses to sympathetic nerve activity in the rat cutaneous vasculature (Häbler et al., 1997).

In addition to regional variation among different vascular beds, there may be developmental changes that affect the ability of this pathway to modulate arteriolar tone. For instance, Linderman and Boegehold (1998) found that arterioles in the rat spinotrapezius muscle did not express basal NO release or NO-dependent modulation of sympathetic tone until 7-8 weeks of age. Since all of the animals used in the current project were 1-2 weeks older than those studied by Linderman and Boegehold, it is difficult to speculate as to whether the 
intestinal circulation may have undergone a similar developmental change. However, based on the similarities in growth and development between the intestine and skeletal muscle, it seems likely that the intestine would have undergone a similar functional change. During juvenile growth, spinotrapezius muscle size doubles and this tissue enlargement is typically accompanied by extensive growth of the arteriolar network (Linderman and Boegehold, 1996). Similarly, the rat intestine more than doubles in size during juvenile growth and is accompanied by an elongation of the preexisting vasculature (Unthank and Bohlen, 1987). Due to structural changes such as these, the microvasculature of both tissues would be subjected to an ever-changing hemodynamic milieu, which may serve as the stimulus for the development of various microvascular control mechanisms. Therefore, the delayed appearance of this particular microvascular control mechanism in the spinotrapezius muscle may be the result of the subsequent microvascular development previously described by this laboratory.

In the third study, I sought to ascertain the origin of the adenosine that links the fall in local $\mathrm{O}_{2}$ tension to endothelial $\mathrm{NO}$ release. Based on the results of the second study, I decided to evaluate two potential sites of adenosine formation that were typically within $50 \mu \mathrm{m}$ of the arteriolar wall. Within this distance there are a number of potential sites of adenosine formation including the wall itself, the neighboring parenchymal cells, the nearby paired venule, and the erythrocytes circulating within the arteriolar and/or venular lumen. In the third study, we evaluated the hypothesis that the extracellular conversion of ATP to 
adenosine is necessary to ensure endothelial NO synthesis in rat intestinal arterioles under our experimental conditions. However, the results of this study indicate that the extracellular conversion of ATP to adenosine is not necessary for continued NO synthesis under these conditions.

In addition to evaluating the importance of the extracellular conversion of ATP to adenosine during sympathetic constriction, we indirectly evaluated the possibility that the neighboring first-order venules serve as an additional source of adenosine under the current conditions. With most of the arterioles studied in these experiments located within $50 \mu \mathrm{m}$ of a paired venule, it is possible that at least some of the adenosine responsible for sustaining arteriolar NO synthesis during sympathetic constriction could have diffused from the venules to the nearby arterioles. However, we found no correlation between arteriole-venule separation distance and the effect of L-NMMA or the high- $\mathrm{O}_{2}$ superfusate on arteriolar responses to sympathetic nerve stimulation. Therefore, it appears unlikely that a significant fraction of the vasoactive pool of adenosine originated within the venules.

Although these results suggest that extracellular ATP hydrolysis does not contribute to adenosine formation during sympathetic nerve stimulation in the intestine, they do provide indirect information about the nature of adenosine release under these experimental conditions. Based on the results of the second study, I concluded that the adenosine involved in stimulating NO release during sympathetic stimulation must come from a site within $50 \mu \mathrm{m}$ of the vessel wall. 
Within this range, possible sources of adenosine include the arteriolar wall itself, the nearby parenchymal cells, the paired venule, and ATP released from erythrocytes circulating within the arteriolar and venular lumen. As reported here, ATP released from arteriolar and/or venular erythrocytes does not appear to contribute importantly to the formation of adenosine under the current experimental conditions, nor is there any evidence of the venular blood or venular wall cells serving as direct sources of adenosine. The elimination of these two potential sources leaves the arteriolar wall and/or the periarteriolar parenchymal cells as the most likely sites of adenosine release under these conditions (see Figure 2 next page for summary).

In conclusion, the results of this dissertation project demonstrate that a flowdependent fall in local $\mathrm{O}_{2}$ tension limits the arteriolar response to sympathetic nerve stimulation in the rat intestine by promoting the release of adenosine, which subsequently stimulates endothelial NO release through its interaction with $A_{1}$ receptors. Furthermore, these results indicate that neither the extracellular conversion of ATP to adenosine nor the release of adenosine from nearby paired venules contribute importantly to the vasoactive pool of adenosine under these conditions. 


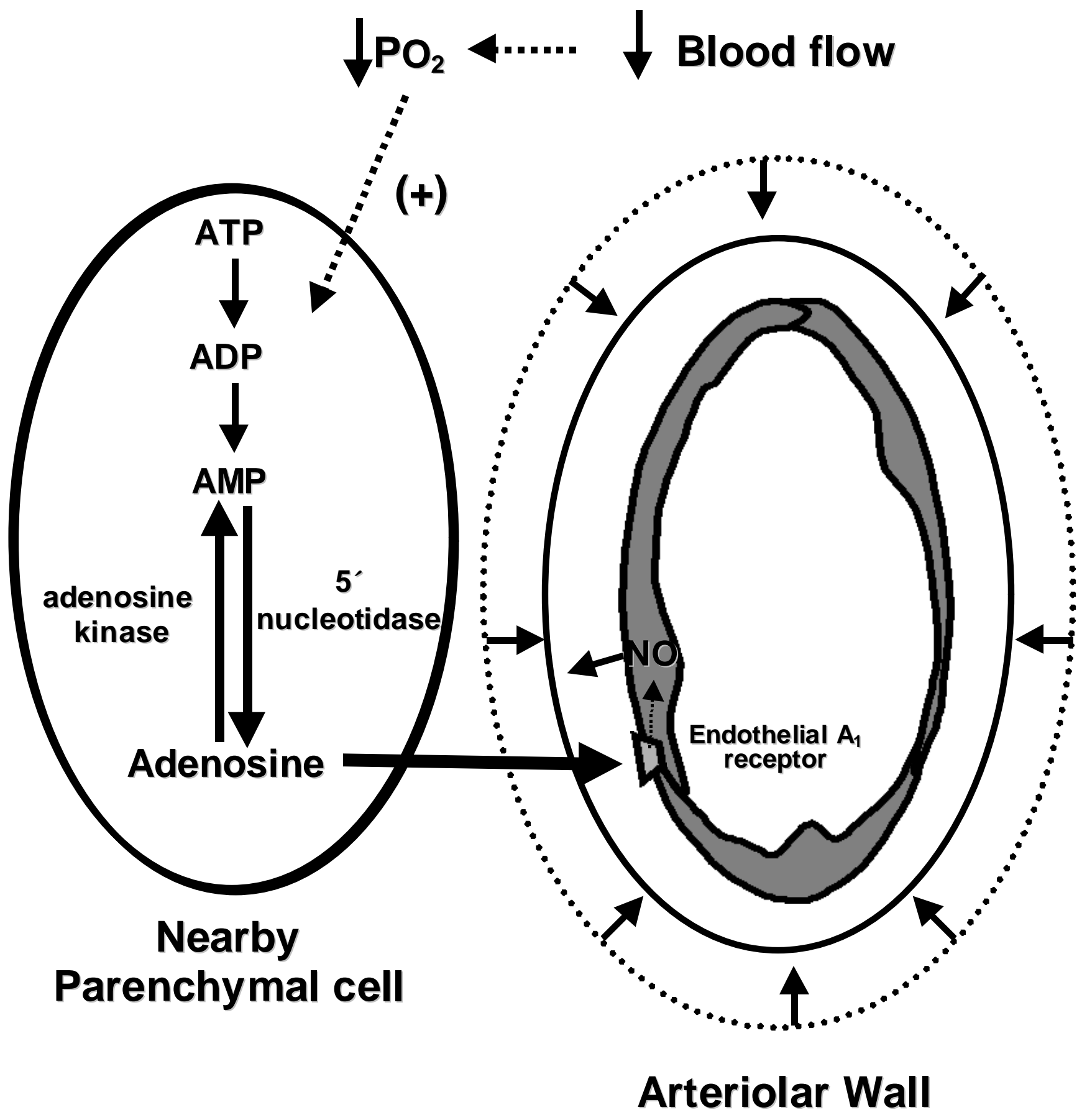

Figure 1. Schematic representation of the two most likely sources of adenosine under the conditions of this project. 


\section{REFERENCES FOR LITERATURE REVIEW AND}

\section{GENERAL DISCUSSION}

Abbracchio, M. and G. Burnstock. Purinoceptors: are there families of $P_{2 x}$ and $P_{2 y}$ purinoceptors? Pharmacol. Ther. 64:445-475, 1994.

Abe, T., D.A. Morgan, and D.D. Gutterman. Role of adenosine receptor subtypes in neural stunning of sympathetic coronary innervation. Am. J. Physiol. 272:H25-H34, 1997.

Abebe, W., S.R. Makujina, and S.J. Mustfa. Adenosine receptor-mediated relaxation of porcine coronary artery in presence and absence of endothelium. Am. J. Physiol. 266:H2018-H2025, 1994.

Abou-Soud, H.M. and D.J. Steuhr. Nitric oxide synthases reveal a role for calmodulin in controlling electron transfer. Proc. Natl. Acad. Sci. 90:1076910772, 1993.

Adams, D.J., J. Barakeh, R. Laskey, and C. Van Breeman. Ion channels and regulation of intracellular calcium in vascular endothelial cells. FASEB J. 3(12):2389-2400, 1989.

Andriantsitohaina, R., G.J. Lagaud, A. Andre, B. Muller, and J.C. Stoclet. Effects of cGMP on calcium handling in ATP-stimulated rat resistance arteries. Am. J. Physiol. 268:H1223-H1231, 1995.

Arch, J.R.S. and E.A. Newsholme. Activities and some properties of 5'nucleotidase, adenosine kinase and adenosine deaminase in tissues from vertebrates and invertebrates in releation to the control of the concentration and the physiological role of adenosine. Biochem. J. 174 (3):965-977, 1978.

Archer, S.L., J.M. Huang, V. Hampl, D.P. Nelson, P.J. Shultz, and E.K. Weir. Nitric oxide and cGMP cause vasorelaxation by activation of a charybdotoxinsensitive K channel by cGMP-dependent protein kinase. Proc. Natl. Acad. Sci. 91:7583-7587, 1994.

Ayajiki, K., M. Kindermann, M. Hecker, I. Fleming, and R. Busse. Intracellular $\mathrm{pH}$ and tyrosine phosphorylation but not calcium determine shear stress-induced nitric oxide production in native endothelial cells. Circ. Res. 78:750-758, 1996. 
Ayotunde, S.O. and C.R. Triggle. Interactions of nitric oxide synthase inhibitors and dexamethasone with $\alpha$-adrenoceptor-mediated responses in rat aorta. $B r$. J. Pharmacol. 109:495- 501,1993b.

Bao, J.X., F. Gonon, and L. Stjärne. Frequency- and train length-dependent variation in the roles of postjunctional $\alpha_{1}-\alpha_{2}$-adrenoceptors for the field stimulation-induced neurogenic contraction of the rat tail artery. Naunyn Schmiedeberg's Arch. Pharmacol. 347:601-616, 1993.

Bassenge, E. Endothelial function in different organs. Prog. Cardiovasc. Dis. 39 (3):209-228, 1996.

Bauersachs, J., M. Hecker, and R. Busse. Display of the characteristics of endothelium-derived hyperpolarizing factor by a cytochrome P450-derived arachidonic acid metabolite in the coronary microcirculation. Br. J. Pharmacol. 113:1548-1553, 1994.

Baylis, C., B. Mitruka, and A. Deng. Chronic blockade of nitric oxide synthesis in the rat produces systemic hypertension and glomerular damage. J. Clin. Invest. 90:278-281, 1992.

Beckman, J.S. and W.H. Koppenol. Nitric oxide, superoxide, and peroxynitrite: the good, the bad and the ugly. Am. J. Physiol. 271 (Suppl 5):C1424-C1437, 1996.

Bény, J.L. and P.C. Brunet. Electrophysiological and mechanical effects of substance $\mathrm{P}$ and acetylcholine on rabbit aorta. J. Physiol. 398:277-289, 1988.

Berne, R.M. Cardiac nucleotides in hypoxia: possible role in regulation of coronary blood flow. Am. J. Physiol. 204:317-322, 1963.

Bevan, R.D., A. Clementson, E. Joyce, and J.A. Bevan. Sympathetic denervation of resistance arteries increases contraction and decreases relaxation to flow. Am. J. Physiol. 264(2 pt 2):H490-H494, 1993.

Blitzer, M.L., L. Lee, and M.A. Creager. Endothelium-derived nitric oxide mediates hypoxic vasodilation of resistance vessels in humans. Am. J. Physiol. 271:H1182-H1185, 1996.

Boegehold, M.A. Flow-dependent arteriolar dilation in normotensive rats fed low- or high-salt diets. Am. J. Physiol. 269:HI407-HI414, 1995.

Boegehold, M.A. Heterogeneity of endothelial function within the circulation. Curr. Opin. Nephrol. Hypertens. 7(1):71-78, 1998). 
Boegehold, M.A. and P.C. Johnson. Periarteriolar and tissue $\mathrm{PO}_{2}$ during sympathetic escape in skeletal muscle. Am. J. Physiol. 254:H929-H936, 1988a.

Boegehold, M.A. and P.C. Johnson. Response of arteriolar network of skeletal muscle to sympathetic nerve stimulation. Am. J. Physiol. 254:H919-H928, 1988b.

Bohlen, H.G. Intestine Microcirculation. In "Clinically Applied Microcirculation Research" eds. J.H. Baker, G.L. Anderson, and M.D. Menger. New York: CRC Press pgs. 227-237,1995.

Bohlen, H.G. Integration of intestinal structure, function, and microvascular regulation. Microcirculation 5:27-37, 1998a.

Bohlen, H.G. Mechanism of increased vessel wall nitric oxide concentrations during intestinal absorption. Am. J. Physiol. 275:H542-H550, 1998b.

Bohlen, H.G. and R.W. Gore. Comparison of microvascular pressures and diameters in the innervated and denervated rat intestine. Microvasc. Res. 14:251-264,1977.

Bohlen, H.G. and J.M. Lash. Intestinal absorption of sodium and nitric oxidedependent vasodilation interact to dominate resting vascular resistance. Circ. Res. 78:231-237, 1996.

Bohlen, H.G. and G.P. Nase. Dependence of intestinal arteriolar regulation on flow-dependent nitric oxide formation. Am. J. Physiol. 279:H2249-H2258, 2000.

Bohlen, H.G. and G.P. Nase. Arteriolar nitric oxide concentration is decreased during hyperglycemia-induced $\beta$ II PKC activation. Am. J. Physiol. 280:H621H627, 2001.

Bohlen, H.G., H. Henrich, R.W. Gore, and P.C. Johnson. Intestinal muscle and mucosal blood flow during direct sympathetic stimulation. Am. J. Physiol. 235(1):H40-H45, 1978.

Bordeau-Martini, J., C.L. Odoroff, and C.R. Honig. Dual effect of oxygen on magnitude and uniformity of coronary intercapillary distance. Am. J. Physiol. 226:800-810, 1974.

Bornstein, J.C., J.B. Furness, and M. Costa. Sources of excitatory synaptic inputs to nerurochemically identified submucous neurons of guinea-pig small intestine. J. Auton. Nerv. Syst. 18 (1):83-91, 1987. 
Borst, M.M. and J. Schrader. Adenine nucleotide release from isolated perfused guinea pig hearts and extracellular formation of adenosine. Circ. Res. 68 (3):797-806, 1991.

Brake, A.J., M.J. Wagenbach, and D. Julius. New structural motif for ligandgated ion channels defined by ionotropic ATP receptor. Nature 371:519-523, 1994.

Bredt, D.S. and S.H. Snyder. Isolation of nitric oxide synthetase, a calmodulinrequiring enzyme. Proc. Natl. Acad. Sci. 87:682-685,1991.

Bredt, D.S., P.M. Hwang, C.E. Glatt, C. Lowenstein, R.R. Reed, and S.H. Snyder. Cloned and expressed nitric oxide synthase structurally resembles cytochrome P-450 reductase. Nature 351:714-718, 1991.

Brenman, J.E., D.S. Chao, H. Xia, K. Aldape, and D.S. Bredt. Nitric oxide synthase complexed with dystrophin and absent from skeletal muscle sarcolemma in Duchenne muscular dystrophy. Cell 82:743-752, 1995.

Bryan, P.T. and J.M. Marshall. Adenosine receptor subtypes and vasodilatation in rat skeletal muscle during systemic hypoxia: a role for $A_{1}$ receptors. J. Physiol. 514.1: 151-162, 1999a.

Bryan, P.T. and J.M. Marshall. Cellular mechanisms by which adenosine induces vasodilatation in rat skeletal muscle: significance for systemic hypoxia. J. Physiol. 514.1: 163-175, $1999 \mathrm{~b}$.

Buckley, N.M., S. Diamant, I.D. Frasier, and K. Owusu. Histamine or adenosine blockade alters intestinal blood flow autoregulation in swine. Am. J. Physiol. 254 (2pt1):G156-G161, 1988.

Burnstock, G. Do some nerve cells release more than one transmitter? Neuroscience 1:239-248, 1976.

Burnstock, G. A basis for distinguishing two types of purinergic receptor. In Cell Membrane Receptors for Drug and Hormones: A multisciplinary approach, eds. R Von Straub and L. Bolis. pgs. 107-118. Raven Press, New York, 1978.

Burnstock, G. and C. Kennedy. Is there a basis for distinguishing two types of $\mathrm{P}_{2}$-purinoceptor? Gen. Pharmacol. 16:433-440, 1985.

Busse, R., U. Pohl, C. Kellner, U. Klemm. Endothelial cells are involved in the vasodilatory response to hypoxia. Pflügers Arch. 397(1):78-80, 1983. 
Busse, R., A. Mulsch, I. Fleming, and M. Hecker. Mechanisms of nitric oxide release from the vascular endothelium. Circ Res. (suppl V):V18-V25, 1993.

Carpenter, L.B., R.S. Baker, S. Greenberg, and K.E. Clark. The role of nitric oxide in mediating adenosine-induced increases in uterine blood flow in the oophorectomized nonpregnent sheep. Am. J. Obstet. Gynecol. 183:46-51, 2000.

Carrier, G.O., L.C. Fuchs, A.P. Winecoff, A.D. Giulumian, and R.E. White. Nitrovasodilators relax mesenteric microvessels by cGMP-induced stimulation of Ca-activated K channels. Am. J. Physiol. 273:H76-H84, 1997.

Chataigneau, T., M. Feletou, C. Thollon, N. Villeneuve, J.P. Vilaine, J. Duhault, and P.M. Vanhoutte. Cannabinoid $\mathrm{CB}_{1}$ receptor and endotheliumdependent hyperpolarization in guinea-pig carotid, rat mesenteric and porcine coronary arteries. Br. J. Pharmacol. 123:968-974, 1998.

Chatziantoniou, C. and W.J. Arendshorst. Prostaglandin interactions with angiotensin, norepinephrine, and thromboxane in rat renal vasculature. Am. J. Physiol. 262:F68-F76, 1992.

Cho, H.J., Q.W. Xie, J. Calaycay, R.A. Mumford, K.M. Swiderek, T.D. Lee, and C. Nathan. Calmodulin is a subunit of nitric oxide synthase from macrophages. J. Exp. Med. 176:599-604, 1992.

Cohen, R.A. and R.M. Weisbrod. The endothelium inhibits norepinephrine release from adrenergic nerves of the rabbit carotid artery. Am. J. Physiol. 254:H871-H878, 1988.

Cohen, M.V., R.S. Walsh, M. Goto, and J.M. Downey. Hypoxia preconditions rabbit myocardium via adenosine and catecholamine release. J. Mol. Cell Cardiol. 27:1527-1534, 1995.

Conant, A.R. and S.M. Jarvis. Nucleoside influx and efflux in guinea-pig ventricular myocytes. Biochem. Pharmacol. 48:873-880, 1994.

Corriu, C., M. Feletou, E. Canet, and P.M. Vanhoutte. Inhibitors of the cytochrome P450-monooxygenase and endothelium-dependent hyperpolarization in the guinea-pig isolated carotid artery. Br. J. Pharmacol. 117:607-610, 1996a.

Corriu, C., M. Feletou, E. Canet, and P.M. Vanhoutte. Endothelium-derived factors and hyperpolarization of the isolated carotid artery of the guinea-pig. Br. J. Pharmacol. 119:959-964, 1996b. 
Costa, F., N.J. Christensen, G. Farley, and I. Biaggioni. NO modulates norepinephrine release in human skeletal muscle: implications for neural preconditioning. Am. J. Physiol. Regul. Integr. Comp. Physiol. 280 (5):R1494R1498, 2001.

Cowan, C.L. and R.A. Cohen. Two mechanisms mediate relaxation by bradykinin of pig coronary artery: NO-dependent and independent responses. Am. J. Physiol. 261:H830-H835, 1991.

Danialou, G., E. Vicaut, A. Sambe, M. Aubier, and J. Boczkowski. Predominant role of $A_{1}$ receptors in mediating adenosine induced vasodilatation of rat diaphragmatic arterioles: involvement of nitric oxide and the ATPdependent K ${ }^{+}$channels. Br. J. Pharmacol. 121(7):1355-1363, 1997.

Davies, P.F. Flow-mediated endothelial mechanotransduction. Physiol. Rev. 75:519-560, 1995.

Davis, C.A., A.J. Sherman, Y. Yaroshenko, K.R. Harris, S. Hedjbeli, M.A. Parker, and F.J. Klocke. Coronary vascular responsiveness to adenosine is impaired additively by blockade of nitric oxide synthesis and a sulfonylurea. J. Am. Coll. Cardiol. 31:816-820, 1998.

Decking, K.M., G. Schlieper, K. Kroll, and J. Schrader. Hypoxia-induced inhibition of adenosine kinase potentiates cardiac adenosine release. Circ. Res. 81; 154-164, 1997.

De Mey, J.G. and P.M. Vanhoutte. Role of the intima in cholinergic and purinergic relaxation of isolated canine femoral arteries. J. Physiol. 316:347-355, 1981.

Desjardins, C. and B. Duling. Microvessel hematocrit: Measurement and implications for capillary oxygen transport. Am. J. Physiol. 252:H494-H503, 1987.

Dietrich, H.H., M.L. Ellsworth, R.S. Sprague, and R.G. Dacey. Red blood cell regulation of microvascular tone through adenosine triphosphate. Am. J. Physiol. 278:H1294-H1298, 2000.

Di Virgilio, F., P. Chiozzi, and S. Falzoni. Cytolytic P2X purinoceptors. Cell Death Differ. 5:191-199, 1998. 
Di Virgilio, F., P. Chiozzi, D. Ferrari, S. Falzoni, J.M. Sanz, A. Morelli, M. Torboli, G. Bolognesi, and O.R. Baricordi. Nucleotide receptors: an emerging family of regulatory molecules in blood cells. Blood 97 (3):587-600, 2001.

Drury, A.N. and A. Szent-Györgyi. The physiological activity of adenine compounds with special reference to their action upon the mammalian heart. J. Physiol. 68:213-237, 1929.

Dubey, R.K., D.G. Gillespie, and E.K. Jackson. Cyclic AMP-adenosine pathway induces nitric oxide synthesis in aortic smooth muscle cells. Hypertension 31 (pt 2):296-302, 1998.

Dubyak, G.R. and C. el-Moatassim. Signal transduction via P2-purinergic receptors for extracellular ATP and other nucleotides. AM. J. Physiol. 265 (3 pt 1):C577-C606, 1993.

Duling, B.R. and R,M. Berne. Longitudinal gradient in periarteriolar oxygen tension. A possible mechanism for the participation of oxygen in the local regulation of blood flow. Circ. Res. 27:669-678, 1970.

Duling, B.R. and C. Desjardins. Capillary hematocrit - What does it mean? New Physiol. Sci. 2:66, 1987.

Duling, B.R., W. Kushinsky, and M. Whal. Measurement of perivascular $\mathrm{pO}_{2}$ in the vicinity of pial vessels in the cat. Pflügers Arch. 383:29-34, 1979.

Duza, T., C.L. Murrant, and I.H. Sarelius. ATP induced changes in arteriolar endothelial cell calcium are dependent on the local vasomotor response. (Abstract) FASEB J. 15 (4 pt 1):A31, 2001.

Ellsworth, M.L. The red blood cell as an oxygen sensor: what is the evidence? Acta Physiol. Scand. 168 (4):551-9, 2000.

Ellsworth, M.L. and R.N. Pittman. Arterioles supply oxygen to capillaries by diffusion as well as convection. Am. J. Physiol. 258:H1240-H1243, 1990.

Ellsworth, M.L, T. Forrester, C.G. Ellis, and H.H. Dietrich. The erythrocyte as a regulator of vascular tone. Am. J. Physiol. 269:H2155-H2161, 1995.

Evans, R.J. and A. Surprenant. Vasoconstriction of guinea pig submucosal arterioles following sympathetic nerve stimulation is mediated by the release of ATP. Br. J. Pharmacol. 106:242-249, 1992. 
Eriksson, E. and B. Lisander. Changes in precapillary resistance in skeletal muscle vessels studied by intravital microscopy. Acta. Physiol. Scand. 84:295305, 1972.

Fisslthaler, B., I. Fleming, and R. Busse. EDHF: a cytochrome P450 metabolite in coronary arteries. Sem. Perinatol. 24 (1):15-19, 2000.

Folkow, B., D.H. Lewis, O. Lundgren, S. Mellander, and I. Wallentin. The effect of the sympathetic vasoconstrictor fibre stimulation on the intestinal resistance and capacitance vessels. Acta. Physiol. Scand. 61:445-457,1964.

Folkow, B., R. Sonnenschein, and D. Wright. The loci of neurogenic and metabolic effects on precapillary vessels of skeletal muscle. Acta. Physiol. Scand. 81:459-471,1971.

Forrester, T. and C.A. Williams. Release of adenosine triphosphate from isolated adult heart cells in response to hypoxia. J. Physiol. 268:371-390, 1977.

Förstermann, U., G. Trogisch and R. Busse. Species-dependent differences in the nature of endothelium-derived relaxing factor. Eur. J. Pharmacol. 106:639643, 1985.

Fredricks, K.T., Y. Liu, N.J. Rusch, and J.H. Lombard. Role of endothelium and arterial $\mathrm{K}^{+}$channels in mediating hypoxic dilation middle cerebral arteries. Am. J. Physiol. 267:H580-H586, 1994a.

Fredricks, K.T., Y. Liu and J.H. Lombard. Response of extraparenchymal resistance arteries of rat skeletal muscle to reduced $\mathrm{PO}_{2}$. Am. J. Physiol. 267:H706-H715, 1994b.

Fredholm, B.B., M.P. Abbracchio, G. Burnstock, J.W. Daly, T.K. Harder, K.A. Jacobson, P. Leff, and M.VI. Williams. Nomenclature and classification of purinoceptors. Pharmacol. Rev. 46:143-156, 1994.

Fredholm, B.B., G. Arslan, L. Halldner, B. Kull, G. Schulte, and W. Wasserman. Structure and function of adenosine receptors and their genes. Naunyn Schmiedebergs Arch. Pharmacol. 362 (4-5):364-374, 2000.

Freissmuth, M., E. Selzer, and W. Schütz. Interactions of purified bovine brain $A_{1}$-adenosine receptors with G-proteins. Reciprocal modulation of agonist and antagonist binding. Biochem. J 275:651-656, 1991. 
Freund, S., M. Ungerer, and M.J. Lohse. $A_{1}$ adenosine receptors expressed in $\mathrm{CHO}$-cells coupled to adenylyl cyclase and to phospholipase C. NaunynSchmiedeberg's Arch. Pharmacol. 350 (1):49-56, 1994.

Friebel, M., K.E. Klotz, K. Ley, P. Gaehtgens and A.R. Pries. Flow-dependent regulation of arteriolar diameter in rat skeletal muscle in situ: role of endotheliumderived relaxing factor and prostanoid. J. Physiol. 483:715-726,1995.

Fukao, M., Y. Hattori, M. Kanno, I. Sakuma, and A. Kitabatake. Evidence against a role of cytochrome P450-derived arachidonic acid metabolites in endothelium-dependent hypolarization by acetylcholine in rat isolated mesenteric artery. Br. J. Pharmacol. 120:439-446, 1997.

Fulton, D., K. Mahboudi, J.C. McGigg, and J. Quilley. Cytochrome P450dependent effects of bradykinin in the rat heart. Br. J. Pharmacol. 114:99-102, 1995.

Fung, Y.C. Stochastic flow in capillary blood vessels. Microvasc. Res. 5:34-48, 1973.

Furchgott, R.F. and J.V. Zawadzki. The obligatory role of endothelial cells in the relaxation of arterial smooth muscle by acetylcholine. Nature 288:373-376, 1980.

Furchgott, R.F., P.D. Cherry, J.V. Zawadzki, and D. Jothianandan. Endothelial cells as mediators of vasodilation of arteries. J. Cardiovasc. Pharmacol. 2:S336-S343, 1984.

Furness, J.B. The adrenergic innervation of the vessels supplying and draining the gastrointestinal tract. Z. Zellforsch. Mikrosk. Anat. 113:67-82,1971.

Furness, J.B. and J.M. Marshall. Correlation of the directly observed responses of mesenteric vessels of the rat to nerve stimulation and noradrenaline with the distribution of adrenergic nerves. J. Physiol. 239:7588,1974 .

Gaehtgens, P. Regulation of capillary hematocrit. Int. Microcirc. Clin. Exp. 3:147-160, 1984. 
Gao, Z., T. Chen, M.J. Weber, and J. Linden. $A_{2 B}$ adenosine and $P 2 Y_{2}$ receptors stimulate mitogen-activated protein kinase in human embryonic kidney293 cells. Cross-talk between cyclic AMP and protein kinase C pathways. J. Biol. Chem. 274 (9):5972-5980, 1999.

Garcia-Cardeña, G., P. Oh, J. Liu, J.E. Schnitzer, and W.C. Sessa. Targeting of nitric oxide synthase to endothelial cell caveolae via palmitoylation: implications for nitric oxide signaling. Proc. Natl. Acad. Sci. 93:6448-6453, 1996.

Garcia-Pascual, A., A. Labadia, E. Jimenez, and G. Costa. Endotheliumdependent relaxation to acetylcholine in bovine oviductal arteries: mediation by nitric oxide and changes in apamin-sensitive $\mathrm{K}^{+}$conductance. Br. J. Pharmacol. 115:1221-1230, 1995.

Gardiner, S.M., A.M. Compton, T. Bennett, R.M. Palmer, and S. Moncada. Regional haemodynamic changes during oral ingestion of NG-monomethyl-Larginine or NG-nitro-L-arginine methyl ester in conscious Brattleboro rats. Br. J. Pharmacol. 101 (1):10-12, 1990.

Gaskell, W.H. On the vasomotor nerves of striated muscles. J. Anat. Physiol. 10:720-753, 1876.

Gaskell, W.H. On the changes of the blood-stream in muscles through stimulation of their nerves. J. Anat. Physiol. 10:360-402, 1876.

Gebremedhin, D., P. Bonnet, A.S. Greene, S.K. England, N.J. Rusch, J.H. Lombard, and D.R. Harder. Hypoxia increase the activity of $\mathrm{Ca}^{2+}$-sensitive $\mathrm{K}^{+}$ channels incat cerabral arterial muscle cell membranes. Pflügers Arch. 428:621630, 1994.

Gerritsen, M.E. Functional heterogeneity of vascular endothelial cells. Biochemical Pharmacol. 36(17):2701-2711, 1987.

Gerwins, P. and B.B. Fredholm. Activation of adenosine $A_{1}$ and bradykinin receptors increases protein kinase $C$ and phospholipase $D$ activity in smooth muscle cells. Naunyn-Schmiedeberg's Arch. Pharmacol. 351:186-193, 1995.

Gooenwardene, I.P. and F. Karim. Attenuation of exercise vasodilation by adenosine deaminase in anaesthetized dogs. J. Physiol. 442:65-79, 1991. 
Gräser, T. and G.M. Rubanyi. Different mechanisms of hypoxic relaxation in canine coronary arteries and rat abdominal aortas. J. Cardiovasc. Pharmacol. (Suppl. 12): S117-S119, 1992.

Greenberg, S., F.P.J. Diecke, K. Peevy and T.P. Tanaka. The endothelium modulates adrenergic neurotransmission to canine pulmonary arteries and veins. Eur. J. Pharmacol. 162:67- 80, 1989.

Griendling, K.K., T. Tsuda, and R.W. Alexander. Endothelin stimulates diacylglycerol accumulation and activates protein kinase $C$ in cultured vascular smooth muscle cells. J. Biol. Chem. 264:8237-8240, 1989.

Griffith, T .M., D.B. Edwards, M.J. Lewis and A.H. Henderson. The nature of endothelium- derived vascular relaxant factor. Nature 308:645-647,1984.

Gudi, S.R., C.B. Clark, and J.A. Frangos. Fluid flow rapidly activates G proteins in human endothelial cells. Involvement of $G$ proteins in mechanochemical signal transduction. Circ. Res. 79 (4):834-839, 1996.

Gutierrez, G. The rate of oxygen release and its effect on capillary $\mathrm{O}_{2}$ tension: a mathematical analysis. Respir. Physiol. 63:79-96, 1986.

Gutierrez, G., R.J. Pohil, and R. Strong. Effect of flow on $\mathrm{O}_{2}$ consumption during progressive hypoxemia. J. Appl. Physiol. 65(2):601-607, 1988.

Häbler, H.J., G. Wasner, and W. Jänig. Attenuation of neurogenic vasoconstriction by nitric oxide in hindlimb microvascular beds of the rat in vivo. Hypertension 30:957-961, 1997.

Hampl, V., D.N. Cornfield, N.J. Cowan, and S.L. Archer. Hypoxia potentiates nitric oxide synthesis and transiently increases cytosolic calcium levels in pulmonary artery endothelial cells. Eur Respir. J. 8 (4):513-514, 1995.

Harden, T.K., J.L. Boyer, and R.A. Nicholas. P2-purinergic receptors: subtypeassociated signaling responses and structure. Annu. Rev. Pharmacol. Toxicol. 35:541-579, 1995.

Harder, D.R., J. Narayanan, E.K. Birks, J.F. Liard, J.D. Imig, J.H. Lombard, A.R. Lange, and R.J. Roman. Identification of a putative microvascular oxygen sensor. Circ. Res. 79: 54-61, 1996. 
Hassoun, P.M., F.S. Yu, A.L. Shedd, J.J. Zulueta, V.J. Thannickal, J.J. Lanzillo, and B.L. Fanburg. Regulation of endothelial cell xanthine dehydrogenase xanthine oxidase gene expression by oxygen tension. Am. J. Physiol. 266 (2 Pt 1):L163-L171, 1994.

Haynes, W.G. and D.J. Webb. Venoconstriction to endothelin-1 in humans: the role of calcium and potassium channels. Am. J. Physiol. 265:H1676-H1691, 1993.

Haynes, W.G. and D.J. Webb. Endothelin as a regulator of cardiovascular function in health and disease. J. Hypertens. 16:1081-1098, 1998.

Headrick, J.P., G.P. Matherne, and R.M. Berne. Myocardial adenosine formation during hypoxia: effects of ecto-5"-nucleotidase inhibition. Mol. Cell Cardiol. 24:295-303, 1992.

Hecker, M., I. Sigle, H. Macarthur, and J.R. Vane. Role of intracellular thiols in release of EDRF from cultured endothelial cells. Am. J. Physiol. 262:H888-H896, 1992.

Hedqvist, P. Prostaglandin-induced inhibition of vascular tone and reactivity in the cat's hindleg in vivo. Eur. J. Pharmacol. 17: 157-162, 1972.

Hein, T.W. and L. Kuo. CAMP-independent dilation of coronary arterioles to adenosine: role of nitric oxide, $\mathrm{G}$ proteins, and $\mathrm{K}_{\text {ATP }}$ channels. Circ. Res. 85:634642, 1999.

Herget, J., J. Wilhelm, J. Novotna, A. Eckhardt, R. Vytasek, L. Mrazkova, and M. Ostadal. A possible role of the oxidant tissue injury in the development of hypoxic pulmonary hypertension. Physiol. Res. 49 (5):493-501, 2000.

Hester, R.L., A. Eraslan, and Y. Saito. Differences in EDNO contribution to arteriolar diameters at rest and during functional dilation in striated muscle. Am. J. Physiol. 265:HI46- H151, 1993.

Hilton, S.M., O. Hudlicka, and J.M. Marshall. Possible mediators of functional hyperaemia in skeletal muscle. J. Physiol. 282:131-147, 1978.

Hirata, Y., H. Yoshimi, S Takata, T.X. Watanabe, S. Kumagi, and K. Nakajima. Cellular mechanisms of action by a novel vasoconstrictor endothelin in cultured rat vascular smooth muscle cells. Biochem. Biophys. Res. Commun. 154:868-875, 1988. 
Hirst, G.D. and F.R. Edwards. Sympathetic neuroeffector transmission in arteries and arterioles. Physiol. Rev. 69 (2):546-604, 1989.

Hoka, S., H. Arimura, Z.J. Bosnjak, and J.P. Kampine. Regional venous outflow, blood volume, and sympathetic nerver activity during hypercapnia and hypoxic hypercapnia. Can. J. Physiol. Pharmacol. 70 (7):1032-1039, 1992.

Holton, P. The liberation of adenosine triphosphate on antidromic stimulation of sensory nerves. J. Physiol. 145:494-504, 1959.

Honig, C.R., C.L. Odoroff, and J.L. Frierson. Capillary recruitment in exercise: rate, extent, uniformity, and relation to blood flow. Am. J. Physiol. 238:H31-H42, 1980.

Honig, C.R. and C.L. Odoroff. Calculated dispersion of capillary transit times: significance for oxygen exchange. Am. J. Physiol. 27:H199-H208, 1984.

Ignarro, L.J., R.E. Byrns, G.M. Buga, and K.S. Wood. Endothelium-derived relaxing factor from pulmonary artery and vein possesses pharmacological and chemical properties that are identical to those from nitric oxide radical. Circ. Res. 61:866-879,1987.

Illiano, S.C., T. Nagao, and P.M. Vanhoutte. Calmidazolium, a calmodulin inhibitor, inhibits endothelium-dependent relaxations resistant to nitro-L-arginine in the canine artery. Br. J. Pharmacol. 107:387-392, 1992.

Inscho, E.W. Purinoceptor-mediated regulation of the renal microvasculature. J. Auton. Pharmacol. 16 (6):385-388, 1996.

Ishibashi, Y., D.J. Duncker, J. Zhang, and R.J. Bache. ATP-sensitive $\mathrm{K}^{+}$ channels, adenosine, and nitric oxide-mediated mechanisms account for coronary vasodilation during exercise. Circ. Res. 82:346-359, 1998.

Ishida, T., T.E. Peterson, N.L. Kovach, and B.C. Berk. MAP kinase activation by flow in endothelial cells. Role of $\beta 1$ integrins and tyrosine kinases. Circ. Res. 79:310-316, 1996.

Ivanov, K.P., M.K. Kalinina, and Y.I. Levkovich. Microcirculation velocity changes under hypoxia in brain, muscle, liver, and their physiological significance. Microvasc. Res. 30:10-18, 1985. 
Ivanov, K.P., A.N. Derii, M.O. Samoilov, and D.G. Semenov. Direct measurement of oxygen tension at the surface of arterioles, capillaries, and venules of the cerebral cortex. Pflügers Arch. 393:118-120, 1982.

Jacobson, K.A. and F. Suzuki. Recent developments in selective agonists and antagonists acting at purine and pyrimidine receptors. Drug Devel. Res. 39:289300, 1996.

Jagger, J.E., R.M. Bateman, M.L. Ellsworth, and C.G. Ellis. Role of erythrocyte in regulating local $\mathrm{O}_{2}$ delivery mediated by hemoglobin oxygenation. Am. J. Physiol. 280:H2833-H2839, 2001.

Janigro, D., T.S. Nguyen, J. Meno, G.A. West, and H.R. Winn. Endotheliumdependent regulation of cerebrovascular tone by extracellular and intracellular ATP. Am. J. Physiol. 273:H878-H885, 1997.

Jimenez, A.H., M.A. Tanner, W.M. Caldwell, and P.R. Myers. Effects of oxygen tension on flow-induced vasodilation in porcine coronary resistance arterioles. Microvasc. Res. 51: 365-377, 1996.

Jo, H., K. Sipos, Y.M. Go, R. Law, J. Rong, and J.M. McDonald. Differential effect of shear stress on extracellular signal-regulated kinase and $\mathrm{N}$-terminal jun kinase in endothelial cells. Gi2- and Gbeta/gamma-dependent signaling pathways. J. Biol. Chem. 272:1395-1401, 1997.

Jones, C.H., D.V. DeFily, J.L. Patterson, and W.M. Chilian. Endotheliumdependent relaxation competes with $\alpha_{1^{-}}$and $\alpha_{2}$-adrenergic constriction in the canine epicardial coronary microcirculation. Circulation 87:1264-1274, 1993.

Kadowitz, P.J., C.S. Sweet, and M.J. Brody. Potentiation of adrenergic responses by angiotensin, prostaglandin $\mathrm{F}_{2 \alpha}$ and cocaine. J. Pharmacol. Exp. Ther. 176:167-173, 1971.

Kaminski, P.M. and K.G. Proctor. Attenuation of no-reflow phenomenon, neutrophil activation, and reperfusion injusry in intestinal microcirculation by topical adenosine. Circ. Res. 65 (2):426-435, 1989.

Kanaide, H. Endothelin regulation of vascular tonus. Gen. Pharmacol. 27(4):559-563, 1996. 
Karim, F. and I.P. Goonewardene. The role of adenosine in functional hyperemia in the coronary circulation of anaesthetized dogs. J. Physiol. 490 (pt 3):793-803, 1996.

Katusic, Z.S. and J.T. Sheperd. Endothelium-derived vasoactive factors II: Endothe1ium- dependent contraction. Hypertension Suppl III:III86-III92, 1991.

Katusic, Z.S., J.T. Sheperd and P.M. Vanhoutte. Endothelium-dependent contractions to calcium ionophore A23187, arachidonic acid and acetylcholine in canine basilar arteries. Stroke 19:476-479,1988.

Katuski, S. W. Arnold, C. Mittal, and F. Murad. Stimulation of guanylate cyclase by sodium nitroprusside, nitroglycerin and nitric oxide in various tissue preparations and comparison to the effects of sodium azide and hydroxylamine. J. Cyclic Nucleotide Protein Phosphor. Res. 3:23- 35, 1977.

Kennedy, C., V.L. Saville, and G. Burnstock. The contributions of noradrenaline and A TP to the responses of the rabbit central ear artery to sympathetic nerve stimulation depend on the parameters of stimulation. Eur. J. Pharmacol. 122:291-300,1986.

Kety, S.S. Determinants of tissue oxygen tension. Fed. Proc. 16:666-670, 1957.

King-VanVlack, C.E., S.E. Curtis, and J.D. Mewburn. Endothelial modulation of neural sympathetic vascular tone in canine skeletal muscle. J. Appl. Physiol. 85(4):1362-1367, 1998.

Klatt, P., K. Schmidt, and B. Mayer. Brain nitric oxide synthase is a haemoprotein. Biochem. J. 288:15-17, 1992.

Kleppisch, T. and M.T. Nelson. Adenosine activates ATP-sensitive potassium channels in arterial myocytes via $A_{2}$ receptors and cAMP-dependent protein kinase. Proc. Natl. Acad. Sci. 92:12441-12445, 1995.

Knowles, R.G. and S. Moncada. Nitric oxide synthases in mammals. Biochem. J. 298:249-258, 1994.

Kollai, M. and K. Koizumi. Patterns in single unit activity in sympathetic postganglionic nerves. J. Auton. Nerv. Syst. I:299-311, 1980. 
Koller, A. and G. Kaley. Endothelium regulates skeletal muscle microcirculation by a blood flow velocity-sensing mechanism. Am. J. Phyisol. 258:H916-H920, 1990.

Koller, A., D. Sun, A. Huang and G. Kaley. Shear stress and endothelial prostaglandins mediate flow-dependent dilation of rat gracilis muscle arterioles. Am. J. Physiol. 267:H326- H332,1994.

Koller, A., E.J. Messina, M.S. Wolin, and G. Kaley. Endothelial impairment inhibits prostaglandin and EDRF-mediated arteriolar dilation in vivo. AM. J. Physiol. 257:H1966-H1970, 1989.

Koller, A., J.M. Rodenburg, M.S. Wolin, E.J. Messina, and G. Kaley. Modified arteriolar responses to ATP after impairment of endothelium by light-dye techniques in vivo. Microvasc. Res. 41 (1):63-72, 1991.

Komalavilas, P. and T.M. Lincoln. Phosphorylation of the inositol 1,4,5triphosphate receptor by cyclic GMP-dependent protein kinase. J. Biol. Chem. 269:8701-8707, 1994.

Komalavilas, P. and T.M. Lincoln. Phosphorylation of the inositol 1,4,5triphosphate receptor. Cyclic GMP-dependent protein kinase mediates cAMP and cGMP dependent phosphorylation in the intact rat aorta. . J. Biol. Chem. 271:21933-21938, 1996.

Konduri, G.G. and S. Mital. Adenosine and ATP cause nitric oxide-dependent pulmonary vasodilation in fetal lambs. Biol. Neonate 78:220-229, 2000.

Korenaga, R., J. Ando, A. Ohtsuka, I. Sakuma, W. Yang, T. Toyo-oka, and A. Kamiya. Close correlation between cytoplasmic $\mathrm{Ca}^{++}$levels and release of an endothelium-derived relaxing factor from cultured endothelial cells. Cell Struct. Funct. 18 (2):95-104, 1993.

Krogh, A. The number and distribution of capillaries in muscles with calculations of the oxygen pressure head necessary for supplying the tissues. J. Physiol. 52:409-415, 1919.

Kroll, K., M.K. Kelm, K.F. Burrig, and J. Schrader. Transendothelial transport and metabolism of adenosine and inosine in the intact rat aorta. Circ. Res. 64:1147-1157, 1989. 
Kuan, C. and E.K. Jackson. Role of adenosine in noradrenergic neurotransmission. Am. J. Physiol. 255:H386-H393, 1988.

Kuchan, M.J., H. Jo, and J.A. Frangos. Role of G proteins in shear stressmediated nitric oxide production by endothelial cells. Am. J. Physiol. 267:C753C758, 1994.

La, M. and J.J. Reid. Endothelin-1 and the regulation of vascular tone. Clin. Exp. Pharmacol. Physiol. 22:315-323, 1995.

Lash, J.M. and H.G. Bohlen. Acute hyperglycemia depresses arteriolar NO formation in skeletal muscle. Am. J. Physiol. 277:H1513-H1520, 1999.

Laurikainen, E.A., T. Ren, J.M. Miller, A.L. Nuttall, and W.S. Quirk. The tonic sympathetic input to the cochlear vasculature in guinea pig. Hear Res. 105(12):141-145, 1997.

Lautt, W.W., D.J. Legare, and L.K. Lockhart. Vascular escape from vasoconstriction and post-stimulatory hyperemia in the superior mesenteric artery of the cat. Can. J. Physiol. Pharmacol. 66 (9):1174-1180, 1988.

Li, H. and U. Forstermann. Nitric oxide in the pathogensis of vascular disease. J. Pathol. 190 (3):244-254, 2000.

Li, J., R.A. Fenton, B.S. Cutler, and J.G. Dobson. Adenosine enhances nitric oxide production by vascular endothelial cells. Am. J. Physiol. 269:C519-C523, 1995.

Li, J., R.A. Fenton, H.B. Wheeler, C.C. Powell, B.D. Peyton, B.S. Cutler, and J.G. Dobson. Adenosine $A_{2 A}$ receptors increase arterial endothelial cell nitric oxide. J. Surg. Res. 80:357-364, 1998.

Li, P.L., A.P. Zou, and W.B. Campbell. Regulation of potassium channels in coronary arterial smooth muscle by endothelium-derived vasodilators. Hypertension 29 (1 Pt 2):262-267, 1997.

Lincoln, T.M. and T.L. Cornwell. Intracellular cyclic GMP receptor proteins. FASEB J. 7:328-338, 1993. 
Linden, J., T. Thai, H. Figler, X. Jin, and A.S. Robeva. Characterization of human $A_{2 B}$ adenosine receptors: radioligand binding, western blotting, and coupling to $G_{\mathrm{q}}$ in human embryonic kidney 293 cells and HMC-1 mast cells. Mol. Pharmacol. 56:705-713, 1999.

Linderman, J.R. and M.A. Boegehold. Modulation of arteriolar sympathetci constriction by local nitric oxide: onset during rapid juvenile growth. Microvasc. Res. 56 (3):192-202, 1998.

Londos, C., D.M. Cooper and J. Wolff. Subclasses of external adenosine receptors. Proc. Natl. Ac. Sci. 77:2551-2554, 1980.

Lückhoff, A., U. Pohl, A. Mülsch, and R. Busse. Differential role of extra- and intracellular calcium in the release of EDRF and prostacyclin from cultured endothelial cells. Br. J. Pharmacol. 95:189-196, 1988.

Lustig, K.D., A.K. Shiau, A.J. Brake, and D. Julius. Expression cloning of an ATP receptor from mouse neuroblastoma cells. Proc. Natl. Ac. Sci. 90:51135117, 1993.

Mackie, B.G. and R.L. Terjung. Blood flow to different skeletal muscle fiber types during contraction. Am. J. Physiol. 242:H265-H275, 1983.

Marletta, M.A. Mammalian synthesis of nitrite, nitrate, nitric oxide, and Nnitrosating agents. Chem. Res. Toxicol. 1:249-257, 1988.

Marlette, M.A. Nitric oxide synthase structure and mechanism. J. Biol. Chem. 268:12231-12234, 1993.

Marshall, J.M. The influence of the sympathetic nervous system on individual vessels of the microcirculation of skeletal muscle of the rat. J. Physiol. 332:169$186,1982$.

Marshall, J.J. and H.A. Kontos. Endothelium-derived relaxing factors; A perspective from in vivo data. Hypertension 16:371-386, 1990.

Martin, W., R.F. Furchgott, G.M. Villani, and D. Jothianadine. Depression of contractile responses in rat aorta by spontaneously released endotheliumderived relaxing factor. J. Pharmacol. Exp. Ther. 237(2):529-538,1986.

Masters, B.S.S. Nitric Oxide synthases: Why so complex? Annu. Rev. Nutr. 14:131-145, 1994. 
Mateo, A.O. and M.A.A. de Artiñano. Nitric oxide reactivity and mechanisms involved in its biological effects. Pharmacol. Res. 42:421-427, 2000.

McCulloch, K.M., O.N. Osipenko, and A.M. Gurney. Oxygen-sensing potassium currents in pulmonary artery. Gen. Pharmacol. 32:403-411, 1999.

McCullough, W.T., D.M. Collins, and M.L. Ellsworth. Arteriolar responses to extracellular ATP in striated muscle. Am. J. Physiol. 272:H1886-H1891, 1997.

McMillan, K., D.S. Bredt, D.J. Hirsch, S.H. Snyder, J.E. Clark, and B.S.S. Masters. Cloned, expressed rat cerebellar nitric oxide synthase contains stoichiometric amounts of heme, which binds carbon monoxide. Proc. Natl. Acad. Sci. 89:11141-11145, 1992.

Meghji, P. Storage, release, uptake, and inactivation of purines. Drug Dev. Res. 28:214-219, 1993.

Mendizabal, V.E., E.C. Feleder, and E. Adler-Graschinsky. Effects of the chronic in vivo administration of L-NAME on the contactile responses of the rat perfused mesenteric bed. J. Auton. Pharmacol. 19(4):241-248, 1999.

Messina, E.J., D. Sun, A. Koller, M.S. Wolin, and G. Kaley. Role of endothelium-derived prostaglandins in hypoxia-elidited arteriolar dilation in rat skeletal muscle. Circ. Res. 71:790-796, 1992.

Mirhashemi, S., S. Ertefai, K. Messmer, and M. Intaglietta. Model analysis of the enhancement of tissue oxygenation by hemodilution due to increased microvascular flow velocity. Microvasc. Res. 34:290-301, 1987.

Mohrman, D.E. Lack of influence of potassium or osmolality on steady-state exercise hyperemia. Am. J. Physiol. 242 (6):H949-H954, 1982.

Mohrman, D.E., and R.R. Regal. Relaxation of blood flow to VO2, PO2, and PCO2 in dog gastrocnemius muscle. Am. J. Physiol. 255:H1004-H1010, 1988.

Moncada, S. and A. Higgs. The L-arginine-nitric oxide pathway. N. Engl. J. Med. 329:2002-2012, 1993.

Moncada, S., R.M.J. Palmer, and E.A. Higgs. Nitric oxide: Phsyiology, pathophysiology, and pharmacology. Pharmacol. Rev. 43:109-142, 1991. 
Mulle, J.M., M.J. Davis, L. Kuo, and W.M. Chilian. Changes in coronary endothelial cell $\mathrm{Ca}^{2+}$ concentration during shear stress- and agonist-induced vasodilation. Am. J. Physiol. 276:H1706-H1714, 1999.

Murphy, M.E. and J.E. Brayden. Apamin-sensitive $\mathrm{K}^{+}$channels mediate an endothelium-dependent hyperpolarization in rabbit mesenteric arteries. $J$. Physiol. 489:723-734, 1995.

Myers, P.R., J.M. Muller, and M.A. Tanner. Effects of oxygen tension on endothelium dependent responses in canine coronary microvessels. Cardiovasc. Res. 25: 885-894, 1991.

Nagao, T. and P.M. Vanhoutte. Characterization of endothelium-dependent relaxations resistant to nitro-L-arginine in the porcine coronary artery. $\mathrm{Br}$. J. Pharmacol. 107:1102-1107, 1992.

Nakamura, T. and R.L. Prewitt. Effect ofW-monomethyl-L-arginine on arcade arterioles of rat spinotrapezius muscles. Am. J. Physiol. 261:H46-H52, 1991.

Nase, G.P. and M.A. Boegehold. Nitric oxide modulates arteriolar responses to increased sympathetic nerve activity. Am. J. Physiol. 271: H860-H869, 1996.

Nase, G.P. and M.A. Boegehold. Modulation of sympathetic constriction by the arteriolar endothelium does not involve the cyclooxygenase pathway. Int. J. Microcirc. 17:41-47, 1997.

Nase, G.P. and M.A. Boegehold. Endothelium-derived nitric oxide limits sympathetic neurogenic constriction in intestinal microcirculation. Am. J. Physiol. 273: H426-H433, 1997.

Nase, G.P. and M.A. Boegehold. Postjunctional $\alpha_{2}$-adrenoceptors are not present in proximal arterioles of rat intestine. Am. J. Physiol. 274:H202-H208, 1998.

Nase, G.P. and H.G. Bohlen. Reduced oxygen availability stimulates endothelium-derived nitric oxide production in the intestinal circulation. (Abstract) FASEB J. 15(4 pt 1):A103, 2001.

Nathan, C. Nitric oxide as a secretory product of mammalian cells. FASEB J. 6:3051-3064, 1992.

Nathan, C. and Q. Xie. Regulation of biosynthesis of nitric oxide. J. Biol. Chem. 269:13725-13728, 1994. 
Neylon, M. and J.M. Marshall. The role of adenosine in the respiratory and cardiovascular response to systemic hypoxia in the rat. J. Physiol. 440:529-545, 1991.

Nollert, M.U., S.G. Eskin, and L.V. McIntire. Shear stress increases inositol trisphosphate levels in human endothelial cells. Biochem. Biophys. Res. Commun. 170:281-287, 1990.

Nurkiewicz, T.R. and M.A. Boegehold. Limitation of arteriolar myogenic activity by local nitric oxide: segment-specific effect of dietary salt. Am. J. Physiol. 277:H1946-H1955, 1999.

Offermanns, S. and M.I. Simon. G alpha 15 and $G$ alpha 16 couple a wide variety of receptors to phospholipase C. J. Biol. Chem. 270:15175-15180, 1995.

Ohyanagi, M., K. Nishigaki and J.E. Faber. Interaction between microvascular $\alpha \mathrm{l}$ - and $\alpha 2$ - adrenoceptors and endothelium-derived relaxing factor. Circ. Res. 71:188-200, 1992.

Okada, T. Hypoxia-induced change in prostanoids production and coronary flow in isolated rat heart. J. Mol. Cell Cardiol. 23: 939-948, 1991.

Olah, M.E. Identification of $A_{2 a}$ adenosine receptor domains involved in selective coupling to $\mathrm{G}_{\mathrm{S}}$. Analysis of chimeric $\mathrm{A}_{1} / \mathrm{A}_{2 \mathrm{a}}$ adenosine receptors. J. Biol. Chem. 272:337-344, 1997.

Olah, M.E. and G.L. Stiles. Adenosine receptor subtypes: characterization and therapeutic regulation. Annual Rev. Pharmacol. Toxicol. 35:581-606, 1995.

Olesen, S., D.E. Clapham, and P.F. Davies. Haemodynamic shear stress activates a K ${ }^{+}$current in vascular endothelial cells. Nature 331:168-170, 1988.

Olsson, R.A., E.M. Khouri, J.L. Bedynek, and J. McLean. Coronary vasoactivity of adenosine in the conscious dog. Circ. Res. 45:468-478, 1979.

Pal, M., A. Toth, P. Ping, P.C. Johnson. Capillary blood flow and tissue metabolism in skeletal muscle during sympathetic trunk stimulation. Am. J. Physiol. 274(2 pt 2):H430-H440, 1998.

Palade, G.E., M. Simionescu and N. Simionescu. Structural aspects of permeability of the microvascular endothelium. Acta. Physiol. Scand. 463: 11-32, 1978. 
Palmer, R.M.J., A.G. Ferrige and S. Moncada. Nitric oxide release accounts for the biological activity of endothelium-derived relaxing factor. Nature 327:524526, 1987.

Park, K.H., L.E. Rubin, S.S. Gross, and R. Levi. Nitric oxide is a mediator of hypoxic coronary vasodilatation. Circ. Res. 71:992-1001, 1992.

Pawlik, W.W., O.D. Hottenstein, T.E. Palen, T. Pawlik, and E.D. Jacobson. Adenosine modulates reactive hyperemia in rat gut. J. Physiol. Pharmacol. 44 (2):119-137, 1993.

Pearce, M.J., T.M. Mclntyre, S.M. Prescott, G.A. Zimmerman, and R.E. Whatley. Shear stress activates cytosolic phospholipase $A_{2}\left(\mathrm{CPLA}_{2}\right)$ and MAP kinase in human endothelial cells. Biochem. Biophys. Res. Commun. 218:500504, 1996.

Pearson, J.D. and J.L. Gordon. Nucleotide metabolism by endothelium. Annu. Rev. Physiol. 47:617-627, 1985.

Peralta, C., G. Hotter, D. Closa, N. Prats, C. Xaus, E. Gelpi, J. RosellóCatafau. The protective role of adenosine in inducing nitric oxide synthesis in rat liver ischemia preconditioning is mediated by activation of adenosine $A_{2}$ receptors. Hepatology 29:126-132, 1999.

Phong, A., J. Julianne, and M.J. Rand. Attenuation of vasoconstriction by endogenous nitric oxide in rat caudal artery. Br. J. Pharmacol. 107:1120-1128, 1992.

Pierce, K.D., T.J. Furlong, L.A. Selbie, and J. Shine. Molecular cloning and expression of an adenosine $A_{2 B}$ receptor from human brain. Biochem. Biophys. Res. Commun. 187:86-93, 1992.

Pittman, R.N. Determinants of oxygen exchange in the microcirculation. In "New Horizons. Oxygen transport and utilization Vol. 2". Eds. C.W. Bryan-Brown and S.M. Ayres. Fullerton, CA, Society of Critical Care Medicine. pgs 271-292, 1986.

Pohl, U. and R. Busse. Hypoxia stimulates release of endothelium-derived relaxant factor. Am. J. Physiol. 256:H1595-H1600, 1989.

Prasad, A.R.S., S.A. Logan, R.M. Nerem, C.J. Schwartz and E.A. Sprague. Flow-related responses of intracellular inositol phosphate levels in cultures aortic endothelial cells. Circ. Res. 72:827-836, 1993. 
Pratt, P.F., C.J. Hillard, W.S. Edgemond, and W.B. Campbell. Narachidonylethanolamide relaxation of bovine coronary artery is not mediated by CB1 cannabinoid receptor. Am. J. Physiol. 43:H375-H381, 1998.

Pries, A.R., J. Heide, K. Ley, K.F. Klutz and D. Gaehtgens. Effect of oxygen tension on regulation of arteriolar diameter in skeletal muscle in situ. Microvas. Res. 49:289-299, 1995.

Proctor, K.G. Reduction of contraction-induced arteriolar vasodilation by adenosine deaminase or theophylline. Am. J. Physiol. 247:H195-H205, 1984.

Proctor, K.G. Possible role for adenosine in local regulation of absorptive hyperemia in rat intestine. Circ. Res. 59:474-481, 1986.

Proctor, K.G. and B.R. Duling. Adenosine and free-flow functional hyperemia in striated muscle. Am. J. Physiol. 242:H688-H697, 1982.

Raatikainen, M.J.P., K.J. Peuhkurinen, and I.E. Hassinen. Contribution of endothelium and cardiomyocytes to hypoxia-induced adenosine release. J. Mol. Cell Cardiol. 26:1069-1080, 1994.

Ralevic, V. and G. Burnstock. Receptors for purines and pyrimidines. Pharmacol. Rev. 50:413-492, 1998.

Ramme, D., J.T. Regenold, K. Starke, R. Busse, and P. Illes. Identification of the neuroeffector transmitter in jejunal branches of the rabbit mesenteric artery. Naunyn Schmiedeberg's Arch. Pharmacol. 336:267-273, 1987.

Randall, M.D., A.I. McCulloch, and D.A. Kendall. Comparative pharmacology of endothelium-derived hyperpolarizing factor and anandamide in rat isolated mesentery. Eur. J. Pharmacol. 333:191-197, 1997.

Rapoport, R.M. and F. Murad. Agonist-induced endothelium-dependent relaxation in rat thoracic aorta may be mediated through cGMP. Circ. Res. 52:352-357, 1983.

Rees, D.D., R.M.J. Palmer, and S. Moncada. Role of endothelium0derived nitric oxide in the regulation of blood pressure. Proc. Natl. Acad. Sci. 86:33753378, 1989.

Renkin, E.M. Control of microcirculation and blood-tissue exchange. In the cardiovascular system. Vol. 4. Microcirculation. Handbook of Physiology. American Physiology Society, Bethesda, MD, pp 627-687, 1984. 
Richard, V., F.C. Tanner, M.R. Tschudi, T.F. Lüscher. Different activation of Larginine pathway by bradykinin, serotonin, and clonidine in coronary arteries. Am. J. Physiol. 259:H1433-H1439, 1990.

Richardt, G., W. Waas, R. Kranzhöfer, B. Cheng, M.J. Lohse, and A. Schömig. Interaction between the release of adenosine and noradrenaline during sympathetic stimulation: a feed-back mechanism in rat heart. J. Mol. Cell Cardiol. 21:269-277, 1989.

Robard, S. Vascular caliber. Cardiology 60:4-49, 1975.

Rorie, D.K. Metabolism of norepinephrine in vitro by dog pulmonary arterial endothelium. Am. J. Physiol. 243:H732-H737, 1982.

Ruiz-Velasco, V., J. Zhong, J. Hume, and K.D. Keef. Modulation of $\mathrm{Ca}^{2+}$ channels by cyclic nucleotide cross activation of opposing protein kinases in rabbit portal vein. Circ. Res. 82:557-565, 1998.

Ruth, P., G.X. Wang, I. Boekhoff, B. May, A. Pfeifer, R. Penner, M. Korth, H. Breer, and F. Hofmann. Transfected cGMP-dependent protein kinase suppresses calcium transients by inhibition of inositol 1,4,5-trisphosphate production. Proc. Natl. Acad. Sci. 90:2623-2627, 1993.

Ryan, U.S. and J. W .Ryan. Vital functions and activities of endothelial cells, In "The Biology of the Endothelial Cell". Eds. Nossel, B.L. and Vogel, B.I., Academic Press, New York, 1982.

Ryan, U.S., J.W .Ryan, C. Whitaker and A. Chiu. Localization of angiotensin converting enzyme (kininase II): Immunocytochemistry and immunofluorescence. Tissue Cell 8:125-127, 1976.

Sabine, B., R. Willenbrock, H. Haase, P. Karczewski, G. Wallukat, R. Dietz, and E.G. Krause. Cyclic GMP-mediated phospholamban phosphorylation in intact cardiomyocytes. Biochem. Biophys. Res. Commun. 214:75-80, 1995.

Sarelius, I.H. Cell flow path influences transit time through striated muscle capillaries. Am. J. Physiol. H899-H907, 1986.

Sarelius, I.H. and B.R. Duling. Direct measurement of microvessel hematocrit, red cell flux, velocity, and transit time. Am. J. Physiol. 243:H1018-H1026, 1982.

Schrader, J. and U. Decking. Regulation of coronary circulation by adenosine. Z. Kardiol. 85 (Suppl 6):153-159, 1996. 
Schrader, J., F.J. Haddy, and E. Gerlach. Release of adenosine, inosine and hypoxanthine from the isolated guinea pig heart during hypoxia, flowautoregulation and reactive hyperemia. Pflügers Arch. 369:1-6, 1977.

Schwartz, L.M. and J.E. McKenzie. Adenosine and active hyperemia in soleus and gracilis muscle of cats. Am. J. Physiol. 259 (4 pt 2):H1295-H1304, 1990.

Schwarz, P., R. Diem, N.J. Dun, and U. Förstermann. Endogenous and exogenous nitric oxide inhibits norepinephrine release from rat heart sympathetic nerves. Circ. Res. 77:841-848, 1995.

Shryock J.C. and L. Belardinelli. Adenosine and adenosine receptors in the cardiovascular system: biochemistry, physiology, and pharmacology. Am. J. Cardiol. 79(12A):2-10, 1997.

Silva, D.G., G. Ross and L. W .Osbome. Adrenergic innervation of the ileum of the cat. Am. J. Physiology. 220(2):347-352, 1971.

Simpson, R.E. and J.W. Phillis. Adenosine deaminase reduces hypoxic and hypercapnic dilatation of rat pial arterioles: evidence for mediation by adenosine. Brain Res. 553 (2):305-308, 1991.

Smiesko, V., D.J. Lang and P.C. Johnson. Dilator response of rat mesenteric arcading arterioles to increased blood flow velocity. Am. J. Physiol. 257:H1958H1965, 1989.

Smith, K.M., J.B. Macmillan, K.M. McCulloch, and J.C. McGrath. NOS inhibition potentiates norepinephrine but not sympathetic nerve-mediated cotransmission in resistance arteries. Cardiovasc. Res. 15;43(3):762-771, 1999.

Soto, F., M. Garcia-Guzman, and W. Stuhmer. Cloned ligand-gated channels activated by extracellular ATP (P2X receptors). J. Membr. Biol. 160:91-100, 1997.

Stuehr, D.J. Structure-function aspects in the nitric oxide synthases. Annu. Rev. Pharmacol. Toxicol. 37:339-359, 1997.

Surprenant, A. Neural control of the gastrointestinal tract. Annu. Rev. Physiol. 56:117-140, 1994.

Tamaoki, J., E. Tagaya, K. Nishimura, K. Isono, and A. Nagai. Role of $\mathrm{Na}^{+}-\mathrm{K}^{+}$ ATPase in cyclic GMP-mediated relaxation of canine pulmonary artery smooth muscle cells. Br. J. Pharmacol. 122:112-116, 1997a. 
Tamaoki, J., E. Tagaya, A. Chiyotani, H. Takemura, A. Nagai, K. Konno, T. Onuki, and S. Nitta. Effect of adenosine on adrenergic neurotransmission and modulation by endothelium in canine pulmonary artery. Am. J. Physiol. 272:H1100-H1105, 1997b.

Tenney, S.M. A theoretical analysis of the relatioship between venous blood and mean tissue oxygen pressures. Respir. Physiol. 20:283-296, 1974.

Tesfamariam, B. and W. Halpern. Modulation of adrenergic responses in pressurized resistance arteries by flow. Am. J. Physiol. 253(5 pt 2):H1112H1119, 1987.

Tefamariam, B., R.M. Weisbrod and R.A. Cohen. Endothelium inhibits responses of rabbit carotid artery to adrenergic nerve stimulation. Am. J. Physiol. 253(4 pt 2):H792-H798, 1987.

Thomas, G.D. and R.G. Victor. Nitric oxide mediates contraction-induced attenuation of sympathetic vasoconstriction in rat skeletal muscle. J. Physiol. 506(pt 3):817-826, 1998.

Thomas, T., B.K. Elnazir, and J.M. Marshall. Differentiation of the peripherallymediated influences of adenosine in the rat during systemic hypoxia. Exp. Physiol. 79:809-822, 1994.

Tyml, K., C.G. Ellis, R.G. Safranyos. Temporal and spatial distribution of red cell velocity in capillaries of resting skeletal muscle, including estimates of red cell transit times. Microvasc. Res. 22:14-31, 1981.

Torres Filho, I.P., H. Kerger, and M. Intaglietta. $\mathrm{pO}_{2}$ measurements in arteriolar networks. Microvasc. Res. 51:202-212, 1996.

Unthank, J.L. and H.G. Bohlen. Quantification of intestinal microvascular growth during maturation: techniques and observations. Circ. Res. 61(5):616624, 1987.

Urabe, M., H. Kawasaki, and K. Takasaki. Effect of endothelium removal on the vasoconstrictor response to neuronally released 5-hydroxytryptamine and noradrenaline in the rat isolated mesenteric and femoral arteries. Br. J. Pharmacol. 102:85-90, 1991.

Valera, S., N. Hussy, R.J. Evans, N. Adani, R.A. North, A. Suprenant, and G. Buell. A new class of ligand-gated ion channel defined by $P_{2 x}$ receptor for extracellular ATP. Nature 371:516-519, 1994. 
Van Calker, D., M. Müller, and B. Hamprecht. Adenosine regulates via two different types of receptors, the accumulation of cyclic AMP in cultured brain cells. J Neurochem. 33:999-1005, 1979.

Vanhoutte, P.M. Endothelium and control of vascular function: State of the art lecture. Hypertension 13:658-667, 1989.

Villanueva, M.M., P. Soares-da-Silva, and W. Osswald. Effect of sympathetic denervation on the relaxing responses of rabbit arterial smooth muscle. J. Auton. Pharmacol. 14(4):275-281, 1994.

Ward, M.E. Effect of inhibition of nitric oxide synthesis on the diaphragmatic microvascular response to hypoxia. J. Appl. Physiol. 81(4): 1633-1641, 1996.

Webb, T.E. J. Simon, B.J. Krishek, A.N. Bateson, T.G. Smart, B.F. King, G. Burnstock, and E.A. Barnard. Cloning and functional expression of a brain Gprotein coupled ATP receptor. FEBS Letters 324:219-225, 1993.

Weis, L. Blood vessels: Tissue components of vascular wall In: Cell and Tissue Biology edited by Urban, D. and M. Schwarzenberg: pp 357-365,1988.

Welsh, D.G., W.F. Jackson, and S.S. Segal. Oxygen induces electrochemical coupling in arteriolar smooth muscle cells: a role for L-type $\mathrm{Ca}^{2+}$ channels. $\mathrm{Am}$. J. Physiol. 274:H2018-H2024, 1998.

White, K.A. and M.A. Marletta. Nitric oxide synthase is a cytochrome P-450 type hemo-protein. Biochemistry 31:6627-6631, 1992.

Wilson, D.F., M. Erecinska, and C. Drown. Effect of oxygen tension on cellular energetics. Am. J. Physiol. 233(5):C135-C140, 1977.

Wood, J.G., J.S. Johnson, L.F. Mattioli, and N.C. Gonzalez. Systemic hypoxia increases leukocyte emigration and vascular permeability in conscious rats. J. Appl. Physiol. 89:1561-1568, 2000.

Xu, X., J.S. Pollock, M.A. Tanner, and P.R. Myers. Hypoxia activates nitric oxide synthase and stimulates nitric oxide production in porcine coronary resistance arteriolar endothelial cells. Cardiovasc. Res. 1995; 30: 841-847.

Yada, T., O. Hiramatsu, H. Tachibana, E. Toyota, and F. Kajiya. Role of NO and $\mathrm{K}^{+}$ATP channels in adenosine-induced vasodilation on in vivo canine subendocardial arterioles. Am. J. Physiol. 277:H1931-H1939, 1999. 
Yoshida, Y., J.Q. Cai, and S. Imai. Plasma membrane $\mathrm{Ca}^{2+}$-pump ATPase is not a substrate for cGMP-dependent protein kinase. J. Biochem. 111:559-562, 1992.

You, J., T.D. Johnson, W.F. Childres, and R.M. Bryan. Endothelial-mediated dilations of rat middle cerebral arteries by ATP and ADP. Am. J. Physiol. 273:H1472-H1477, 1997. 


\section{CURRICULUM VITAE}

\section{Bryan Auston Sauls}

(Updated June 25, 2001)

Date of Birth:

Family Status:

Business Address:

Home Address:

Present Position:
October 17, 1970, Cleveland, $\mathrm{OH}$

Married, two children

Robert C. Byrd Health Sciences Center

West Virginia University School of Medicine Department of Physiology

P.O. Box 9229

Morgantown, WV 26506-9229

Phone: (304) 293-1521

Fax: (304) 293-3850

e-mail: bryansauls@hotmail.com

1421 Northwest Drive

Morgantown ,WV 26505

Graduate Research Assistant

West Virginia University School of Medicine

\section{Education}

Concord College, Athens, WV

B.S. (Biology)

1994

West Virginia University, Morgantown, WV

Ph.D. (Physiology)

2001 Dissertation Title: Integrated Modulation of Sympathetic Tone in the Microcirculation by Oxygen, Adenosine, and Nitric Oxide. (Advisor: Matthew A. Boegehold, Ph.D.)

Marshall University, Huntington, WV

M.D. (Medicine)

in progress

\section{Career History}

West Virginia University

Dept. of Physiology 


\section{Awards and Honors}

$\mathrm{NIH}$ predoctoral traineeship

$1997-2001$

Winner of the Julie Betschart Memorial Research Symposium

2000

Annual award presented for the most outstanding presentation

at a national or international meeting by a physiology student.

Manuscript selected for Journal of Vascular Research Internet Discussion 2001 forum.

\section{Teaching Activities}

\section{West Virginia University}

CCMD 330 "Human Function"

Fall 1998

12 medical students

Topic: Physiology small group facilitator

CCMD 330 "Human Function"

Fall 1999

12 medical students

Topic: Physiology small group facilitator

Physiology 241 "Fundamentals of Physiology"

Fall 2000

180 undergraduates and graduate students

Topic: Cardiac Physiology

\section{Memberships}

American Physiological Society (student member, 1997)

Microcirculatory Society (student member, 2000)

\section{Research Interests}

Local and neural mechanisms of microvascular control

Endothelium-dependent regulation of vascular tone

Endothelial cell signal transduction

Vascular alterations in hypertension

Microvascular alterations and local blood flow control in hypertension

Heart failure 


\section{Publications}

\section{Abstracts}

(1) Lenda, D., B. Sauls, and M. A. Boegehold. Local production of superoxide anion may contribute to reduced arteriolar nitric oxide in rats fed high salt. FASEB J. 13.4:A31, 1999.

(2) Sauls, B. A. and M. A. Boegehold. A reduction in arteriolar wall $\mathrm{PO}_{2}$ may stimulates nitric oxide release during sympathetic vasoconstriction in the rat intestine. FASEB J. 13.4:A31, 1999.

(3) Sauls, B. A. and M. A. Boegehold. Local adenosine production may stimulate arteriolar nitric oxide synthesis during sympathetic constriction in the rat intestine. FASEB J. 14.4:A3, 2000.

(4) Sauls, B. A. and M. A. Boegehold. Local $\mathrm{PO}_{2}$ reduction and adenosine release preserve arteriolar nitric oxide synthesis during sympathetic constriction in the rat intestine. J. Vasc. Res. 37(S1):32, 2000.

(5) Sauls, B. A. and M. A. Boegehold. Conversion to adenosine is not responsible for sustained endothelial nitric oxide synthesis during sympathetic vasoconstriction in the rat intestine. FASEB J. 15(4 pt 1):A103, 2001.

\section{Manuscripts}

(1) Lenda, D. M., B. A. Sauls, and M. A. Boegehold. Reactive oxygen species may contribute to reduced endothelium-dependent dilation in rats fed high salt. Am. J. Physiol. Heart Circ. Physiol. 279:H7-H14, 2000.

(2) Sauls, B. A. and M. A. Boegehold. Arteriolar wall $\mathrm{PO}_{2}$ and nitric oxide release during sympathetic vasoconstriction in the rat intestine. Am. J. Physiol. Heart Circ. Physiol. 279:H484-H491, 2000.

(3) Sauls, B. A. and M. A. Boegehold. Reduced $\mathrm{PO}_{2}$ and adenosine formation preserve arteriolar nitric oxide synthesis during sympathetic constriction in the rat intestine. J. Vasc. Res. 38:104-112, 2001.

(4) Sauls, B. A. and M. A. Boegehold. Conversion to adenosine is not responsible for sustained endothelial nitric oxide synthesis during sympathetic vasoconstriction in the rat intestine. Am. J. Phsyiol. Heart Circ. Physiol. (in press), 2001. 


\section{Lectures and Seminars}

(1) Hypoxia is a potential stimulus for nitric oxide release in the rat intestine. West Virginia University, Dept. of Physiology, August 20, 1998.

(2) A reduction in arteriolar wall $\mathrm{PO}_{2}$ may stimulate nitric oxide release during sympathetic vasoconstriction in the rat intestine. West Virginia University, School of Medicine, March 18, 1999.

(3) Arteriolar wall $\mathrm{PO}_{2}$ and nitric oxide release during sympathetic vasoconstriction in the rat intestine. West Virginia University, Dept. of Physiology, August 26, 1999.

(4) Local $\mathrm{PO}_{2}$ reduction and adenosine release preserve arteriolar nitric oxide synthesis during sympathetic constriction in the rat intestine. West Virginia University, School of Medicine, April 6, 2000.

(5) Local adenosine production may stimulate arteriolar nitric oxide synthesis during sympathetic constriction in the rat intestine. West Virginia University, Dept. of Physiology, May 24, 2000.

(6) Integrated modulation of microvascular tone by oxygen, adenosine, and nitric oxide. West Virginia University, Dept. of Physiology, June 7, 2001.

\section{Participation in International Scientific Meetings}

Twenty-first European Conference on Microcirculation, Stockholm, Sweden 2000

\section{Participation in National Scientific Meetings}

American Microcirculatory Society, Annual Meeting Washington, DC 